\title{
Extracellular protein components of amyloid plaques and their roles in Alzheimer's disease pathology
}

\author{
M. Mahafuzur Rahman ${ }^{*}$ and Christofer Lendel ${ }^{*}$ (D)
}

\begin{abstract}
Alzheimer's disease (AD) is pathologically defined by the presence of fibrillar amyloid $\beta$ (A $\beta$ ) peptide in extracellular senile plaques and tau filaments in intracellular neurofibrillary tangles. Extensive research has focused on understanding the assembly mechanisms and neurotoxic effects of $A \beta$ during the last decades but still we only have a brief understanding of the disease associated biological processes. This review highlights the many other constituents that, beside $A \beta$, are accumulated in the plaques, with the focus on extracellular proteins. All living organisms rely on a delicate network of protein functionality. Deposition of significant amounts of certain proteins in insoluble inclusions will unquestionably lead to disturbances in the network, which may contribute to AD and copathology. This paper provide a comprehensive overview of extracellular proteins that have been shown to interact with $A \beta$ and a discussion of their potential roles in $A D$ pathology. Methods that can expand the knowledge about how the proteins are incorporated in plaques are described. Top-down methods to analyze post-mortem tissue and bottom-up approaches with the potential to provide molecular insights on the organization of plaquelike particles are compared. Finally, a network analysis of A $\beta$-interacting partners with enriched functional and structural key words is presented.
\end{abstract}

Keywords: Alzheimer's disease, Senile plaque, Amyloid- $\beta$, Protein interaction network, Amyloid corona

\section{Background}

Alzheimer's disease (AD) is the most prevalent cause of dementia today, affecting close to 50 million people worldwide [1]. Considering the fact that we still lack curative treatment, $\mathrm{AD}$ is likely to become a serious burden on our future healthcare systems, especially with the increased life span we have experienced during the last century. The clinical symptoms include progressive memory loss, language disturbance, and moodbehavioral changes, but they are not by themselves enough to define the disease. Instead the definition relies on pathological protein inclusions, extracellular senile plaques (Fig. 1) and intracellular neurofibrillary tangles,

\footnotetext{
* Correspondence: mrahma@kth.se; lendel@kth.se Department of Chemistry, KTH Royal Institute of Technology, SE-100 44 Stockholm, Sweden
}

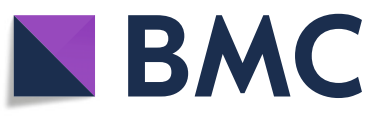

in the patient's brain. Hence, for long time the diagnosis could only be decided post-mortem. More recently, biomarkers in cerebrospinal fluid (CSF; and potentially also blood serum) [2,3] and positron emission tomography (PET) imaging techniques [4] have been shown to correlate well with the protein deposition pathology. The majority of $\mathrm{AD}$ patients also display co-pathologies, that are not necessarily identified by biomarkers or imaging $[5,6]$. It has also been shown that similar protein inclusions are often found in people without any symptoms of dementia [7], hence the disease is believed to have an extended preclinical phase. Along with pathological hallmarks of plaques and tangles, the $\mathrm{AD}$ pathology may be associated with cerebral amyloid angiopathy (CAA), synaptic failure, oxidative damage, neuroinflammation and mitochondrial dysfunction [8]. 


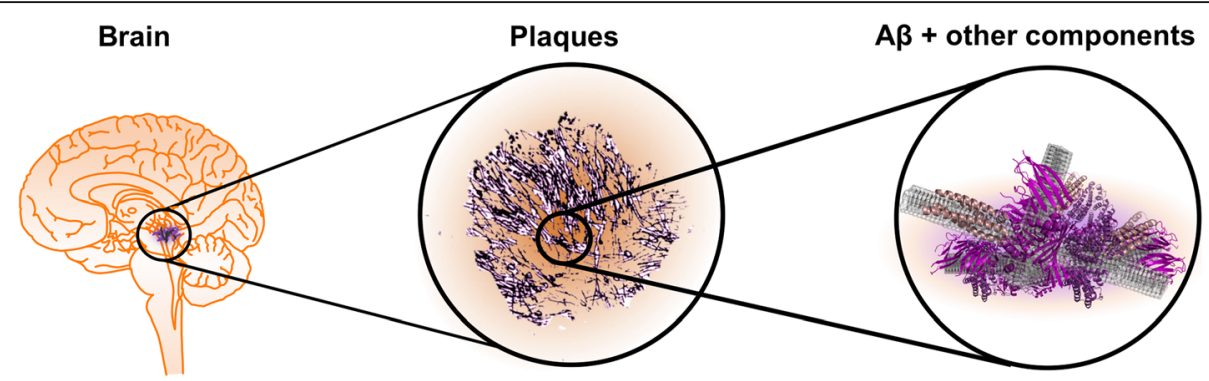

Fig. 1 Extracellular senile plaques are pathological hallmarks of AD brains. The plaques are proteinaceous deposits with $A \beta$ as main constituent but also containing a range of other components

The connection between dementia and the pathological protein inclusions that signify $\mathrm{AD}$ was first reported by Alois Alzheimer in 1906 [9] and the senile plaques were defined as amyloid by the observation of Congo red binding [10]. However, it would take almost 80 years from the first report by Alzheimer before the core components of the amyloid deposits were identified; Glenner and Wong identified amyloid $\beta(A \beta)$ in vascular amyloid in 1984 [11] and Masters et al. in plaques the year after [12]. Tau was found to be the main components of neurofibrillary tangles in 1985 by Brion et al. [13]. The observation of a link between mutations in the gene coding for the $A \beta$ precursor protein (APP) and early onset familial forms of AD [14-16] suggested $\mathrm{A} \beta$ to be the causative agent for the disease and the 'amyloid cascade hypothesis' was founded. This hypothesis states that the pathology is initiated by aggregation of $A \beta$ due to mutations making the peptide more aggregation prone or, in the expanded version, also covering sporadic $\mathrm{AD}$ due to imbalance in the $\mathrm{A} \beta$ production and degradation.

Based on the pathological and genetic findings, research around $A \beta$ turned into a very popular field with thousands of papers published every year. Among the more important progress made within the biochemistry of $\mathrm{AD}$ are the determination of high-resolution structures of $A \beta$ amyloid [17-20], the proposal of a critical role for pre-fibrillar structures (oligomers or protofibrils) $[21,22]$ and the dissection of the microscopic mechanisms of the amyloid formation process [23, 24]. The roles and interplay between various cell types in the central nervous system has also become evident [25]. With all this knowledge one would expect that we would also have effective therapy available, but that is not the case. The biological processes by which $A \beta$ accumulation causes neurodegeneration are far from understood and widely debated. This calls for generation of even more knowledge and exploration of new hypotheses. With this article we want to shift the focus from the $A \beta$ core component of the plaques to the many other proteins that co-aggregate with $A \beta$ amyloid. We first describe methods to investigate the composition of plaques from top-down and bottom-up perspectives. Then we present an overview of extracellular proteins that have been found to interact with aggregated $\mathrm{A} \beta$ in vitro and highlight potential connections to $\mathrm{AD}$ pathology reported in the literature.

\section{Top-down approaches to identify protein components of plaques}

The identification of $A \beta$ in senile plaques from postmortem tissue was indeed a breakthrough in the molecular description of $\mathrm{AD}$. However, $\mathrm{A} \beta$ was not the first protein to be associated with plaques. Immunoglobulins and complement proteins had already been detected [26, 27]. In 1994, at least 35 protein components had been found to be associated with senile plaques [28], including apolipoprotein E (apoE), clusterin, vitronectin, coagulation factors, heat shock proteins, proteases and protease inhibitors. Hence, apoE was indeed identified as a senile plaque component [29] before it was found to be an important genetic risk factor of AD [30].

For the early identification studies, analysis of samples from dedicated purification protocols or immunohistochemical investigation of tissues were used (Fig. 2A). Although these can give clear and reliable results, they are limited to availability and the quality of antibodies and one need to know what to look for in order to find it. The emergence of effective proteomics techniques and in particular mass spectrometry (MS), allowed broader, unbiased investigations of the plaque components. On the other hand, the sample preparation methods become increasingly important and the question what is "in the plaque" and what originates from the surrounding tissue stands out as very critical. Chemical purification methods using harsh conditions may remove too much of the plaque associated components while common methods such as laser capture microdissection (LCM) would include everything within the specified area. The problems can, to some extent, be overcome by appropriate controls, e.g. comparison with LCM of tissue just outside the plaques $[31,32]$ or with samples from 

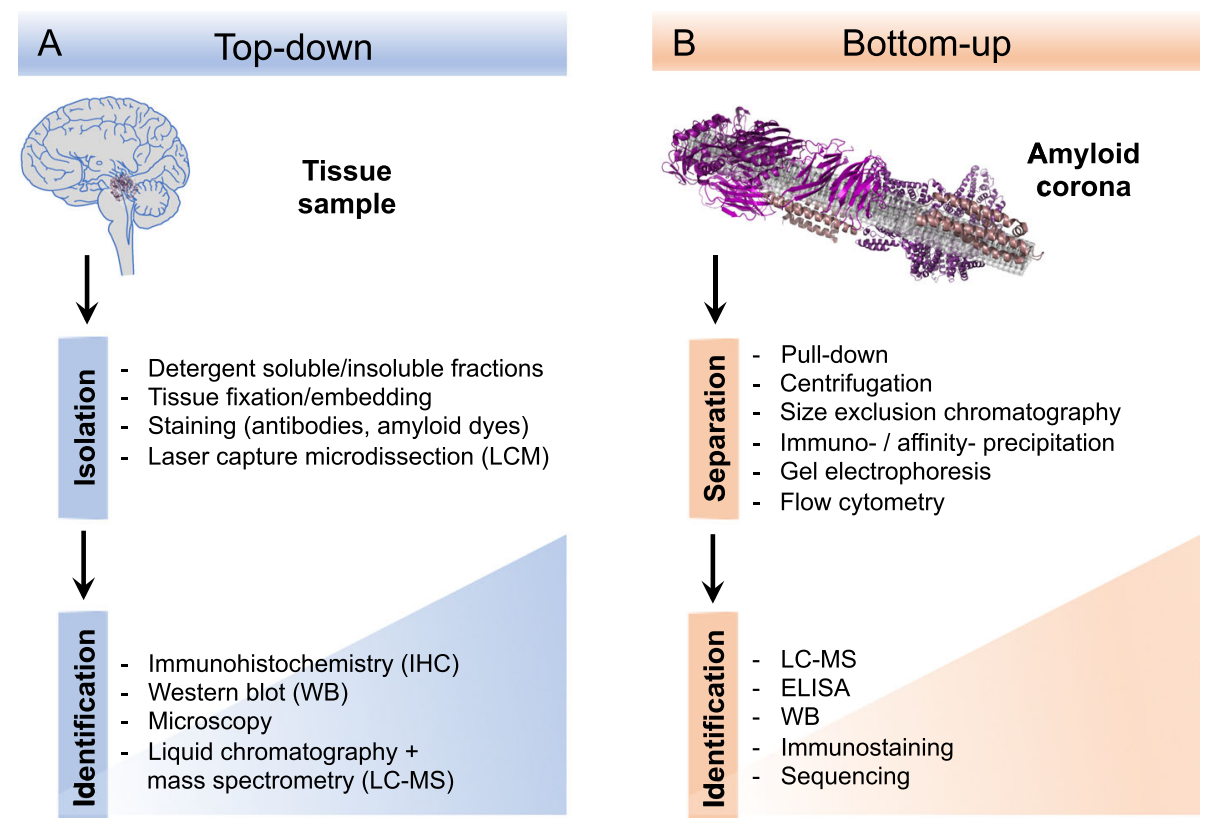

Fig. 2 Approaches to explore the composition and organization of senile plaques. (A) Top-down methods starts from plaque tissue samples and analyze the plaque structure by e.g. microscopy or mass-spectrometry proteomics. (B) Bottom-up methods make use of in vitro models in order to study composition, protein structure and interactions from a molecular perspective. The amyloid corona refers to the layer of proteins from a biological fluid that is sequestered by the amyloid fibrils

different purification protocols, but still the methods report on spatial proximity rather than structural or molecular connections.

Increased sensitivity of MS instrument has also lead to an increasing number of identified proteins. The pioneering study by Liao et al. in 2004 reported 488 proteins found in plaques [31] while Xiong and co-workers in 2019 and Bai and co-workers in 2020 were able to detect more than 4000 and 14,000 proteins, respectively [32, 33]. Notably, a study published 2 years after Liao et al., and employing a different sample preparation protocol, only found $A \beta$ in the plaque cores [34]. Hence, the employed methodology can have substantial effect on which plaque components that are identified.

Investigations of post-mortem tissues are extremely important since they are authentic samples. There are endless opportunities to compare different tissues, different classes of plaques, different individuals etc. This is important since the molecular assembly of all plaque types is not the same $[5,35]$. The neuritic or dense core plaques are formed around a core of fibrillar $\mathrm{A} \beta$ structure and have neighboring reactive astrocytes and activated microglial cells. Diffuse plaques are poorly marginated assemblies of filamentous $A \beta$, which is weakly stained by amyloid-specific dyes, and do not have associated toxicities as the neuritic plaque. The diffuse plaques often lack of neuritic elements, nevertheless, diffuse neuritic plaques can be observed in advanced $\mathrm{AD}$.
Yet another class are the cerebrovascular $A \beta$ deposits, in the course of CAA. There are, however, limitations in the possibilities to acquire a detailed molecular understanding of the plaque structures. For examples, which components are directly sequestered by $A \beta$ amyloid fibrils, which components may be more loosely bound or bound to some of the already sequestered proteins and which components just happened to be localized in vicinity of the plaques? Crosslinking protocols could potentially resolve some of these question [36, 37]. Such studies have been carried out to identify binders of tau and APP in murine models $[38,39]$ but not yet to explore the architecture of plaques.

Microscopy offers many opportunities to analyze the presence of different components and their structural properties with spatial resolution. Combining specific antibodies and various amyloid probes with conformation-dependent optical properties allows for imaging of heterogeneities within single plaques (see e.g. Ref. [40] for illustration). Confocal imaging allows for 3D reconstruction of the plaque structures. However, these studies are, as all microscopy techniques, limited by the diffraction laws that set a size limit in the micrometer range. Even though new super-resolution techniques have pushed this limit towards the nanometer range, it is still not possible to derive molecular information about the deposits. Cryo-electron microscopy has become an increasingly important method for the structural characterization of amyloid fibrils [41] allowing resolution below nanometer range. 
Moreover, cryo-electron tomography has recently provided impressive 3D images of in situ deposits of fibrillar proteins that also include organelle structures such as endoplasmic reticulum, ribosomes and proteasomes [42, 43]. Proteinspecific information, e.g. for investigating co-localization, can also be achieved in electron microscopy through immunolabeling with colloidal gold. Hence, imaging of senile plaques with molecular resolution may soon give us the first glimpses of the arrangement of the different molecular components.

Proper knowledge of the structural and functional connections within the plaques is likely as important (or even more) for the understanding of the pathology as a detailed understanding of the $A \beta$ amyloid formation process. Any pathological process triggered by $A \beta$ (as monomer, oligomer or amyloid fibrils) must proceed via interactions with other biomolecules. Hence, it is not enough to know which proteins are found in the plaques (or close to them) we must also decipher how they are organized and what functional consequences the deposition has for each protein, process and biological pathway. Therefore, biochemical model systems that can capture these effects are, and will continue to be, important for the progress of AD research.

\section{Bottom-up approaches to identify interaction partners of amyloid}

There are many methods that enable in vitro studies of interactions between biomolecules and with the opportunity to derive structural as well as functional parameters. One of the challenges when approaching systems, such as senile plaques, is the complexity in terms of the number of different components. There is always a balance between the simplicity of an in vitro model and its ability to capture biologically relevant features. If we accept that $A \beta$ fibril formation is a central process in the pathology, that should also be the starting point for building in vitro models. Studies of $A \beta$ fibrillation have been a popular field for quite some time. The progress in these studies has provided in-depth understanding of how $A \beta$, and proteins in general, assemble into amyloid fibrils. Although the experiments are typically carried out in pure systems with the addition of only a few additional components, the mechanism rapidly become very complex. Fibrillation of $\mathrm{A} \beta$ in in vivo-like environments, e.g. CSF [44], has demonstrated that the kinetics is affected, indicating that the amyloid interacts with other components. However, it remains to be described which roles the different components play and potential synergistic effects. We therefore need ways to map out which components are involved (Fig. 2B).

In a pioneering study from 2012, Olzscha et al. studied intracellular protein aggregation in a cell model and found a correlation between the toxicity of artificial $\beta$ sheet proteins and their ability to sequester cellular proteins [45]. Experiments with $A \beta$ in the same model system confirmed that also these aggregates attracted a range of protein binding partners. Many of the sequestered proteins were hubs in functional cellular networks indicating the ability of amyloids to trigger multifactorial toxic responses. The question of which proteins from a physiological environment that are sequestered to amyloid aggregates and how that affect the biological response (toxicity) of the aggregates has some similarities with a central question in another field of research: the biological effects of synthetic nanoparticles. A nanoparticle that enters a biological system will be covered with proteins, creating a "corona", and it is the structural and functional properties of these proteins that to a large extent determine the biological effects of the nanoparticle $[46,47]$. Recent studies have highlighted the fact that these features are not unique for synthetic nanoparticles. Viruses were shown to attract protein coronae when introduced into various biological fluids, such as human plasma or human bronchoalveolar lavage fluid [48]. Interestingly, the viruses also seemed to accelerate the aggregation of $A \beta$ into amyloid, which suggest a potential role of heterogenous nucleation in amyloid diseases [49]. In another study, we demonstrated that pre-fibrillar $A \beta$ aggregates (protofibrils) attract a range of different proteins when exposed to human serum or CSF [50]. In a follow-up study, proteins binding to $A \beta$ amyloid fibrils were investigated and fibrils were found to sequester more proteins than the protofibrils and with distinct functional characteristics [51]. Other studies have confirmed the formation of protein coronae around $A \beta$ fibrils and for amyloid fibrils of IAPP, $\alpha$-synuclein, a Cterminal fragment of $\alpha_{1}$-antitrypsin, the FAS4 domain from human cornea and the human hormone glucagon [52-54].

The amyloid corona concept offers a new and interesting perspective on the assembly of plaque-like multiprotein aggregates and could potentially be the starting point for studying plaque formation with molecular resolution. However, the methods to identify, analyze and quantify the components need to be developed and advantages and drawbacks of each approach evaluated. Common separation methods are filtration [53, 54], centrifugation [52] and pull-down assays using magnetic beads $[50,51]$. New applications of old techniques could also offer opportunities in this field. Madasamy et al. demonstrated that flow-cytometry could be used to isolate "plaque particles" formed around $A \beta, \alpha$-synuclein, tau or cholesterol added to serum samples [55]. In addition to the added "seeds", almost 200 serum proteins were identified in the particles. We recently developed this approach further and showed that it may have advantages over pulldown methods or at least provide complementary perspectives on the composition of $\mathrm{A} \beta$ amyloid coronae [56]. A central finding in that study is that not all protein bind directly 
to $A \beta$. This illustrate that the assembly is more complex than just sequestration of the proteins by the amyloid structure. Moreover, the recent study from Nandakumar et al. [53] shows that the protein corona around $A \beta$ amyloid can mask the antibody binding epitopes on $A \beta$, which highlights the need to characterize the structural properties of multiprotein amyloid aggregates to obtain a better understanding of the potential for amyloid-targeted immunotherapy.

Taken together, it is clear that there is an emerging interest to explore the composition and organization of amyloid protein coronae, which opens opportunities to acquire new knowledge about the multicomponent structures of senile plaques and new insights about AD pathology.

\section{Survey of extracellular proteins that associate with $A \beta$}

As already stated, thousands of proteins have been identified in post-mortem plaque tissue. A comprehensive review of these proteins is not feasible. Instead we chose to apply a bottom-up perspective and investigate the set of proteins found by recent in vitro studies as $\mathrm{A} \beta$-interacting proteins in human biofluids, including plasma, serum, and CSF. These studies have reported more than a hundred different proteins with the ability to interact with different conformations of $A \beta$. The majority of these proteins are also known to be present in senile plaques. As the survey is limited to proteins from biofluids, cell-surface receptors and intracellular proteins are naturally excluded unless they are also secreted to the fluid. Nevertheless, a brief discussion of these proteins is included in a separate section. The plaques also contain many non-protein components, including proteoglycans, nucleic acids, lipids and metal ions. For more details about these classes of molecules we refer to recent reviews: $[57,58]$.

In this section, we will discuss the implications of the interactions between $A \beta$ and other proteins for $A D$ pathology as well as the potential role of these binding partners as modulators of $A \beta$ fibrillogenesis. The proteins are categorized and presented according to their main biological functions. We have listed the proteins that are found in the literature to interact with $\mathrm{A} \beta$ in at least two separate studies in Table 1 with notes on the isoform and conformation of $A \beta$, methodology used, and binding affinity. Furthermore, confirmed existence in senile plaque as well as the reported potential as AD biomarker are indicated.

\section{Immunoglobulins}

Immunoglobulins were among the first proteins to be identified in senile plaques $[26,27]$ and it was suggested that $\mathrm{AD}$ may be a localized form of immunoglobulin amyloidosis, potentially caused by an antigen that could not be disposed by regular degradation routes. Immunoglobulins constitute a special case among the binding proteins as their natural function is to recognize foreign structures. Hence, it is not clear if their occurrence in the plaque is due to antigen recognition (from the amyloid or some other component) or binding to their constant parts. The fact that the constant part is identified by MS does not exclude that the variable domain is also present but not found the MS analysis.

Auto-antibodies against A $\beta$ were first reported in 1993 [140] and some studies showed that AD patients have lower concentrations of such antibodies [141, 142]. The origin and functional roles of these antibodies are not yet fully understood but they have been heavily investigated with immunotherapy approaches in mind. Interestingly, IgM antibodies purified from AD patients have been found to have catalytic abilities to hydrolyze $A \beta$ and would thereby actively counteract the accumulation of $A \beta$ [143]. The antibodies were demonstrated to inhibit $A \beta$ aggregation as well as toxicity in cell culture.

Moreover, $A \beta$ is not the only antigen for $A D$-related autoantibodies. Immunoglobulin response against several other proteins/structures, e.g. oxidized low-density lipoprotein, RAGE, and S100b, have also been found [144], potentially reflecting the multiprotein nature of the senile plaques. Recognition of plaque structures by immunoglobulins, either it is the amyloid itself or any other molecular component acting as antigen, can activate inflammatory response and the complement cascade and lead to the effects described below.

\section{Complement and inflammatory response proteins}

Complement activation is critical in normal inflammatory responses to injury and in removing apoptotic cells, tissue debris, and other macromolecular aggregates. Likewise, complement proteins have fundamental roles in the development and protection of the central nervous system. Inappropriate activation of the complement system in the brain may cause neuroinflammation, or even neuronal cell death. Activation of the neuronal complement in $\mathrm{AD}$ brain is supported by the identification of several initial and terminal proteins of complement cascade, including complement 1q (C1q) [26, 28, 31, 32, 59, 60, 66, 70, 73], complement 1s (C1s) [32], complement $1 \mathrm{r}$ (C1r) [32], complement 3 (C3) [26, 28, 31, 32, 59, 60, 66, 73], complement 4 (C4) [26, 31, 32, 59, 60, 66, 73], complement 5 (C5) [32], complement 7 (C7) [32], and complement factor $\mathrm{H}[32,59]$ in $\mathrm{AD}$ plaques. It is likely that the complement system could be activated by $\mathrm{A} \beta$ deposition. Indeed, studies demonstrated that $A \beta$ can bind $C 1 q[70,71]$, an initiating protein of classical complement activation, and activate the cascade in $\mathrm{AD}$ brain in the absence of immunoglobulins [70].

C1q has been found highly increased in human and mouse brains with age $[145,146]$ and may damage synapses. An adult mouse model lacking $\mathrm{C} 1 \mathrm{q}(\mathrm{C} 1 \mathrm{qKO})$ exhibited better synaptic plasticity and significantly less cognitive and memory decline compared to wild-type 
Table 1 Biochemical and biophysical evidence of interactions of $A \beta$ with other proteins, and their presence in senile plaque and potential for AD biomarker

\begin{tabular}{|c|c|c|c|c|c|}
\hline \multirow[t]{2}{*}{ Protein name } & \multicolumn{2}{|l|}{ Bound to $A \beta$ in vitro } & \multicolumn{2}{|c|}{ Found in post-mortem $A D$ plaque and $C A A$} & \multirow{2}{*}{$\begin{array}{l}\text { Candidate } \\
\text { biomarker } \\
\text { for } A D\end{array}$} \\
\hline & $\begin{array}{l}A \beta \text { monomer, oligomers, } \\
\text { and protofibrils }\end{array}$ & $A \beta$ fibrils & Reported by & $\begin{array}{l}\text { Brain region; and plaque } \\
\text { types/CAA }\end{array}$ & \\
\hline \multicolumn{6}{|l|}{ Immunoglobulins } \\
\hline Ig alpha-1 chain $C$ region & {$[50]^{\mathrm{a}}$} & {$[52,56]^{b, d}$} & {$[32,33,59,60]^{f, j t, g, h}$} & $\begin{array}{l}\mathrm{HC}^{f}, \mathrm{FCtx}^{j \dagger}, \mathrm{HC}^{g}, \mathrm{CCtx} \text { and } \\
\mathrm{Cve}^{\mathrm{h}}\end{array}$ & $\begin{array}{l}{[61]: \uparrow P} \\
{[62]: \uparrow C}\end{array}$ \\
\hline Ig gamma-1 chain $C$ region & {$[50]^{\mathrm{a}}$} & {$[51,52,56]^{e, b, d}$} & {$[26,32,33,59]^{\mathrm{i}, \mathrm{f}, \mathrm{j} t, \mathrm{~g}}$} & F-tCtx ${ }^{i}, H C^{f}, F C t x^{j \dagger}, H^{g}$ & {$[61]: \downarrow P$} \\
\hline Ig gamma-2 chain $C$ region & {$[50]^{\mathrm{a}}$} & {$[52,56]^{\mathrm{b}, \mathrm{d}}$} & {$[26,32,33,59]^{i, j, j t, g}$} & $F-t C t x^{i}, H C^{f}, F C t x^{j \dagger}, H C^{g}$ & \\
\hline Ig gamma-3 chain $C$ region & {$[50]^{\mathrm{a}}$} & {$[52,56]^{b, d}$} & {$[26,32,33,59]^{\mathrm{i}, \mathrm{i}, \mathrm{j}, \mathrm{g}}$} & F-tCtx ${ }^{i}, H C^{f}, F C t x^{j \dagger}, H C^{g}$ & \\
\hline Ig kappa chain $\mathrm{C}$ region & {$[50]^{\mathrm{a}}$} & {$[51,52,56]^{e, b, d}$} & $\begin{array}{l}{[26,32,33,59} \\
60] \text { ],ifit,g,h }\end{array}$ & $\begin{array}{l}\text { F-tCtxi, } \mathrm{HC}^{\mathrm{f}}, \mathrm{FCttx}^{\mathrm{j} \dagger}, \mathrm{HC}^{\mathrm{g}}, \\
\mathrm{CC} \mathrm{Ctx} \text { and } \mathrm{Cve}^{\mathrm{h}}\end{array}$ & {$[61]: \uparrow P$} \\
\hline Ig mu chain $C$ region & {$[50]^{\mathrm{a}}$} & {$[51,52,56]^{\mathrm{e}, \mathrm{b}, \mathrm{d}}$} & {$[32,33]^{\mathrm{fj} t}$} & $H C^{f}, F C t x^{j \dagger}$ & {$[61]: \downarrow P$} \\
\hline $\begin{array}{l}\text { Immunoglobulin heavy } \\
\text { constant alpha } 2\end{array}$ & & {$[51,56]^{e, d}$} & & & \\
\hline $\begin{array}{l}\text { Immunoglobulin heavy } \\
\text { variable 3-7 }\end{array}$ & & {$[51,53]^{\mathrm{e}, j}$} & & & \\
\hline \multicolumn{6}{|l|}{ Complement system } \\
\hline Alpha-1-antichymotrypsin & {$[50,63-65]^{a, k, 1, n}$} & {$[56]^{d}$} & $\begin{array}{l}{[28,31,32,59,60} \\
66,67]^{\text {qr, r, } f, g, h, s, t}\end{array}$ & $\begin{array}{l}\text { FCtx and TCtx }{ }^{r}, H_{C}^{f, g}, C C t x \\
\text { and } C v e^{h}, \text { PreFCtx }{ }^{s}\end{array}$ & $\begin{array}{l}{[68]: \uparrow P} \\
{[69]: \uparrow C}\end{array}$ \\
\hline $\begin{array}{l}\text { C4b-binding protein alpha } \\
\text { chain }\end{array}$ & & {$[52,53,56]^{\mathrm{bj,d}}$} & {$[28,32,33]^{9,9, j+}$} & $H C^{f}, F C t x^{j \dagger}$ & \\
\hline $\begin{array}{l}\text { Complement } \mathrm{Clq} \\
\text { subcomponent subunit } \\
\text { A/subunit B/subunit C }\end{array}$ & {$[50,70]^{\mathrm{a}, \mathrm{u}}$} & $\begin{array}{l}{[51,56,71} \\
72]^{e, d, v, w}\end{array}$ & $\begin{array}{l}{[26,28,31-33,59,} \\
60,66,73]^{-, q, r, f, g, j, h, h, s, x}\end{array}$ & $\begin{array}{l}\text { F-tCtx', FCtx and TCtx' } H^{r} C^{f} \\
F C t x^{j+}, H C^{g}, C C t x \text { and } C v e^{h}, \\
\text { PreFCtx }\end{array}$ & $\begin{array}{l}{[74]: \downarrow C} \\
\text { (subunit } B / C \text { ) }\end{array}$ \\
\hline $\begin{array}{l}\text { Complement } \mathrm{C} 1 \mathrm{r} \\
\text { subcomponent }\end{array}$ & & $\begin{array}{l}{[51-53,} \\
56]^{\mathrm{e}, \mathrm{b}, \mathrm{j}, \mathrm{d}}\end{array}$ & {$[32,33]^{\mathrm{fj} j \mathrm{j}}$} & $H C^{f}, F C t x^{j+}$ & \\
\hline $\begin{array}{l}\text { Complement } \mathrm{C} 1 \mathrm{~s} \\
\text { subcomponent }\end{array}$ & & $\begin{array}{l}{[51-53,} \\
56]^{\mathrm{e}, \mathrm{b}, \mathrm{j}, \mathrm{d}}\end{array}$ & {$[32,33]^{f, j t}$} & $H C^{f}, \mathrm{FCtx}^{j+}$ & {$[74]: \downarrow C$} \\
\hline Complement C3 & $\begin{array}{l}{[50]^{\mathrm{a}}} \\
0.3 \mu \mathrm{M}(\mathrm{A} \beta 42 \mathrm{PF})^{\mathrm{a}}\end{array}$ & $\begin{array}{l}{[51-53,56,72} \\
75]^{\mathrm{e}, b, j, d, w, y}\end{array}$ & $\begin{array}{l}{[26,28,31-33,59,} \\
60,66,73]^{i, q, r, f, j, t, h, h, s, x}\end{array}$ & 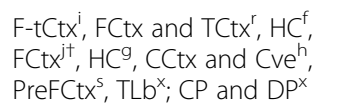 & $\begin{array}{l}{[76,77]: \uparrow P / S,} \\
{[78]: \uparrow C}\end{array}$ \\
\hline Complement C4-A/C4-B & {$[50]^{\mathrm{a}}$} & $\begin{array}{l}{[51-53,56} \\
72]^{e, b, d, d, w}\end{array}$ & $\begin{array}{l}{[26,31,32,59,60} \\
66,73] \text { i,r, }, \text {, }, h, h, x, x\end{array}$ & $\begin{array}{l}\text { F-tCtx }{ }^{i}, F C t x \text { and TCtx }{ }^{r}, H^{f, g}, \\
\text { CCtx and Cve }{ }^{h}, \text { PreFCtx } \\
\text { TLb }^{x} ; C P \text { and DP }\end{array}$ & $\begin{array}{l}{[61,76]: \uparrow \downarrow S} \\
{[79]: \uparrow C}\end{array}$ \\
\hline Complement C5 & & {$[53,56,72]^{j, d, w}$} & {$[32,33]^{\mathrm{f}, \mathrm{j} \dagger}$} & $H C^{f}, F C t x^{j+}$ & \\
\hline Complement component C7 & & {$[51,53,56]^{\mathrm{ej,j}, \mathrm{d}}$} & {$[32,33]^{\mathrm{fj} j \mathrm{j}}$} & $H C^{f}, F C t x^{j+}$ & \\
\hline $\begin{array}{l}\text { Complement component C8 } \\
\text { gamma chain }\end{array}$ & & $[53,56]]^{\mathrm{j} d}$ & {$[32,33,60]^{\mathrm{fj} j, \mathrm{~h}}$} & $\mathrm{HC}^{\mathrm{f}}, \mathrm{FCtx}{ }^{\mathrm{j} \dagger}, \mathrm{CCtx}$ and $\mathrm{Cve}^{\mathrm{h}}$ & \\
\hline Complement component C9 & & {$[51,53,56]^{\mathrm{ej,d}}$} & {$[32,33]^{\mathrm{fj} t}$} & $H C^{f}, F C H x^{j+}$ & \\
\hline Complement factor $\mathrm{H}$ & & $\begin{array}{l}{[51-53,} \\
56]^{\mathrm{e}, \mathrm{b}, \mathrm{j}, \mathrm{d}}\end{array}$ & {$[32,33,59]^{\mathrm{fj} \mathrm{j}, \mathrm{g}}$} & $H C^{f}, F C t x^{j \dagger}, H C^{g}$ & {$[61,76]: \uparrow P / S$} \\
\hline $\begin{array}{l}\text { Complement factor } \mathrm{H} \text {-related } \\
\text { protein } 5\end{array}$ & {$[50]^{a}$} & {$[51,56]^{\mathrm{e}, \mathrm{d}}$} & & & \\
\hline $\begin{array}{l}\text { Inter-alpha-trypsin inhibitor } \\
\text { heavy chain } \mathrm{H} 4\end{array}$ & {$[50]^{\mathrm{a}}$} & {$[51,53,56]^{e, j, d}$} & {$[32,33]^{\mathrm{fj} t}$} & $H C^{f}, F C t x^{j+}$ & $\begin{array}{l}{[61]: \downarrow P,} \\
{[80]: \uparrow C}\end{array}$ \\
\hline $\begin{array}{l}\text { Monocyte differentiation } \\
\text { antigen CD14 }\end{array}$ & {$[50]^{a}$} & {$[51,56]^{\mathrm{e}, \mathrm{d}}$} & {$[32,33]^{\mathrm{f}, \mathrm{jt}}$} & $H C^{f}, F C t x^{j+}$ & \\
\hline Plasma protease $\mathrm{C} 1$ inhibitor & & {$[51,56]^{e, d}$} & {$[32,33,60]^{\mathrm{fj} j, \mathrm{~h}}$} & $\mathrm{HC}^{f}, \mathrm{FCtx}{ }^{j \dagger}, \mathrm{CCtx}$ and $\mathrm{Cve}^{\mathrm{h}}$ & \\
\hline \multicolumn{6}{|l|}{$\begin{array}{l}\text { Lipid metabolism/ } \\
\text { transport }\end{array}$} \\
\hline Apolipoprotein A-I & $\begin{array}{l}{[50,81-84]^{a, z, a t, b+, d \dagger}} \\
3 \mu M(A \beta 42 P F)^{a}\end{array}$ & $\begin{array}{l}{[51-53,56,} \\
85]^{\text {e,bid, d,et }}\end{array}$ & $\begin{array}{l}{[32,33,59,60,66} \\
86]^{\text {jit, g,h, h, ff }}\end{array}$ & $\begin{array}{l}\mathrm{HC}^{f}, \mathrm{FCtx}^{j \dagger}, \mathrm{HC}^{\mathrm{g}}, \mathrm{CCtx} \text { and } \\
\mathrm{Cve}^{\mathrm{h}}, \mathrm{PreFCtx}^{\mathrm{s}}, \mathrm{HC}^{\mathrm{ft}}\end{array}$ & $\begin{array}{l}{[87-89]: \downarrow S / P,} \\
{[90]: \uparrow C}\end{array}$ \\
\hline
\end{tabular}


Table 1 Biochemical and biophysical evidence of interactions of $A \beta$ with other proteins, and their presence in senile plaque and potential for AD biomarker (Continued)

\begin{tabular}{|c|c|c|c|c|c|}
\hline \multirow[t]{2}{*}{ Protein name } & \multicolumn{2}{|l|}{ Bound to $A \beta$ in vitro } & \multicolumn{2}{|c|}{ Found in post-mortem $A D$ plaque and CAA } & \multirow{2}{*}{$\begin{array}{l}\text { Candidate } \\
\text {-biomarker } \\
\text { for AD }\end{array}$} \\
\hline & $\begin{array}{l}A \beta \text { monomer, oligomers, } \\
\text { and protofibrils }\end{array}$ & $A \beta$ fibrils & Reported by & $\begin{array}{l}\text { Brain region; and plaque } \\
\text { types/CAA }\end{array}$ & \\
\hline Apolipoprotein A-\| & {$[50,82]^{\mathrm{a}, \mathrm{a} \dagger}$} & $\begin{array}{l}{[51-53,56} \\
85]^{e, b, j, d, e t}\end{array}$ & {$[32,33]^{\mathrm{fjt}}$} & $\mathrm{HC}^{f}, \mathrm{FCtx}^{\mathrm{j}+}$ & \\
\hline Apolipoprotein A-IV & {$[50,83]^{\mathrm{a}, \mathrm{b}+}$} & $\begin{array}{l}{[51-53,} \\
56]^{e, b, j, d}\end{array}$ & {$[32,33]^{\mathrm{fj} t}$} & $H C^{f}, F C t x^{j+}$ & $\begin{array}{l}\text { [88]: } \uparrow, \\
\text { [80]: } \uparrow C\end{array}$ \\
\hline Apolipoprotein B-100 & {$[50]^{a}$} & {$[52]^{b}$} & {$[32,33,60]^{\mathrm{fj}, \mathrm{j}, \mathrm{h}}$} & $H C^{f}, F C t x^{j \dagger}, C C t x$ and $C v e^{h}$ & {$[76,89]: \uparrow \downarrow S$} \\
\hline Apolipoprotein C-I & & {$[51,52,56]^{e, b, d}$} & & & {$[91]: \downarrow C$} \\
\hline Apolipoprotein C-II & {$[92]^{9 \dagger}$} & {$[51,52]^{e, b}$} & {$[32,33]^{\mathrm{fj} t}$} & $H C^{f}, F C t x^{j+}$ & \\
\hline Apolipoprotein C-III & & $\begin{array}{l}{[51-53,} \\
56]^{\mathrm{e}, \mathrm{b}, \mathrm{j}, \mathrm{d}}\end{array}$ & {$[32,33,59]^{\mathrm{fj}, \mathrm{g}, \mathrm{g}}$} & $H C^{f}, F C t x^{j \dagger}, H C^{g}$ & \\
\hline Apolipoprotein C-IV & {$[50]^{a}$} & {$[51,56]^{e, d}$} & & & \\
\hline Apolipoprotein D & {$[50]^{\mathrm{a}}$} & {$[51,52,56]^{e, b, d}$} & $\begin{array}{l}{[32,33,59,60,66,} \\
93,94]^{f, j t, g, h, s, h t, i t}\end{array}$ & $\begin{array}{l}\mathrm{HC}^{f}, \mathrm{FCtx}^{j+}, \mathrm{HC}^{g}, \mathrm{CCtx} \text { and } \\
\mathrm{Cve}^{h}, \mathrm{PreFCtx}^{\mathrm{s}}, \mathrm{CCtx} \text { and } \\
\mathrm{HC}^{h+, i t ;}, \mathrm{DP} \text {, around } \mathrm{CP} \text {, and } \\
\mathrm{CAA}^{\mathrm{ht}, i+}\end{array}$ & {$[95,96]: \downarrow C$} \\
\hline Apolipoprotein E & $\begin{array}{l}{[50,63,82-84]^{a, k, a t, b t, d t}} \\
3 \text { nM (Aß42PF) } \\
19 \text { nM (Aß40M) }\end{array}$ & $\begin{array}{l}{[51-53,56,} \\
85]^{e, b, j, d, d e t}\end{array}$ & $\begin{array}{l}{[28,31-33,59,60} \\
66,94]^{q, r, f, j], g, h, h, i t}\end{array}$ & 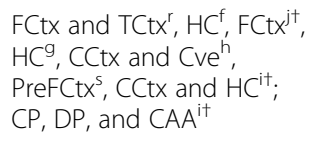 & 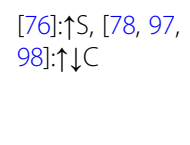 \\
\hline Apolipoprotein L1 & & {$[51,53,56]^{\mathrm{ej,d}}$} & {$[32,33]^{\mathrm{fjt}}$} & $H C^{f}, F C t x^{j \dagger}$ & \\
\hline Beta-2-glycoprotein 1 & & {$[51,56]^{e, d}$} & {$[32,33]^{\mathrm{f}, \mathrm{j} t}$} & $H C^{f}, F C t x^{j \dagger}$ & \\
\hline Clusterin (a.k.a, ApoJ) & $\begin{array}{l}{[50,81-83,99,100]^{a, z, a t, b+, k+, l+}} \\
4.8 \mathrm{nM}(\mathrm{A} \beta 40 \mathrm{M})^{\mathrm{kt}} \\
2 \mathrm{nM}(\mathrm{A} \beta \mathrm{M})^{1+}\end{array}$ & $\begin{array}{l}{[51-53,56} \\
85]^{e, b, j, d, d e t}\end{array}$ & $\begin{array}{l}{[28,31-33,59,60} \\
66,73 \\
101]^{q, r, f, j t, g, h, s, x, n+}\end{array}$ & $\begin{array}{l}\text { FCtx and TCtx' }, \mathrm{HC}^{f}, \mathrm{FCtx}^{\mathrm{j} \dagger}, \\
\mathrm{HC}^{\mathrm{g}}, \mathrm{CCtx} \text { and } \mathrm{Cve}^{h}, \\
\text { PreFCtx } \\
\mathrm{CP}^{\mathrm{x}, \mathrm{nt}}, \mathrm{TLb}^{\mathrm{x}}, \mathrm{EntCtx}^{\mathrm{nt}} \text {; }\end{array}$ & $\begin{array}{l}{[102]: \downarrow P,} \\
{[78]: \uparrow C}\end{array}$ \\
\hline Phospholipid transfer protein & {$[50]^{a}$} & {$[51,56]^{e, d}$} & {$[32,33]^{\mathrm{f,jt}}$} & $H C^{f}, F C t x^{j \dagger}$ & \\
\hline $\begin{array}{l}\text { Prostaglandin-H2 D- } \\
\text { isomerase }\end{array}$ & {$[50]^{a}$} & {$[51,56]^{e, d}$} & {$[32,59,60,66]^{f, g, h, s}$} & $\begin{array}{l}\mathrm{HC}^{\mathrm{f}, \mathrm{g}}, \mathrm{CCtx} \text { and } \mathrm{Cve}^{\mathrm{h}} \text {, } \\
\text { PreFCtx }\end{array}$ & {$[62,103]: \uparrow \downarrow C$} \\
\hline Serum amyloid A-4 protein & {$[50]^{\mathrm{a}}$} & {$[51,53,56]^{e, j, d}$} & {$[32,33]^{\mathrm{f}, j \dagger}$} & $H C^{f}, F C t x^{j+}$ & \\
\hline \multicolumn{6}{|l|}{$\begin{array}{l}\text { Blood coagulation/ } \\
\text { hemostasis }\end{array}$} \\
\hline $\begin{array}{l}\text { Adipocyte enhancer-binding } \\
\text { protein } 1\end{array}$ & & {$[51,56]^{e, d}$} & & & \\
\hline Alpha-1-antitrypsin & {$[50]^{a}$} & {$[51,52,56]^{e, b, d}$} & $\begin{array}{l}{[28,31-33,59,60} \\
66]^{q, r, f, j t, g, h, s}\end{array}$ & 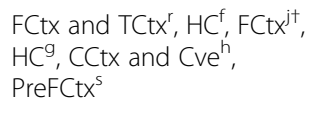 & $\begin{array}{l}{[89,102,104]:} \\
\uparrow \downarrow P / S,[80,96]: \\
\uparrow \downarrow C\end{array}$ \\
\hline Alpha-2-macroglobulin & $\begin{array}{l}{[84,105,106]^{d+, r t, s t}} \\
0.34 \mu M(A \beta 40 M)^{d t} \\
0.35 \mu M(A \beta 40 M)^{r t^{\prime}}, 38 \mu M \\
(A \beta 42 M)^{s \dagger}\end{array}$ & {$[53,56]^{\mathrm{j}, \mathrm{d}}$} & $\begin{array}{l}{[28,31-33,59,60} \\
66]^{q, r, f, j t, g, h, s}\end{array}$ & $\begin{array}{l}\text { FCtx and TCtx } x^{r}, H C^{f}, \mathrm{FCtx}^{\mathrm{j}+}, \\
\mathrm{HC}^{\mathrm{g}}, \mathrm{CCtx} \text { and } \mathrm{Cve}^{\mathrm{h}}, \\
\text { PreFCtx }\end{array}$ & $\begin{array}{l}{[61,76,107]:} \\
\uparrow P / S\end{array}$ \\
\hline Angiotensinogen & {$[50]^{a}$} & {$[51,56]^{e, d}$} & {$[32,33,59]^{\mathrm{f}, \mathrm{j}, \mathrm{g}}$} & 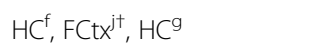 & \\
\hline Antithrombin-III & $\begin{array}{l}{[50]^{\mathrm{a}}} \\
0.6 \mu \mathrm{M}(\mathrm{A} \beta 42 \mathrm{PF})^{\mathrm{a}}\end{array}$ & {$[51,53,56]^{\mathrm{ej,d}}$} & {$[32,33,59,108]^{f j, g, g, t t}$} & $\mathrm{HC}^{\mathrm{f}}, \mathrm{FCtx}^{\mathrm{j}+}, \mathrm{HC}^{\mathrm{g}}, \mathrm{CCtx}^{\mathrm{tt}} ; \mathrm{CP}^{\mathrm{tt}}$ & {$[69,80]: \uparrow C$} \\
\hline $\begin{array}{l}\text { Beta-1,4- } \\
\text { glucuronyltransferase } 1\end{array}$ & & {$[51,56]^{e, d}$} & {$[32,59]^{f, g}$} & $H C^{f, g}$ & \\
\hline Carboxypeptidase B2 & & {$[53,56]^{\mathrm{j}, \mathrm{d}}$} & {$[33]^{j+}$} & $\mathrm{FCtx}^{\mathrm{j}+}$ & \\
\hline Coagulation factor $V$ & {$[50]^{\mathrm{a}}$} & {$[51,56]^{e, d}$} & {$[33]^{j+}$} & $\mathrm{FCtx}^{\mathrm{j}+}$ & \\
\hline Coagulation factor $X$ & & $\begin{array}{l}{[51,52,} \\
109]^{e, b, u t}\end{array}$ & {$[33]^{\dagger+}$} & $\mathrm{FCtx}^{\mathrm{j}+}$ & \\
\hline Coagulation factor XII & {$[110]^{v+}$} & $\begin{array}{l}{[53,56,} \\
111]]^{j, d, w \dagger}\end{array}$ & {$[32,33,66]^{f, j t, s}$} & $\mathrm{HC}^{f}, \mathrm{FCtx}^{\mathrm{j}}{ }^{\dagger}$, PreFCtx $^{\mathrm{s}}$ & \\
\hline
\end{tabular}


Table 1 Biochemical and biophysical evidence of interactions of $A \beta$ with other proteins, and their presence in senile plaque and potential for AD biomarker (Continued)

\begin{tabular}{|c|c|c|c|c|c|}
\hline \multirow[t]{2}{*}{ Protein name } & \multicolumn{2}{|l|}{ Bound to $A \beta$ in vitro } & \multicolumn{2}{|c|}{ Found in post-mortem $A D$ plaque and CAA } & \multirow{2}{*}{$\begin{array}{l}\text { Candidate } \\
\text {-biomarker } \\
\text { for } A D\end{array}$} \\
\hline & $\begin{array}{l}A \beta \text { monomer, oligomers, } \\
\text { and protofibrils }\end{array}$ & $A \beta$ fibrils & Reported by & $\begin{array}{l}\text { Brain region; and plaque } \\
\text { types/CAA }\end{array}$ & \\
\hline $\begin{array}{l}\text { Fibrinogen alpha-, beta-, } \\
\text { and gamma-chain }\end{array}$ & $\begin{array}{l}{[50,112]^{a, x+}} \\
26 \mathrm{nM}(\mathrm{A} \beta 42 \mathrm{M})^{\mathrm{x}}\end{array}$ & {$[51,52,56]^{e, b, d}$} & $\begin{array}{l}{[31-33,59,60,66} \\
113]^{r, f j t, g, h, h, s y t}\end{array}$ & $\begin{array}{l}\mathrm{FCtx} \text { and } \mathrm{TCtx}{ }^{r}, \mathrm{HC}^{f}, \mathrm{FCtx}^{\mathrm{j}}, \\
\mathrm{HC} \mathrm{C}^{\mathrm{g}}, \mathrm{CCtx} \text { and } \mathrm{CVe}^{\mathrm{h}}, \\
\text { PreFCtx }, \mathrm{FCtx}^{\mathrm{y}+} ; \mathrm{CAA}^{\mathrm{y}+}\end{array}$ & $\begin{array}{l}{[77,88,89]:} \\
\uparrow \downarrow P / S,[98]: \uparrow C\end{array}$ \\
\hline Fibronectin & {$[50]^{\mathrm{a}}$} & $\begin{array}{l}{[51-53,56,} \\
109]^{e, b j, d, d, ~ u t ~}\end{array}$ & {$[32,33,59,66]^{j+f, g, s}$} & $H C^{f}, F C t x^{j \dagger}, H C^{g}, P r e F C t x^{s}$ & [89]: $\uparrow$ \\
\hline $\begin{array}{l}\text { Growth arrest-specific } \\
\text { protein } 6\end{array}$ & & {$[51,56]^{e, d}$} & {$[33]^{\dagger+}$} & $\mathrm{FCtx}^{\mathrm{j}+}$ & {$[114]: \uparrow C$} \\
\hline Heparin cofactor 2 & {$[50]^{\mathrm{a}}$} & {$[51,56]^{\mathrm{e}, \mathrm{d}}$} & {$[32,33]^{\mathrm{f,j} t}$} & $H C^{f}, F C t x^{j+}$ & \\
\hline Histidine-rich glycoprotein & {$[50]^{\mathrm{a}}$} & {$[52,56]^{\mathrm{b}, \mathrm{d}}$} & {$[32,33,59]^{j+, f, g}$} & $F C t x^{j \dagger}, H C^{f, g}$ & [76]:१S \\
\hline $\begin{array}{l}\text { Hyaluronan-binding } \\
\text { protein } 2\end{array}$ & & {$[52,56]^{\mathrm{b}, \mathrm{d}}$} & {$[31-33]^{r, f, j t}$} & FCtx and TCtx', HC, $\mathrm{FCtx}^{\mathrm{j}+}$ & \\
\hline Kininogen-1 & & {$[51,53,56]^{\mathrm{ej,d}}$} & {$[32,33]^{\mathrm{fj} t}$} & $H C^{f}, F C t x^{j+}$ & \\
\hline Plasminogen & & $\begin{array}{l}{[51,53} \\
109]^{e j, u+}\end{array}$ & {$[32,33]^{\mathrm{f}, j \dagger}$} & $H C^{f}, F C t x^{j \dagger}$ & $\begin{array}{l}{[78]: \uparrow C} \\
{[88]: \downarrow P}\end{array}$ \\
\hline Prothrombin & {$[50]^{\mathrm{a}}$} & $\begin{array}{l}{[51-53,} \\
56]^{\mathrm{e}, \mathrm{b}, \mathrm{j}, \mathrm{d}}\end{array}$ & {$[32,33]^{\mathrm{f}, \mathrm{j} t}$} & $H C^{f}, F C t x^{j+}$ & \\
\hline $\begin{array}{l}\text { Vitamin K-dependent } \\
\text { protein S }\end{array}$ & & $\begin{array}{l}{[51-53,} \\
56]^{e, b, j, d}\end{array}$ & {$[32,33]^{\mathrm{fj} t}$} & $H C^{f}, F C t x^{j+}$ & \\
\hline \multicolumn{6}{|l|}{ Metabolism } \\
\hline Alpha-enolase & {$[50]^{a}$} & {$[51,56]^{e, d}$} & $\begin{array}{l}{[32,33,59,60,66} \\
115]^{f j, t, g, h, s, z+}\end{array}$ & $\begin{array}{l}\mathrm{HC}^{\mathrm{f}}, \mathrm{FCtx}^{\mathrm{j}+}, \mathrm{HC}^{\mathrm{g}}, \mathrm{CCtx} \text { and } \\
\mathrm{Cve}^{\mathrm{h}}, \mathrm{PreFCtx}^{\mathrm{s}}\end{array}$ & \\
\hline $\begin{array}{l}\text { Glyceraldehyde-3-phosphate } \\
\text { dehydrogenase }\end{array}$ & {$[50,63]^{\mathrm{a}, \mathrm{k}}$} & $\begin{array}{l}{[51,56,} \\
116]^{e, d, a \neq}\end{array}$ & $\begin{array}{l}{[31,32,59,60} \\
66]^{r, f, g, h, s}\end{array}$ & $\begin{array}{l}\text { FCtx and TCtx', HC, f,g CCtx } \\
\text { and } \mathrm{Cve}^{\mathrm{h}}, \mathrm{PreFCtx}^{\mathrm{s}}, \mathrm{F}\end{array}$ & \\
\hline Phosphoglycerate kinase 1 & {$[50]^{a}$} & {$[56]^{d}$} & $\begin{array}{l}{[31-33,59,60} \\
66]^{r, f j t, g, h, s}\end{array}$ & $\begin{array}{l}\text { FCtx and TCtx }{ }^{r}, H^{f}{ }^{f} \mathrm{FCtx}^{\mathrm{j}+}, \\
\mathrm{HC} \mathrm{C}^{\mathrm{g}} \text {, CCtx and } \mathrm{Cve}^{\mathrm{h}}, \\
\text { PreFCtx }\end{array}$ & \\
\hline $\begin{array}{l}\text { Procollagen C-endopeptidase } \\
\text { enhancer } 1\end{array}$ & {$[50]^{\mathrm{a}}$} & {$[51,56]^{e, d}$} & & & \\
\hline \multicolumn{6}{|l|}{ Molecular transport } \\
\hline Haptoglobin & {$[50]^{\mathrm{a}}$} & {$[53,56]^{\mathrm{j}, \mathrm{d}}$} & $\begin{array}{l}{[32,33,59,60} \\
66]^{\mathrm{f} j \mathrm{t}, \mathrm{g}, \mathrm{h}, \mathrm{s}}\end{array}$ & $\begin{array}{l}\mathrm{HC}^{f}, \mathrm{FCtx}^{j+}, \mathrm{HC}^{g}, \mathrm{CCtx} \text { and } \\
\mathrm{Cve}^{h}, \text { PreFCtx }^{s}\end{array}$ & [76]:१S \\
\hline $\begin{array}{l}\text { Hemoglobin subunit alpha/ } \\
\text { subunit beta }\end{array}$ & {$[50]^{\mathrm{a}}$} & {$[51,56]^{e, d}$} & $\begin{array}{l}{[31-33,59,60} \\
66]^{r, f j t, g, h, s}\end{array}$ & $\begin{array}{l}\text { FCtx and TCtx } x^{r}, H^{f}, \mathrm{FCtx}^{\mathrm{j}+}, \\
\mathrm{HC}^{\mathrm{g}}, \mathrm{CCtx} \text { and } \mathrm{Cve}^{\mathrm{h}}, \\
\text { PreFCtx }\end{array}$ & [76]:१S \\
\hline Hemopexin & & {$[53,56]^{\mathrm{j}, \mathrm{d}}$} & {$[32,33,59]^{\mathrm{fj}, \mathrm{g}, \mathrm{g}}$} & $H C^{f}, F C t x^{j \dagger}, H C^{g}$ & [104]:^P \\
\hline $\begin{array}{l}\text { Inter-alpha-trypsin inhibitor } \\
\text { heavy chain } \mathrm{H} 2\end{array}$ & {$[50]^{\mathrm{a}}$} & {$[53,56]^{\mathrm{j}, \mathrm{d}}$} & {$[32,33]^{\mathrm{f,jt}}$} & $H C^{f}, \mathrm{FCtx}^{\mathrm{j}+}$ & \\
\hline Serotransferrin & {$[50]^{\mathrm{a}}$} & {$[53,56]^{\mathrm{j}, \mathrm{d}}$} & {$[31-33,59,66]^{r, j, j+g, s}$} & $\begin{array}{l}\text { FCtx and } T C t x^{r}, H C^{f}, F C t x^{j \dagger}, H C^{g} \text {, } \\
\text { PreFCtx }\end{array}$ & \\
\hline Serum albumin & $\begin{array}{l}{[50,83,117-120]^{\mathrm{a}, \mathrm{b}+,}, \mathrm{b \neq}, \mathrm{c} \neq, \mathrm{d} \neq, \mathrm{e} \neq} \\
1-100 \mathrm{nM}(\mathrm{A} \beta 40 \mathrm{O})^{\mathrm{b} \neq}, 1.7 \mu \mathrm{M} \\
(\mathrm{A} \beta 42 \mathrm{M})^{\mathrm{c} \neq}, 5 \mu \mathrm{M}(\mathrm{A} \beta 40 \mathrm{M})^{\mathrm{d} \neq}, \\
\sim 0.1-1 \mathrm{mM}(\mathrm{A} \beta 40 \mathrm{M})^{\mathrm{e} \neq}\end{array}$ & $\begin{array}{l}{[51-53,56} \\
109]^{\mathrm{e}, \mathrm{b} j \mathrm{j}, \mathrm{d}, \mathrm{u}}+\end{array}$ & {$[31-33]^{r, f, j t}$} & FCtx and TCtx ${ }^{r}, H C^{f}, F C t x^{j \dagger}$ & $\begin{array}{l}{[61]: \uparrow P,[62,98]:} \\
\uparrow \downarrow C\end{array}$ \\
\hline Transthyretin & $\begin{array}{l}{[81,121]^{\mathrm{zff}}} \\
\sim 28 \mathrm{nM}(\mathrm{A} \beta 40 \mathrm{M} / \mathrm{O})^{\mathrm{f \neq}}\end{array}$ & $\begin{array}{l}{[51,52,56,} \\
121] \\
{[122]^{e, b, d, f \neq, h \neq}} \\
\sim 28 \mathrm{nM} \\
(\mathrm{A} \beta 42 \mathrm{~F})^{f \neq}\end{array}$ & {$[32,33,66]^{\mathrm{f}, \mathrm{j}, \mathrm{s}}$} & $H C^{f}, F_{C t x}{ }^{j \dagger}$, PreFCtx ${ }^{5}$ & 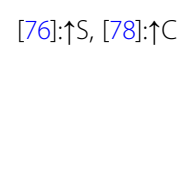 \\
\hline Vitamin D-binding protein & & $\begin{array}{l}{[51-53,} \\
56]^{\mathrm{e}, \mathrm{b}, \mathrm{j}, \mathrm{d}}\end{array}$ & {$[32,33,59]^{\mathrm{fj}, \mathrm{g} g}$} & $H C^{f}, F C t x^{j \dagger}, H C^{g}$ & $\begin{array}{l}\text { [102]:^P, } \\
{[78]: \uparrow C}\end{array}$ \\
\hline
\end{tabular}


Table 1 Biochemical and biophysical evidence of interactions of $A \beta$ with other proteins, and their presence in senile plaque and potential for AD biomarker (Continued)

\begin{tabular}{|c|c|c|c|c|c|}
\hline \multirow[t]{2}{*}{ Protein name } & \multicolumn{2}{|l|}{ Bound to $A \beta$ in vitro } & \multicolumn{2}{|c|}{ Found in post-mortem $A D$ plaque and CAA } & \multirow{2}{*}{$\begin{array}{l}\text { Candidate } \\
\text {-biomarker } \\
\text { for } A D\end{array}$} \\
\hline & $\begin{array}{l}A \beta \text { monomer, oligomers, } \\
\text { and protofibrils }\end{array}$ & $A \beta$ fibrils & Reported by & $\begin{array}{l}\text { Brain region; and plaque } \\
\text { types/CAA }\end{array}$ & \\
\hline \multicolumn{6}{|l|}{ Neural proteins } \\
\hline Amyloid-like protein 1 & & {$[51,52,56]^{e, b, d}$} & {$[32,33,59]^{\mathrm{fj} t, \mathrm{~g}}$} & $H C^{f}, F C t x^{j \dagger}, H C^{g}$ & {$[62,123]: \uparrow \downarrow C$} \\
\hline Brevican core protein & & {$[51,109]^{\text {eut }}$} & $\begin{array}{l}{[32,33,59,60} \\
66]^{\mathrm{fjj}, \mathrm{g}, \mathrm{h}, \mathrm{s}}\end{array}$ & $\begin{array}{l}\mathrm{HC}^{\mathrm{f}}, \mathrm{FCtx}^{j \dagger}, \mathrm{HC}^{\mathrm{g}}, \mathrm{CCtx} \text { and } \\
\mathrm{Cve}^{h}, \mathrm{PreFCtx}^{\mathrm{s}}\end{array}$ & \\
\hline $\begin{array}{l}\text { Neural cell adhesion } \\
\text { molecule } 1\end{array}$ & & {$[51,56]^{e, d}$} & $\begin{array}{l}{[31-33,59,60} \\
66]^{r, f j t, g, h, h, s}\end{array}$ & $\begin{array}{l}\text { FCtx and TCtx', } \mathrm{HC}^{f}, \mathrm{FCtx}^{\mathrm{j} \dagger} \text {, } \\
\mathrm{HC}^{\mathrm{g}}, \mathrm{CCtx} \text { and } \mathrm{Cve}^{\mathrm{h}} \text {, } \\
\text { PreFCtx }\end{array}$ & [103]:^C \\
\hline Neurocan core protein & & $\begin{array}{l}{[51,109]^{\mathrm{e}, \mathrm{u} t}} \\
11.7 \mathrm{nM} \\
(\mathrm{A} \beta 42 \mathrm{~F})^{\mathrm{e}}\end{array}$ & $\begin{array}{l}{[32,33,59,60} \\
66]^{j, j, g, h, h}\end{array}$ & $\begin{array}{l}\mathrm{HC}^{f}, \mathrm{FCtx}^{\mathrm{j}}, \mathrm{HC}^{g}, \mathrm{CCtx} \text { and } \\
\mathrm{Cve}^{\mathrm{h}}, \mathrm{PreFCtx}^{\mathrm{s}}\end{array}$ & \\
\hline Neurosecretory protein VGF & & {$[51,56]^{\mathrm{e}, \mathrm{d}}$} & {$[32,33,59,66]^{\mathrm{fj} j \mathrm{j}, \mathrm{g}, \mathrm{s}}$} & $H C^{f}, F C t x^{j \dagger}, H C^{g}, P r e F C t x^{s}$ & $\begin{array}{l}{[79,90,124,} \\
125]: \downarrow C\end{array}$ \\
\hline ProSAAS & & {$[51,52,56]^{e, b, d}$} & $\begin{array}{l}{[32,33,59,60,} \\
66]^{\mathrm{fj} j, g, \mathrm{~h}, \mathrm{~s}}\end{array}$ & $\begin{array}{l}\mathrm{HC}^{\mathrm{f}}, \mathrm{FCtx}^{j \dagger}, \mathrm{HC}^{g}, \mathrm{CCtx} \text { and } \\
\mathrm{Cve}^{\mathrm{h}}, \mathrm{PreFCtx}^{\mathrm{s}}\end{array}$ & {$[62,78]: \uparrow \downarrow C$} \\
\hline \multicolumn{6}{|l|}{$\begin{array}{l}\text { Cell adhesion, extracellular } \\
\text { matrix, and proteoglycans }\end{array}$} \\
\hline Agrin & & $\begin{array}{l}{[51,109,} \\
126]^{e, u+, i \neq} \\
3.5 \mathrm{nM} \\
(\mathrm{A} \beta 42 \mathrm{~F})^{\mathrm{e}}\end{array}$ & $\begin{array}{l}{[32,33,59,60,66} \\
126]^{\mathrm{fj}, \mathrm{t}, \mathrm{g}, \mathrm{h}, \mathrm{s}, \mathrm{j}=\mathrm{f}}\end{array}$ & 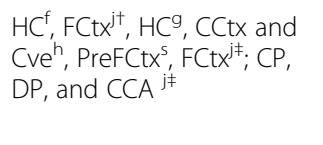 & {$[127]^{k \neq}$} \\
\hline $\begin{array}{l}\text { Basement membrane-specific } \\
\text { heparan sulfate proteoglycan } \\
\text { core protein }\end{array}$ & & {$[51,56]^{e, d}$} & $\begin{array}{l}{[32,33,59,60} \\
66]^{j, j, g, h, h}\end{array}$ & $\begin{array}{l}\mathrm{HC}^{f}, \mathrm{FCtx}^{\mathrm{j}+}, \mathrm{HC}^{\mathrm{g}}, \mathrm{CCtx} \text { and } \\
\mathrm{Cve}^{\mathrm{h}}, \mathrm{PreFCtx}^{\mathrm{s}}\end{array}$ & \\
\hline Cartilage acidic protein 1 & {$[50]^{\mathrm{a}}$} & {$[51,56]^{e, d}$} & {$[32,33,59,60]^{\mathrm{f}, \mathrm{j} t, \mathrm{~g}, \mathrm{~h}}$} & $\begin{array}{l}\mathrm{HC}^{f}, \mathrm{FCtx}^{\mathrm{j}+}, \mathrm{HC}^{g}, \mathrm{CCtx} \text { and } \\
\mathrm{Cve}^{\mathrm{h}}\end{array}$ & \\
\hline Collagen alpha-1(XVIII) chain & {$[50]^{\mathrm{a}}$} & {$[51,56]^{e, d}$} & {$[32,33,59,66]^{\mathrm{fj} t, \mathrm{~g}, \mathrm{~s}}$} & $H C^{f}, F C t x^{j \dagger}, H C^{g}, P r e F C t x^{s}$ & \\
\hline Decorin & {$[50,128]^{\mathrm{a}, 1 \neq}$} & $\begin{array}{l}{[51,56,} \\
109]^{\text {ed, dit }}\end{array}$ & {$[32,33,129]^{\mathrm{f}, \mathrm{j}, \mathrm{n} \neq}$} & $H C^{f}, F C t x^{j \dagger}, H C^{n \neq} ; C P^{n \neq}$ & \\
\hline Desmoplakin & {$[50]^{\mathrm{a}}$} & {$[51,56]^{e, d}$} & {$[32,33,59,66]^{\mathrm{fj} t, g, s}$} & $H C^{f}, \mathrm{FCtx}^{\mathrm{j}}{ }^{\dagger}, \mathrm{HC}^{\mathrm{g}}, \operatorname{PreFCtx^{5}}$ & {$[61]: \uparrow P$} \\
\hline $\begin{array}{l}\text { EGF-containing fibulin-like } \\
\text { extracellular matrix protein } 1\end{array}$ & {$[50]^{\mathrm{a}}$} & {$[51,52]^{e, b}$} & {$[32]^{f}$} & $H C^{f}$ & {$[74]: \downarrow C$} \\
\hline Extracellular matrix protein-1 & & {$[53,109]^{\mathrm{j}, \mathrm{ut}}$} & {$[32]^{f}$} & $H C^{f}$ & \\
\hline Extracellular matrix protein-2 & {$[50]^{\mathrm{a}}$} & {$[51,56]^{e, d}$} & {$[32]^{f}$} & $H C^{f}$ & \\
\hline Fibulin-1 & {$[50,83]^{\mathrm{a}, \mathrm{b}+}$} & $\begin{array}{l}{[51-53,} \\
56]^{e, b, j, d}\end{array}$ & {$[32]^{f}$} & $H C^{f}$ & [89]:१S \\
\hline Galectin-3-binding protein & {$[50]^{\mathrm{a}}$} & {$[51,56]^{e, d}$} & {$[32,33,60,66]^{\mathrm{fj} j \mathrm{t}, \mathrm{h}, \mathrm{s}}$} & $\begin{array}{l}\mathrm{HC}^{\mathrm{f}}, \mathrm{FCtx}^{\mathrm{j}{ }^{\dagger}}, \mathrm{CCtx} \text { and } \mathrm{Cve}^{\mathrm{h}} \text {, } \\
\text { PreFCtx }\end{array}$ & \\
\hline Glypican-1 & & $\begin{array}{l}{[51,109} \\
130]^{\text {eutq }} \neq\end{array}$ & {$[32,33,59]^{\mathrm{fj}, \mathrm{j}, \mathrm{g}}$} & $H C^{f}, F C t x^{j \dagger}, H C^{g}$ & \\
\hline $\begin{array}{l}\text { Microfibril-associated } \\
\text { glycoprotein } 4\end{array}$ & {$[50]^{\mathrm{a}}$} & {$[56]^{d}$} & {$[33,66]^{j+, s}$} & $\mathrm{FCtx}^{\mathrm{j}}{ }^{+}$, PreFCtx $^{\mathrm{s}}$ & \\
\hline Mimecan & {$[50]^{\mathrm{a}}$} & {$[51,52,56]^{e, b, d}$} & {$[33,66]^{j+s}$} & $\mathrm{FCtx}^{\mathrm{j}}{ }^{+}$, PreFCtx $^{\mathrm{s}}$ & \\
\hline Osteomodulin & & {$[51,56]^{e, d}$} & & & \\
\hline Osteopontin & & {$[51,56]^{e, d}$} & {$[32,33]^{f, j t}$} & $H C^{f}, F C t x^{j+}$ & [123]:^C \\
\hline Prolargin & {$[50]^{\mathrm{a}}$} & {$[51,56]^{e, d}$} & {$[32,33]^{f, j \dagger}$} & $H C^{f}, F C t x^{j \dagger}$ & \\
\hline SPARC-like protein 1 & & $\begin{array}{l}{[51,52,56,} \\
109]^{\mathrm{e}, \mathrm{b}, \mathrm{d}, \mathrm{ut}} \\
6.2 \mathrm{nM} \\
(\mathrm{A} \beta 42 \mathrm{~F})^{\mathrm{e}}\end{array}$ & {$[32,33,59,60]^{f, j t, g, h}$} & $\begin{array}{l}\mathrm{HC}^{f}, \mathrm{FCtx}^{\mathrm{j}+}, \mathrm{HC}^{g}, \mathrm{CCtx} \text { and } \\
\mathrm{Cve}^{\mathrm{h}}\end{array}$ & [98]:个C \\
\hline
\end{tabular}


Table 1 Biochemical and biophysical evidence of interactions of $A \beta$ with other proteins, and their presence in senile plaque and potential for AD biomarker (Continued)

\begin{tabular}{|c|c|c|c|c|c|}
\hline \multirow[t]{2}{*}{ Protein name } & \multicolumn{2}{|l|}{ Bound to $A \beta$ in vitro } & \multicolumn{2}{|c|}{ Found in post-mortem $A D$ plaque and CAA } & \multirow{2}{*}{$\begin{array}{l}\text { Candidate } \\
\text { biomarker } \\
\text { for AD }\end{array}$} \\
\hline & $\begin{array}{l}A \beta \text { monomer, oligomers, } \\
\text { and protofibrils }\end{array}$ & $A \beta$ fibrils & Reported by & $\begin{array}{l}\text { Brain region; and plaque } \\
\text { types/CAA }\end{array}$ & \\
\hline Vitronectin & {$[50,83]^{a, b+}$} & $\begin{array}{l}{[51-53,} \\
56]^{e, b j, d,}\end{array}$ & $\begin{array}{l}{[32,33,59,101} \\
131]^{f, j t, g, n+, \text {, sł }}\end{array}$ & $\begin{array}{l}\mathrm{HC}^{f}, \mathrm{FCtx}^{\mathrm{j} \dagger}, \mathrm{HC}^{g}, \mathrm{EntCtx}^{\mathrm{nt}, s \neq} ; \\
\mathrm{CP}^{n+, s \neq}\end{array}$ & {$[76]: \uparrow S$} \\
\hline \multicolumn{6}{|l|}{ Other proteins } \\
\hline Actin, cytoplasmic 1 & {$[50]^{\mathrm{a}}$} & {$[51,56]^{e, d}$} & {$[32,59,60,115]^{f, g, h, z \dagger}$} & $\mathrm{HC}^{\mathrm{f}, \mathrm{g}}, \mathrm{CCtx}$ and $\mathrm{Cve}^{\mathrm{h}}$ & \\
\hline Alpha-1B-glycoprotein & & {$[53,56]^{\mathrm{j}, \mathrm{d}}$} & {$[32,33]^{\mathrm{fj} t}$} & $H C^{f}, F C t x^{j+}$ & \\
\hline Alpha-2-HS-glycoprotein & & $\begin{array}{l}{[51-53,} \\
56]^{e, b, j, d}\end{array}$ & {$[32]^{f}$} & $H C^{f}$ & $\begin{array}{l}{[62,79]: \downarrow C,} \\
{[88]: \downarrow P}\end{array}$ \\
\hline Beta-Ala-His dipeptidase & & {$[51,56]^{e, d}$} & {$[32,33]^{\mathrm{f,j} t}$} & $H C^{f}, \mathrm{FCtx}^{\mathrm{j} \dagger}$ & {$[90]: \downarrow C$} \\
\hline Cystatin-C & $\begin{array}{l}{[50,132,133]^{a, t \neq, u \neq}} \\
11-17 \text { nM }(A \beta 40 / 42 M)^{u \neq}\end{array}$ & {$[51,52,56]^{e, b, d}$} & $\begin{array}{l}{[31-33,59,60} \\
66]^{\text {rf, fijt, g,h,s }}\end{array}$ & $\begin{array}{l}\text { FCtx and TCtx }{ }^{r}, \mathrm{HC}^{f}, \mathrm{FCtx}^{\mathrm{j}}{ }^{\dagger}, \\
\mathrm{HC}^{\mathrm{g}}, \mathrm{CCtx} \text { and } \mathrm{Cve}^{\mathrm{h}}, \\
\text { PreFCtx }\end{array}$ & {$[91,96,97]: \uparrow \downarrow C$} \\
\hline Dermcidin & {$[50]^{\mathrm{a}}$} & {$[51,56]^{\mathrm{e}, \mathrm{d}}$} & {$[31-33,59,66]^{r, f j t, g, s}$} & $\begin{array}{l}\text { FCtx and TCtx } x^{r}, H C^{f}, F C t x^{j+}, \\
H C^{g}, \text { PreFCtx }\end{array}$ & \\
\hline Dickkopf-related protein 3 & & $\begin{array}{l}{[51,52,56]^{e, b, d}} \\
26.2 n M \\
(A \beta 42 F)^{e}\end{array}$ & {$[32,33,59,134]^{\mathrm{fj} j \mathrm{~g}, \mathrm{r} \neq}$} & $\begin{array}{l}\mathrm{HC}^{f}, \mathrm{FCtx}^{\mathrm{j}+}, \mathrm{HC}^{g, r \neq} ; \mathrm{CP} \text { and } \\
\mathrm{DP}^{\mathrm{r \neq}}\end{array}$ & {$[134]^{\mathrm{v}}$} \\
\hline Gelsolin & $\begin{array}{l}{[50,135-137]^{a, w \neq, x \neq, y \neq}} \\
1.38 \mu M(A \beta 40 M)^{w \neq}\end{array}$ & $\begin{array}{l}{[51-53,} \\
56]^{e, b, j, d}\end{array}$ & $\begin{array}{l}{[31-33,59,60} \\
66]^{r, f j t, g, h, s}\end{array}$ & $\begin{array}{l}\text { FCtx and TCtx }{ }^{r}, \mathrm{HC}^{f}, \mathrm{FCtx}^{\mathrm{j}}{ }^{\mathrm{j}}, \\
\mathrm{HC} \mathrm{C}^{\mathrm{g}}, \mathrm{CCtx} \text { and } \mathrm{Cve}^{\mathrm{h}}, \\
\text { PreFCtx }\end{array}$ & {$[89]: \uparrow S$} \\
\hline $\begin{array}{l}\text { Hepatocyte growth factor } \\
\text { activator }\end{array}$ & & {$[53,56]^{\mathrm{j}, \mathrm{d}}$} & {$[33]^{\dagger+}$} & $\mathrm{FCtx}^{\mathrm{j}+}$ & \\
\hline $\begin{array}{l}\text { Latent-transforming growth } \\
\text { factor beta-binding protein } 4\end{array}$ & {$[50]^{a}$} & {$[51,56]^{e, d}$} & {$[32]^{f}$} & $H C^{f}$ & \\
\hline Protein AMBP & & {$[51,53,56]^{e, j, d}$} & {$[32,33]^{f, j t}$} & $H C^{f}, \mathrm{FCtx}^{\mathrm{j}+}$ & \\
\hline Olfactomedin-like protein 3 & {$[50]^{a}$} & {$[51,56]$} & {$[32,33,59]^{\mathrm{fj}, \mathrm{g}}$} & $H C^{f}, F C t x^{j \dagger}, H C^{g}$ & \\
\hline $\begin{array}{l}\text { Secreted frizzled-related } \\
\text { protein } 3\end{array}$ & & {$[51,56]^{e, d}$} & {$[32,33]^{f, j t}$} & $H C^{f}, \mathrm{FCtx}^{j+}$ & \\
\hline Secretogranin-1 & & {$[51,56]^{e, d}$} & {$[32,33,59]^{\mathrm{fj}, \mathrm{g}, \mathrm{g}}$} & $H C^{f}, F C t x^{j \dagger}, H C^{g}$ & {$[62,138]: \downarrow C$} \\
\hline Serum amyloid P-component & $\begin{array}{l}{[50,83,139]^{a, b+z \neq}} \\
6 \mathrm{nM}(A \beta 40 M)^{2 \neq}\end{array}$ & {$[51,56]^{e, d}$} & $\begin{array}{l}{[28,32,33,59,60} \\
66]^{q, f, j t, g, h, s}\end{array}$ & 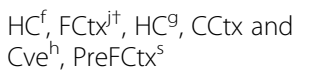 & {$[61]: \uparrow P$} \\
\hline
\end{tabular}

Abbreviations used in Table:

C Cerebrospinal fluid, CCtx Cerebral cortex, CP Core plaque, CVe Cerebral vessel, DP Diffuse plaque, EntCtx Entorhinal cortex, F Fibrils, FCtx Frontal cortex, F-tCtx Fronto-temporal cortex, HC Hippocampus, M Monomer, O Oligomers, P Plasma, PF Protofibrils, PreFCtx Prefrontal cortex, S Serum, TCtx Temporal cortex, TLb Temporal lobe

Table note:

${ }^{a} A \beta 42 P F ;$ pull-down from serum/CSF, LC-MS/MS, SPR. b ${ }^{\text {A }} 340$; incubation with plasma/CSF, SDS-PAGE, LC-MS/MS. ${ }^{\mathrm{A}} \mathrm{A} \beta 40 \mathrm{~F}, \mathrm{~A} \beta 42 \mathrm{~F} ;$ flow cytometry sorting from

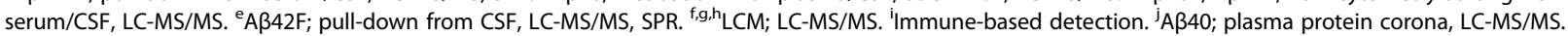
${ }^{k} A \beta 40 M$; affinity isolation from rat brain, immunostaining, sequencing. 'A $A 42 M$; SDS-stable complex, WB. ${ }^{n} A \beta 42 M$; incubation, gel electrophoresis. ${ }^{q,} \mathrm{r} L C M$; LC-MS/ MS, immune-based. ${ }^{\mathrm{s} D e t e r g e n t-i n s o l u b l e ~ p l a q u e ~ m a t e r i a l ; ~ L C-M S / M S . ~}{ }^{\mathrm{t}}$ Molecular cloning, immune-based detection. ${ }^{\mathrm{u}} \mathrm{A} \beta 28 \mathrm{M}, \mathrm{A} \beta 38 \mathrm{M}$; dot blots. ${ }^{\mathrm{v}} \mathrm{A} \beta 42 \mathrm{~F} ; \mathrm{EM}$, ELISA. ${ }^{\mathrm{w}} \mathrm{A} \beta 42 \mathrm{~F}$; incubation with serum, WB. ${ }^{\mathrm{x}}$ Immune-based detection. ${ }^{\mathrm{y}} \mathrm{A} \beta 42 \mathrm{~F}$; incubation with serum, WB. ${ }^{\mathrm{z}} \mathrm{A} \beta 40 \mathrm{M}$; SDS-stable complex, immune- and affinityprecipitation. ${ }^{\text {at }} A \beta 40 M$; incubation with plasma, $S E C$, immunostaining. ${ }^{\text {b† }} A \beta 40 M$; affinity isolation from serum. ${ }^{d \dagger} A \beta 40 M$; $E L I S A .{ }^{e t} A \beta$; centrifugal isolation from

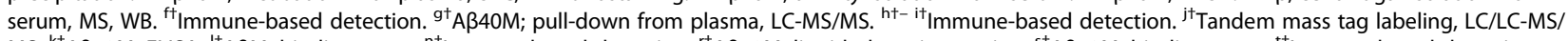
MS. ${ }^{k+} A \beta 40 M$; ELISA. ${ }^{1+} A \beta M$; binding assay. ${ }^{\text {nt }}$ Immune-based detection. ${ }^{r+} A \beta 40 M$; liquid phase interaction. ${ }^{\text {st }} A \beta 42 M$; binding assay. ${ }^{\mathrm{tt}}$ Immune-based detection. ${ }^{\mathrm{ut}} A \beta 42$; SPR (K $\mathrm{K}_{\mathrm{D}}$ not reported). ${ }^{\mathrm{v \dagger}} A \beta 42 \mathrm{M}$; pull-down from plasma, WB. ${ }^{\mathrm{w}+} A \beta 40 \mathrm{~F}$; dot blots. ${ }^{\mathrm{xt}} A \beta 42 \mathrm{M}$; pull-down, fluorescence polarization. ${ }^{\mathrm{y}}$ Immune-based

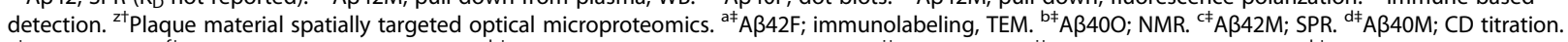
${ }^{\mathrm{e}} \mathrm{A} A 40 \mathrm{M}$; NMR. ${ }^{\mathrm{f}} \mathrm{A} \beta 42 \mathrm{M}, \mathrm{A} \beta 42 \mathrm{O}$; binding assay. ${ }^{\mathrm{h} \neq} \mathrm{A} \beta 40 \mathrm{~F}, \mathrm{~A} \beta 42 \mathrm{~F} ; \mathrm{SPR}$ (KD not reported). ${ }^{\mathrm{i}} \mathrm{A} \beta 40 \mathrm{~F} ;$ ELISA. ${ }^{\mathrm{j \neq}}$ Immune-based detection. ${ }^{\mathrm{k} \neq}$ No significant changes, CSF.

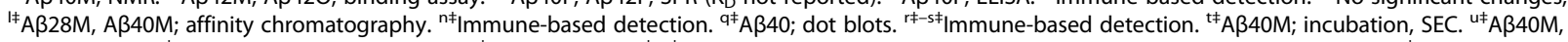

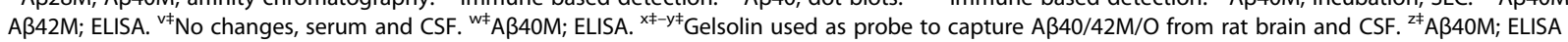

littermate [145]. In a recent study, soluble $A \beta$ oligomer was injected into $\mathrm{C} 1 \mathrm{q}$ deficient mice (C1qaKO) that exhibited no $A \beta$ induced synaptic losses suggesting $C 1 q$ is required for $A \beta$ induced toxic effect on synapses in vivo [146]. Interestingly, C1q has been found to possess a distinct binding site for $A \beta$ [147] and C1q dramatically enhance $A \beta$ aggregation in vitro [148]. Hence, the blocking of $\mathrm{C} 1 \mathrm{q}-\mathrm{A} \beta$ interaction may have potential in $\mathrm{AD}$ therapy, which is further supported by the finding that the inhibition of $\mathrm{C} 1 \mathrm{q}$ binding to $\mathrm{A} \beta$ protects 
hippocampal cells against $A \beta$ induced complement dysfunction [147].

In addition to $\mathrm{C} 1 \mathrm{q}, \mathrm{A} \beta$ can bind several other complement proteins in vitro [51-53, 56, 72, 75]. A $\beta 42$ aggregates has been found to bind complement proteins such as C1q, C3, C4, C5, and C6 with higher affinity compared to aggregates formed by other $A \beta$ isoforms [72]. Hence, changes in the relative concentrations of $A \beta$ isoforms could play a part in complement activation. Nonfibrillar $A \beta$ has also been found to bind and activate complement components, e.g., $\mathrm{C} 1 \mathrm{~s}$ and $\mathrm{C} 4$, in human plasma in a dose-dependent manner [149]. A $\beta$-mediated neuronal complement activation may bring toxicity to the neuron cell [150], and thereby contribute to neurodegeneration.

Like C1q, C3 may also damage synapses during the aging process since the protein is found to be increased in the brain and CSF of AD patients as well as mouse models of $\mathrm{AD}$ [151]. Indeed, C3 deficient (C3KO) mice did not show age-related synapse loss whereas age-matched C57BL/6J wild type did [152]. Likewise, C3 is also required in AD-related synapse loss as demonstrated using a $\mathrm{C} 3$ deleted PS2APP $\times$ C3KO mouse model [151]. Interestingly, it has been shown that neuronal $A \beta$ can modulate amyloid pathology through a complement-dependent pathway, in which $\mathrm{C} 3$ is a central molecule. Overproduction of neuronal $A \beta$ may activate astrocytic complement pathway, via astroglial nuclear factor kappa $\mathrm{B}$, which subsequently releases $\mathrm{C} 3$, this $\mathrm{C} 3$ interacts with microglial C3a receptor, thereby impair $A \beta$ phagocytosis [153]. Beneficial roles of $\mathrm{C} 3$ in $\mathrm{AD}$ pathology are also reported. For instance, aged C3 deficient AD mice (APP; C3(-/-)) showed twofold increased total $A \beta$ and fibrillar plaque burden in cortex and hippocampus compared to aged-match APP transgenic mice with C3 [154]. C3 knockout mice (APP/PS1; C3/KO) also exhibited better performance on a learning and memory task [155].

Alpha 1-antichymotrypsin (ACT) is an inflammatory protein and belongs to the serine protease inhibitor family. Like the complement-related inflammatory proteins, $\mathrm{ACT}$ is often found in $\mathrm{AD}$ plaques $[28,31,32,59,60$, 66, 67]. Moreover, ACT is overexpressed in the AD brain [156], and elevated levels of ACT has been reported in plasma and CSF of AD patients [68, 69, 157], which also correlate well with the severity of the disease [157]. Likewise, the AD risk allele apoE4 is linked to elevated ACT expression. Mice carrying apoE4 showed an increased expression of serpina3 family gene (which coding ACT) compared to apoE2 or apoE3 genotype carriers mouse [158]. Furthermore, the protein has been shown to bind $A \beta$ in vitro [50,63-65] and to promote A $\beta$ fibrillation $[65,159]$. Mouse model studies also support the in vitro findings. ACT was found to promote $\mathrm{A} \beta$ deposition, particularly in hippocampus, in a double
ACT/APP transgenic mouse model compared to the mouse that only express APP [160].

In summary, $A \beta$ interacts with several proteins associated with innate immune response and inflammation and could thereby trigger and modulate neuroinflammation, which is a critical part of AD pathogenesis.

\section{Proteins related to lipid transport and metabolism}

Lipids have central roles in cell signaling as well as many physiological processes related to normal brain development and functions [161]. Binding of amyloid aggregates to lipid membranes can affect their integrity [162] and a variety of lipids are found associated with the senile plaques [163, 164]. Brain uptake, metabolism, and utilization of lipids and lipoprotein particles are intimately associated with $\mathrm{AD}$ pathology. Two of the apolipoproteins, apoE and apoJ (a.k.a, clusterin; $\mathrm{CLU})$, are associated with $\mathrm{AD}$ as major risk genes. The $\varepsilon 4$ allele of apoE was early identified as susceptible for late-onset $\mathrm{AD}$ [30] and recently two genome-wide association studies have identified CLU variant (rs11136000), which is also associated with late-onset $\mathrm{AD}[165,166]$. Curiously, apoE has recently been shown to affect $\mathrm{AD}$ pathology through its immunomodulatory function which is thought to be associated with its binding to microglial triggering receptor expressed on myeloid cells 2 (TREM2; reviewed in Ref. [167]). Both of these apolipoproteins and many more can directly bind $A \beta$ as discussed below.

ApoE exists in three isoforms-apoE2, apoE3, and apoE4. The protein plays a role in $A \beta$ metabolism and clearance, in which apoE4 is the least efficient variant and thereby represents an increased risk of developing AD [168, 169]. Strittmatter et al. [169, 170] reported one of the first lines of evidence for in vitro binding of apoE to $A \beta$ and demonstrated that the binding event required residues $12-28$ of $A \beta$. The binding affinity of apoE to $\mathrm{A} \beta$ was found to be in the order of apoE2 $>\operatorname{apoE} 3 \gg$ apoE4, which inversely correlated with the risk of developing $\mathrm{AD}[169,171,172]$. However, the binding efficiency of different isoforms of apoE to $A \beta$ can vary substantially depending on the preparation condition of apoE as well as the species and isoforms of $A \beta$ being used [172]. It has also been shown that apoE can modulate $A \beta$ aggregation in vitro, though the actual effect of apoE on $A \beta$ aggregation is contentious. Some of the studies suggest that the binding of apoE to $A \beta$ increases $A \beta$ oligomerization [173], and subsequently promotes its aggregation $[159,174,175]$. In this aspect, apoE4 has been found to be more efficient compared to other isoforms [174]. Mouse model studies also revealed that apoE4 differentially affect $A \beta$ aggregation than other isoforms in vivo. A transgenic mouse model expressing apoE4 (E4FAD) showed compact and greater $A \beta$ deposits while apoE2 (E2FAD) and apoE3 (E3FAD) expressing mice exhibited diffuse plaque type [176]. The 
astrocytic overexpression of apoE4, but not apoE3, suppressed $A \beta$ clearance and also promoted amyloid deposition in cell-type-specific and apoE inducible mouse model [177]. However, the greater effects of apoE4 on $\mathrm{A} \beta$ aggregation in vivo likely take place during the early stage (seeding stage) of amyloid development [177]. Besides $A \beta$-associated $A D$ pathology, apoE4 is also found to aggravate tau-mediated $\mathrm{AD}$ pathogenesis [178].

Contrary to the aggregation promoting effect, apoE has also been found to have an inhibitory effect on $A \beta$ fibrillation in some studies [179-182]. This inhibitory effect is thought to be directed by the binding of apoE to monomeric $A \beta$, which results in reduced nucleation and a slower fibrillation process $[180,181]$. Furthermore, apoE has been reported to stabilize $A \beta$ oligomers [179, 181] and fibrils [181], though the latter event required a higher concentration of apoE. Nevertheless, it is evident that the apoE- $\mathrm{A} \beta$ interaction has direct effects on modulation and clearance of $A \beta$ and hence a key role in the pathogenesis of $\mathrm{AD}$. Therefore, many therapeutic strategies targeting apoE-A $\beta$ interaction have been investigated and some are under way (reviewed in Ref. [183]).

Like apoE, CLU is also a key player in AD pathology and capable of modifying $A \beta$ aggregation. However, CLU may have beneficial roles in AD. The protein has a chaperone function that can specifically inhibit the elongation of $A \beta$ fibrils [184] and it is involved in neural health and $A \beta$ metabolism. CLU has been found to be upregulated in the brain of $\mathrm{AD}$ patients $[185,186]$, and co-deposits with $A \beta$ in the senile plaque $[73,101]$. Hence, it may be part of the biological defenses against local damage to neurons, for instance as a consequence of $A \beta$ deposition $[185,187]$. In vitro studies support this protective mechanism since many studies have shown that CLU can bind $A \beta$ and protect against $A \beta$ aggregation $[99,100,188,189]$ as well as reduce $A \beta$-associated toxicity [187]. Transgenic mouse model studies also evident that CLU can suppress amyloid formation and reduce amyloid toxicity in vivo. The astrocytic overexpression of CLU in APP/PS1 transgenic mouse $\left(\mathrm{APP} / \mathrm{PS} 1^{\mathrm{AAV}-\mathrm{CLU}}\right)$ showed a significant reduction of total and fibrillar $A \beta$ in cortex and hippocampus compared to APP/PS1 ${ }^{\mathrm{AAV}-\mathrm{GFP}}$ control [190]. Moreover, CLU overexpression resulted in reduced amyloid-associated neurotoxicity [190]. In support of these findings, the reduction of CLU showed opposite results i.e., substantial increase of amyloid plaque load in both cortex and hippocampus of APP/PS1; $\mathrm{Clu}^{+/-}$mice [190], and in CAA within the cerebrovasculature of APP/PS1; $\mathrm{Clu}^{-1-}$ mice [191]. Furthermore, clusterin has been shown to enhance $A \beta$ clearance across the blood-brain-barrier via low density lipoprotein-related protein 2 (LRP2) in C57B16 mice [192], which is in agreement with CLU lacking APP/PS1; $\mathrm{Clu}^{-/-}$mice that showed impaired $\mathrm{A} \beta$ clearance [191]. The evidence clearly illustrate the importance of clusterin in $\mathrm{AD}$.

In addition to apoE and CLU, several other apolipoproteins including apoA-I, apoA-II, apoA-IV, apoB-100, apoC-I, apoC-II, apoC-III, apoC-IV, and apoD are in the center of interest in the field of AD research. Accumulation of these proteins in amyloid deposits may disturb the brain lipid metabolism and thereby cause cognitive dysfunction. These proteins can also bind $A \beta$ and modulate its aggregation and toxicity. For example, apoA-I, an abundant plasma protein, can bind $A \beta$ and inhibit its fibrillation [84]. The morphology of pre-formed $A \beta$ aggregates can change when exposed to apoA-I [193] and apoA-I can attenuate $\mathrm{A} \beta$-induced toxicity as demonstrated in two different studies using hippocampal neuronal cells [84, 193]. Not only as individual lipoprotein, but also the high-density lipoproteins (HDL) particles may have inhibitory effects against $A \beta$ fibrillation, as the HDL-complex (containing apoA-I, apoE, and CLU) isolated from CSF of $A D$ patients effectively inhibits $A \beta$ fibrillation in vitro [194].

The internalization of $A \beta$ is considered as one of the contributing factors to the toxicity and cell damage in AD. Hence, inhibition of such events may be beneficial against AD. ApoA-II, while forming complex with apoE, appears to have inhibitory effects on $A \beta$ internalization in cell culture [195]. Likewise, apoA-IV may also diminish $\mathrm{AD}$ pathogenesis. The genetic reduction of apoA-IV in $5 \times$ FAD APP/PS1 transgenic AD mice (5×FAD APP/PS1; apo-IV ${ }^{-/-}$) augments the A $\beta$ burden and aggravates neuronal loss in the brain compared to $5 \times$ FAD APP/PS1 transgenic mice with apoA-IV [196]. This mouse model study also illustrated that apoA-IV facilitates $A \beta$ uptake by astrocytes [196]. Besides the direct binding to $A \beta$, the level of many apolipoproteins in circulation correlates with AD pathogenesis. For instance, the level of apoA-I [87, 89, 92] and apoC-III [92] in plasma, and apoD in CSF $[95,96]$ were measured to be lower in AD patients compared to nondemented controls, thus suggesting reduced activities of these proteins in lipid metabolism.

Taken together, the close links between the apolipoproteins apoE and CLU, and various aspects of $A \beta$ biochemistry may explain their special recognition as genetic risk factors. Accumulation of these, and other apolipoproteins, in plaques may affect the lipid metabolism and thereby also neuronal function and plasticity.

\section{Proteins involved in blood coagulation and hemostasis}

Vascular dysfunction is commonly observed in AD and may precede onset of the disease [197]. A $\beta$ can deposit and interfere with the vascular cellar milieu, exert toxic effect, induce vascular inflammation, and contribute to vascular pathology. Indeed, $A \beta$ has been shown to bind 
several key components of the coagulation cascade, including coagulation factor $\mathrm{V}[50,51,56]$, factor X [51, 52, 109], factor XII [53, 56, 110, 111], and fibrinogen $[50-52,56,112]$. It has been reported that $A \beta$ can bind and activate blood coagulation factor XII that subsequently activates factor XI [111], which in turn promote thrombin generation and lead to the production of unwanted fibrin. This may contribute to neuronal dysfunction in $\mathrm{AD}$ by inducing inflammation or by affecting cerebral blood flow [110]. Knockdown of plasma coagulation factor XII in TgCRND8 transgenic mouse (FXIIASO) showed reduced brain amyloid pathology and improved cognitive function compared to the control group (CTL-ASO) and wild-type mice [198].

Fibrinogen has a central role in the hemostasis process and is also implicated in AD pathogenesis. In a recent study, fibrinogen was shown to induce spine elimination and to promote synapse loss in a $5 \times \mathrm{FAD}$ transgenic mouse model via CD11b-CD18 microglia activation. In contrast, the inhibition of fibrinogen-CD11b binding led to improved cognition in the animals [199]. Fibrinogen induced spine elimination was also noted around $A \beta$ deposits with fibrinogen [199], indicating potential in vivo $\mathrm{A} \beta$-fibrinogen interactions. In vitro, binding of $\mathrm{A} \beta$ to fibrinogen results in the fibrillation of fibrinogen and $A \beta$ itself [112]. Biochemical and structural investigations have revealed the central region of $A \beta$ as crucial for the $A \beta$-fibrinogen interaction [200]. It is likely that $A \beta$ encounters and binds fibrinogen in the vessel wall, which may lead to CAA and cognitive dysfunctions [113]. Hence, it is evident that $\mathrm{A} \beta$-fibrinogen interactions can lead to neuronal damage and cognitive impairment and may thereby contribute to AD [201].

Plasminogen and antithrombin are parts of negative feedback loops in the coagulation cascade. Both of these proteins can bind $\mathrm{A} \beta[50,51,53,56,109]$ and antithrombin III has also been found in neurofibrillary tangles [108]. Mostly antithrombin acts on thrombin and reduces the amount of thrombin to avoid continuous or excess fibrin production. Antithrombin-III has shown sub-micromolar affinity to $A \beta$ [50] and binding to $A \beta$ may result in loss-of-function effects of antithrombin-III. Indeed, excess thrombin production is reported in the AD brain [202]. However, high CSF levels of antithrombin-III have been reported in the early stage $\mathrm{AD}[69,80]$.

Alpha-1-antitrypsin (A1AT) and alpha-2-macroglobulin $(\alpha 2 \mathrm{M})$ can modulate inflammation, proteostasis, and apoptosis. Both proteins show potential as $\mathrm{AD}$ biomarkers [61, $76,89,102,104,107]$, can interact with $A \beta[51-53,56]$ and may have beneficial roles in AD. For instance, A1AT has been shown to protect primary microglial cells isolated from Swiss Webster mouse embryos from $A \beta$ induced toxicity [203], and $\alpha 2 \mathrm{M}$ can prevent $A \beta$ fibrillation in vitro [105,
204]. Moreover, $\alpha 2 \mathrm{M}$ has been suggested to facilitate brain A $\beta$ clearance $[105,106]$.

Hence, co-aggregation of $A \beta$ and blood coagulations proteins may contribute to CAA development and thereby enhance the cognitive deficiencies. However, disturbances of the hemostasis machinery could also impede the coagulation cascade and lead to an increased risk of micro hemorrhage, which is also reported for $\mathrm{AD}$ patients [205].

\section{Proteins involved in metabolism}

Although the proteins in this category have their main roles intracellularly, they can also be secreated or located to the cell surface. Their extracellular concentrations may also increase as result of neuronal death and lysis [206]. Dysfunctional glucose metabolism is thought to play a critical role in the pathogenesis of AD. Factors that contribute to the impaired glycolysis include overuse (to compensate for increased demand in AD condition), inhibition and damage (due to oxidative stress or unwanted binding to other proteins such as $A \beta$ ) of glycolytic enzymes. Among the glycolytic enzymes, glyceraldehyde-3-phosphate dehydrogenase (GAPDH) and enolase are frequently found in senile plaques.

GAPDH is an enzyme, which in its modified forms (e.g., oxidation and glycation) can interact with several molecular partners that are associated with normal cellular as well as pathogenic functions [207]. GAPDH can interact with monomeric $[50,63]$ and fibrillar [51, 56, 116] forms of $A \beta$ and tau [208]. Such interactions may contribute to reduced activity or even inactivation of GAPDH. Indeed, it has been found that the GAPDH activity in $\mathrm{AD}$ brain is low and triggered by oxidative stress [207]. The fact that GAPDH was found to bind A $\beta$ fibrils in biological fluids shows that the plaque-associated GAPDH can originate from secreted GAPDH. Although the main functional roles of this protein are found in the intracellular environment it can also be secreted [209], a process that may be associated with cellular iron imbalance [210]. Moreover, upon exposure to oxidative stress, GAPDH can form amyloid-like fibrils that contribute to neuronal cell death $[211,212]$, possibly by gaining toxic function. Aggregated GAPDH has also been shown to accelerate $\mathrm{A} \beta$ fibrillation in vitro and GAPDH, when coadministered with $A \beta$ into $C 57 \mathrm{BL} / 6 \mathrm{~J}$ mice, showed increased $A \beta$ induced neurotoxicity compared to the mice that were treated with either $A \beta$ or GAPDH alone [213].

Alpha-enolase (ENO1) is expressed on the surface of several cell types, including neurons, and acts as a receptor and activator of plasminogen [214]. It has been identified in senile plaques in several studies $[32,59,60,66$, $115]$ and been found to be up-regulated in the brain of AD patients [215] as well as in the brain of aged $\mathrm{Tg} 2676$ AD mouse model [216]. ENO1 is also oxidatively 
modified in the progression from mild cognitive impairment to AD [217]. Indeed, a mouse model study showed that ENO1 is a target of oxidation in the brain of $3 \times \mathrm{Tg}$ $\mathrm{AD}$ mouse when compared to non-transgenic mouse [218]. This suggests that beside the glucose metabolism, ENO1 may play critical roles in pathological brain functions. The physiological impact of the A $\beta$-ENO1 interactions is unknown. However, binding of $A \beta$ to ENO1 may inactivate the enzyme resulting in loss-of-function effects and thereby contribute to glucose hypometabolism in the AD brain [217].

Procollagen C-endopeptidase enhancer 1 (PCPE1) is a glycoprotein involved in procollagen processing. In addition to its role in procollagens maturation, PCPE1 is thought to have additional functions [219] reinforced by its ability to interact with several proteins. PCPE1 is found to form a complex with $A \beta$ [219], but the consequences are not known. Curiously, PCPE1 is reported to initiate amyloid fibril formation of $\beta 2$-microglobulin [220]. Phosphoglycerate kinase 1 (PGK1) is another glycolytic enzyme, which also binds $A \beta$ in vitro $[50,56]$ and co-deposits with $A \beta$ in plaques [31, 32, 59, 60, 66]. Nevertheless, the role of these proteins in AD has not been investigated.

Binding of metabolic enzymes to amyloid plaques could certainly disturbed their functions and reduce neuron viability. It is, however, not clear how sequestration of extracellular enzymes would affect intracellular processes. The GAPDH and ENO1 examples illustrate that these proteins may have other biological functions that are yet not fully understood.

\section{Molecular transport proteins}

Alteration or interruption of the transport pathways for nutrition and essential biomolecules can have adverse effects on cell viability. Several proteins with transport as main functions have been found in post-mortem plaques and their binding to $A \beta$ have been confirmed by in vitro studies.

Hemoglobin $(\mathrm{Hb})$ is the major transporter of oxygen to the body tissues, including brain tissue. In brain, $\mathrm{Hb}$ is expressed in specific cells, such as neurons [221, 222], and the level of $\mathrm{Hb}$ goes up during aging. Likewise, endogenous $\mathrm{Hb}$ is elevated in the brain in response to hypoxia [223]. Hb from the circulation may also contribute to the higher $\mathrm{Hb}$ level in the brain due to the changes in the blood-brain-barrier structure, which is manifested in aging as well as in $\mathrm{AD}$. $\mathrm{Hb}$ has been found to be upregulated in the brain of APP/PS1 transgenic mice compared to wild-type littermates [224] and in the brain of $\mathrm{AD}$ patients [225]. The protein colocalizes with $A \beta$ in plaques and vascular amyloid deposits $[63,226]$. Hb can bind $A \beta$ in vitro and promote its aggregation [224, 226]. Hence, in aging or $\mathrm{AD}$, the oxygen deficiency in brain may lead to an increased $\mathrm{Hb}$ production, which in turns may modulate $A \beta$ aggregation or clearance in the brain.

$\mathrm{Hb}$ degradation can lead to release of heme and redox-active iron that can trigger the formation of reactive oxygen species and oxidative stress. Indeed, dysfunctional iron homeostasis is part of the AD pathology [227, $228]$. Heme can also bind directly to $A \beta[229,230]$ with resulting peroxidase activity of the complex [231, 232]. This process could further enhance the oxidative stress and potentially also affect $A \beta$ assembly by catalyzing tyrosine crosslinking of $A \beta$ molecules [233].

Protection against the release of heme is achieved through the proteins haptoglobin $(\mathrm{Hpt})$ and hemopexin $(\mathrm{Hpx})$, that are both found to be binding partners of $A \beta$ fibrils. Hpt is well known for binding free hemoglobin after the intravascular hemolysis thereby preventing iron loss [234] while Hpx is a scavenger for free heme groups. Hpx-null $\left(\mathrm{Hpx}^{-/}\right)$mice showed a twofold increase in iron-loaded oligodendrocytes in the basal ganglia and thalamus compared to wild-type mice, which verified that $\mathrm{Hpx}$ is involved in heme scavenging in brain [235]. Hpt appears to act as an extracellular chaperon and counteract protein aggregation [236]. The A $\beta-\mathrm{Hpt}$ complex is found in brain tissue and CSF of AD patients and the interaction is confirmed by in vitro data [237]. The binding affinity $\left(K_{D}\right)$ is $0.30 \mu \mathrm{M}$ [237]. Moreover, Hpt can potently inhibit in vitro $A \beta$ fibrillation [204] and $A \beta$ clearance by enhancing apoE-A $\beta$ complex formation [237]. Hpt as well as Hpx are acute phase proteins that associate with lipoparticles [238], which connect them to inflammatory processes and lipid metabolism described above.

Serum albumin is abundant in both plasma and CSF where it binds and transports a range of different molecules, including $A \beta$ [239]. The protein is thought to bind ca. $90 \%$ of plasma and $50 \%$ of CSF $A \beta$ [240] and may act as a potent inhibitor of $A \beta$ self-assembly in the circulation. In vitro studies showed that albumin inhibits $A \beta$ fibrillation by binding to the monomer [239], or by binding to $A \beta$ oligomers and compete for further monomer association to the $A \beta$ assemblies [241,242]. In vivo studies corroborates in vitro finding as a $3 \times \mathrm{Tg}$ mouse model treated with human serum albumin exhibit reduced $A \beta$ deposition and ameliorated cognitive impairment. Moreover, SHSY5Y cell line treated with human serum albumin resulted in a reduction in $\mathrm{A} \beta$ toxicity [243]. Notably, low levels of blood albumin in elderly persons is implicated in cognitive impairment [244], and evidently decreased blood albumin- $A \beta$ complex is found in $\mathrm{AD}$ [245]. In addition, albumin is an attractive target for enhanced brain $A \beta$ clearance through the exchange of plasma albumin with therapeutic albumin molecules, which may also facilitate the efflux of $A \beta$ from brain to plasma $[117,118]$. A pilot plasma exchange (PE) study for mild to moderate $\mathrm{AD}$ patients reported stable cognitive scores, and in phase II clinical trial, the patients 
were found to perform better in the cognitive test [246]. More recently, results from phase IIb/III clinical trials have been published [247], and these results also suggest that PE treatment could slow cognitive and functional decline in AD.

Transthyretin (TTR) is a tetrameric protein predominantly produced in the liver and functions as a carrier of thyroxine and retinol in plasma and CSF [248]. TTR binds $A \beta$ with high affinity, $K_{D}$ of $28 \mathrm{nM}$ [121]. The binding site of $A \beta$ on the TTR monomer appears to be residues 106-117 [249] and in vitro studies showed that TTR can inhibit $A \beta$ fibrillation in buffer and CSF $[121,250]$. TTR-A $\beta$ complex has been detected in CSF [250], and TTR has been suggested as a major $\mathrm{A} \beta$-sequestering protein in CSF [251]. The protein has also been shown to promote $A \beta$ clearance and reduced deposition in the brain of A PPPswe/ PS1A246E transgenic mice carrying TTR [252]. Moreover, the overexpression of human TTR in APP23 transgenic mice (APP23/hTTR) showed improved cognitive function compared to control APP23 mice [122]. The TTR concentration in CSF is altered in the course of $\mathrm{AD}$ [253] and TTR has therefore been suggested to play protective roles in $\mathrm{AD}$. The protective mechanism likely relies on the binding of TTR to oligomeric $A \beta$, which inhibits primary and secondary nucleation of $A \beta$ and thereby limits $A \beta$ fibrillation [254].

Other transporter proteins such as inter-alpha-trypsin inhibitor heavy chain H2 (ITIH2) and serotransferrin are found in senile plaques $[31,32,59,66]$. ITIH2 is a carrier of hyaluronan, whose increased level is associated with AD [255]. Serotransferrin is involved in iron transport and abnormal iron metabolism is, as already mentioned, observed in the brain of $\mathrm{AD}$ patients and can also influence $A \beta$ aggregation [256].

Taken together, the described examples highlight two classes of transport proteins that may have key roles in $\mathrm{AD}$ pathology: transporters of $A \beta$ could affect its clearance and accumulation while dysfunctional iron transporters are linked to oxidative stress and neuronal damage.

\section{Neural proteins}

Neurosecretory protein VGF is a nerve growth factor that regulates neuronal development and activity through processing of the precursor protein into bioactive peptides. One such peptide, TLQP-21, has been shown to enhance $A \beta$ clearance through microglial phagocytosis and to promote fibrillar $A \beta$ uptake by microglial BV2 cells through a complement C3a receptor-1 (C3aR1)-dependent mechanism [257]. A more recent study further demonstrated TLQP-21 mediated microglial modulation via C3aR1 using wild-type and C3aR1-null mouse models [258]. TLQP-21 was found to increase motility and phagocytic activity of microglial BV2 cells in wild-type but not in C3aR1-null mice. Furthermore, intracerebroventricular administration of TLQP-21 to 5 months old $5 \times$ FAD mice showed a reduction of amyloid plaques and associated dystrophic neurites [258]. However, the levels of VGF in AD patient CSF has been found to be lower than in controls [79, 90, 124, 125]. A recent bioinformatics study identified VGF as the "key driver" in a multiscale network model of AD [259]. The same study validated the hypothesis by showing that overexpression of VGF in an AD mouse model rescued the animals from $A \beta$-related pathology. Based on these lines of arguments, sequestration and inactivation of VGF in plaques may be a key process in $\mathrm{AD}$ associated neurodegeneration.

Like VGF, proSAAS is a proteolytically processed protein with the main function in the neuroendocrine secretory pathway [260]. It is recurrently found in pathological protein deposits [261-263] and several studies have identified it as a potential biomarker of $\mathrm{AD}[62$, 78]. ProSAAS has been found highly colocalized with $A \beta$, both in dense core and diffuse plaques, in 12month-old APP695/PSEN1dE9 transgenic mice [264]. ProSAAS is thought to have novel anti-aggregation chaperone function demonstrated by its ability to inhibit in vitro $A \beta$ fibrillation and $A \beta$-induced neurotoxicity in Neuro2a cell cultures [264]. Furthermore, proSAAS has also been found to inhibit fibrillation and toxicity of other disease-related proteins e.g., IAPP and $\alpha$-synuclein $[265,266]$.

Neural cell adhesion molecule 1 (NCAM1) is an important component of the central nervous system (CNS) extracellular interface but also found in soluble form in CSF and plasma. NCAM1 has key roles in modulation neuron-neuron adhesion, neurite outgrowth, synaptic plasticity, as well as in learning and memory and is also associated with several neurological disorders [267]. It interacts with a range of other proteins and extracellular matrix (ECM) components, including APP [268] and chondroitin sulfate proteoglycans (see below) [269]. Another member in the NCAM superfamily, NCAM2, has been shown to undergo $A \beta$-induced proteolysis resulting in reduced level of NCAM2 in hippocampus of AD patients and APP23 transgenic mice [270].

Brevican and neurocan are chondroitin sulfate proteoglycans specifically expressed in the brain and neural tissues. They are involved in CNS development, cell migration, maturation, and tissue homeostasis and are key components of perineuronal nets [271]. It is known that altered regulation of these proteoglycans, e.g. by ADAMTS family proteases, is associated with AD as well as inflammation and other neurological disorders [272]. $\mathrm{A} \beta$ accumulation may interfere with processing of brevican and thereby inhibit neural plasticity [273]. Indeed, 
brevican has been found differently processed (the size of the chondroitin sulfate chain attached to brevican is smaller) in hippocampal tissue of plaque-bearing APPsw transgenic mice compared to non-transgenic control [273].

Amyloid-like protein 1 (APLP1) is a transmembrane protein, which belongs to the amyloid precursor protein gene family. Members of this family are known to play critical roles in the development of nervous system, the formation and function of synapses, including synaptic plasticity, learning, and memory [274]. APLP1 is closely related to APP and share a similar structural organization [275]. It is processed by the same set of secretases i.e., $\alpha-, \beta-, \gamma-$ secretase, as APP and generates a range of fragments [276], but not $A \beta$ [274]. Immunochemistry and proteomics studies show that APLP1 is present in the senile plaque and the distribution of APLP1 overlaps with APP in the AD brain [32, 59, 277, 278]. APLP1 binds fibrillar $A \beta$ in vitro $[51,52,56]$, although the pathological significance of the interaction is not known. Nevertheless, the binding of fibrillar $A \beta$ to APLP2, from the same family as APLP1, lead to an increased level of APLP2 in primary cultures of astrocytes and neuron [279].

The accumulation of neural proteins in plaques provides a direct link between protein aggregation and reduced neuronal functions. Some of the proteins may also have neuroprotective effects that are lost upon their inactivation.

\section{Cell adhesion, extracellular matrix, and proteoglycans}

The extracellular matrix (ECM) proteins and proteoglycans are often found in senile plaques and it has been confirmed that $A \beta$, and in particular its aggregated forms, can bind a range of ECM-associated proteins [109]. Interactions with these components provide a link between extracellular environment, where the senile plaques are found, and potential intracellular effects. This could be by triggering specific signaling pathways or by allowing entrance of foreign pathogens, such as amyloid oligomers. Proteins such as vitronectin may assist in this [280]. The ECM also determines the contact and interactions between adjacent cells and correct function is crucial for many processes, such as neuronal development and signaling pathways.

Proteoglycans are thought to play functional roles in cell-cell and cell-matrix interactions in the brain. Moreover, proteoglycans appear to modulate $A \beta$ aggregation and deposition and to play roles in $A \beta$ internalization and cytotoxicity [281-283]. A transgenic mouse model study showed that the overexpression of heparanase, a heparan sulfate degrading enzyme, significantly lowered the $\mathrm{A} \beta$ burden in the brain of $\operatorname{tgHpa}{ }^{*}$ Swe mice [282]. In a different study, neuronal heparan sulfate was removed from APP/PS1 transgenic mouse, which led to a reduction of $A \beta$ oligomerization and subsequent deposition [283]. Also, enhanced $A \beta$ clearance from the mouse brain was noted [283]. These studies evident that heparan sulfate proteoglycans participate in $A \beta$ deposition and thereby contribute to amyloid pathology.

Agrin is a heparan sulphate proteoglycan present in different areas of the brain including microvasculature but its functions in the brain remains unclear [284]. The protein has been identified in AD plaque, cerebrovascular $A \beta$ deposits as well as in neurofibrillary tangles in several studies [32, 59, 60, 66, 126, 284]. In vitro studies reported that agrin can bind $A \beta$ and accelerate its fibrillation as well as protect fibrils from proteolytic degradation [126]. Curiously, a mouse model study reports opposite effects of agrin on in vivo A $\beta$ deposition. Endothelial overexpression of agrin in AD transgenic mouse resulted in reduced $A \beta$ accumulation, and conversely, mouse lacking endothelial expression of agrin showed an increased $A \beta$ deposition in the brain [285]. However, it is apparent that agrin affects brain $A \beta$ deposition. Agrin may have a specific affinity towards fibrillar $A \beta\left(K_{D}\right.$ of $3.5 \mathrm{nM}$ [51]) compared to other forms of $\mathrm{A} \beta$ aggregates and monomer [109, 126]. Increased concentration of agrin has been measured in the hippocampus of $\mathrm{AD}$ brains compared to non-AD controls [286]. Moreover, CSF agrin concentration increased with the age of $\mathrm{AD}$ patients [51, 127], which indicates a possible link with the disease progression. Agrin abnormalities are also thought to cause microvascular damage in $\mathrm{AD}$ [286].

Likewise, glypican-1 (Gpc-1) seems to be predominant in senile plaques [287] and cerebrovascular amyloid deposits [288] in AD patients. Notably, Gpc-1 is not present in the normal vessels [289], indicating $A \beta$ may modulate the cellular expression of Gpc-1. Indeed, it has been found that the expression of Gpc-1 is increased in human brain pericytes culture in the presence of $A \beta$ [289]. Within lipid rafts, Gpc-1 is thought to act as a scaffold and interact with normal cellular and diseaseassociated isoforms of prion protein and facilitate misfolding, thereby formation of pathogenetic prion [290]. Such mechanisms may also occur for $A \beta$ pathogenesis. $\mathrm{A} \beta$ production machineries, as well as monomeric and oligomeric $A \beta$, exist in glycosphingolipid enriched domains where Gpc-1 may interact with $A \beta$ and potentially trigger $A \beta$ polymerization and subsequent cell death [130].

Yet another proteoglycan family protein, decorin, is also found in senile plaques [32, 129] and neurofibrillary tangles in AD patients [129]. The protein can interact with $A \beta$ in vitro $[50,51,56,109,128]$. However, the significance of this interaction in vivo has not been investigated broadly although the interaction likely also occurs in the $A D$ brain. The binding of decorin to $A \beta$ may 
account for the deposition of $A \beta$ in cerebrovascular amyloid deposit in AD [128].

Cartilage acidic protein 1 (CRTAC1), an extracellular matrix protein in the $\beta$-propeller protein family, is present in the brain, but its function remains unclear [291]. Nevertheless, CRTAC1 is linked to many diseases, including cardiovascular and neurological disorders [291]. Curiously, the protein has a high propensity to form amyloid-like fibrils that may connect it to disease pathology [292], but this aspect is poorly described. Vitronectin is another cell adhesion protein with the ability to form oligomers and amyloid fibrils [293]. It was early reported to be part of senile plaques [28] and its role in $\mathrm{AD}$ pathology may be related to its modulation of complement activation.

Osteopontin (OPN), a protein with its main role in bone tissue structure, has been confirmed to be elevated in $\mathrm{AD}$ patients and there are findings that link the OPN expression to the $A \beta$ load [294]. It is linked to immune response and neuroinflammation [295, 296] and may also have a role in calcification of vessels in CAA [297]. Increased cerebral expression of OPN (via glatiramer acetate (GA) or GA- and bone marrow-derived monocytes treatments) resulted in reduced plaque burden in ADtg mice compared to mice treated with phosphate buffer. These mice also showed improved phagocytotic clearance of $A \beta$ [298].

Galectin-3-binding protein (G3BP) was just recently shown to inhibit the processing of APP into A $\beta$ by direct interaction with APP [299]. Co-deposition of G3BP in senile plaque may be a consequence of this interaction but it could also result in reduced inhibitory capacity and thereby a positive feedback loop for $A \beta$ production. Direct interaction with APP has also been reported for fibulin-1 with consequent alterations of the neurotrophic activities of APP [300]. This interaction was suggested to be mediated by the calcium-binding EGF motif in fibulin-1 and could then explain also the binding of EGF-containing fibulin-like extracellular matrix protein 1 to $A \beta$.

Some cell adhesion proteins, e.g. vitronectin, osteopontin, fibulin-1 and galectin-3-binding protein, are known to also regulate complement system, immune response, inflammatory response or hemostasis and could thereby contribute to $\mathrm{AD}$ pathology through these processes $[280,295,296,301-303]$. As seen in Table 1, there are several other proteins in this functional category, such as collagen alpha-1(XVIII) chain, desmoplakin, microfibrilassociated glycoprotein 4, mimecan, prolargin, and SPARC-like protein, that are found in senile plaque, and with $A \beta$ interactions demonstrated in vitro. However, the physiological significance of these proteins in $A D$ still needs to be elucidated.

In summary, it is not surprising that many ECM- or cell-surface proteins are found in plaques but several of these proteins appear to be actively involved in the initiation and buildup of $A \beta$ aggregates. $A$ better understanding of these interactions may reveal ways to delay the plaque pathology.

\section{Other proteins}

In addition to the proteins reviewed above, several proteins with confirmed binding to $A \beta$ as well as presence in senile plaques, fall outside the functional categories in Table 1 . Human cystatin $\mathrm{C}(\mathrm{Cys} \mathrm{C})$ was originally identified in CSF and subsequently found in other biofluids and tissues, including brain tissue [304, 305]. The association of $\mathrm{Cys} C$ with $\mathrm{AD}$ has been established by its existence within parenchymal and vascular amyloid deposits in $\mathrm{AD}[31,32,59,60,66,306]$. Evidence suggests that CysC plays protective roles in $\mathrm{AD}$. It can bind monomeric $A \beta$ [307], significantly reduce $A \beta$ oligomerization [132] and subsequent fibrillation [133, 307]. Moreover, CysC has been shown to protect neuroblastoma cells from $A \beta$ induced neurotoxicity [308]. A mouse model study showed $c a$. $50 \%$ decline of $A \beta$ plaque burden in the cortex of $\mathrm{Cys} 68^{+} \mathrm{APP} 23^{+}$transgenic mice overexpressing human $\mathrm{CysC}$ compared to $\mathrm{Cys} 68^{-} \mathrm{APP} 23^{+}$mice [307]. Besides its protective roles, CysC is also implicated in the development of CAA, and its binding with $A \beta$ may initiate $A \beta$ accumulation in vessel walls [306]. Apart from its association with $\mathrm{AD}$, CysC itself form amyloid and is linked to hereditary cystatin $C$ amyloid angiopathy, or Icelandic type amyloidosis [309].

Gelsolin is a ubiquitous actin-binding protein present in plasma and CSF as a secretory protein [310,311]. The protein is linked to a Finish type of systemic amyloidosis (hereditary gelsolin amyloidosis) [312] in which amyloid deposition of abnormally processed gelsolin leads to cranial and sensory peripheral neuropathy, corneal lattice dystrophy, and cutis laxa [312, 313]. Gelsolin has been found in $\mathrm{AD}$ plaques [31, 32, 59,60,66], indicating its potential networking with $A \beta$, which is reinforced by several lines of in vitro studies [50-53, 56, 135]. Moreover, gelsolin inhibits $A \beta$ fibrillation and dissociate preformed fibrils in vitro [314]. Peripheral administration of gelsolin (from bovine plasma) in PS/APP transgenic mice showed reduced fibrillar $\mathrm{A} \beta$ in cerebral cortex and hippocampus [315]. Another study also reported reduced amyloid pathology in mice where human gelsolin was expressed in plasma in two different PS/APP transgenic mice models using a gene delivery approach [316]. These studies indicate that gelsolin may sequester plasma $A \beta$ and thereby represent a candidate for a potential AD therapeutic.

Serum amyloid P component (SAP) is an important regulator of the innate immune system. Nonfibrillar SAP is a universal component of all amyloid deposits, including parenchymal and vascular $\mathrm{A} \beta$ deposit in $\mathrm{AD}[28,32,59,60$, 
66, 317-319]. The role of SAP in amyloidosis has been studied using SAP knockout $\left(\mathrm{SAP}^{-/-}\right)$serum amyloid A amyloidosis mouse. Amyloid deposition in mice lacking SAP was found to be delayed and reduced compared to $\left(\mathrm{SAP}^{+-}\right)$control [320]. However, if and how SAP may contribute to AD pathology remains unclear. Interestingly, the protein has a high binding affinity for $A \beta$, with a $K_{D}$ of $6 \mathrm{nM}$ [139]. Evidence from in vitro studies suggests that SAP accelerates $A \beta$ fibrillation and stabilizes fibrils against proteolytic degradation [139, 321, 322]. SAP may also modulate astrocytic and microglial $A \beta$ uptakes as the ability of adult human astrocytes and microglia to internalize $A \beta$ were found to be reduced when exposed to $A \beta$ and a mixture of SAP-C1q [323]. Besides its role in amyloid deposits, SAP is itself directly toxic to neurons [324, 325]. SAP can be an attractive therapeutic target for $\mathrm{AD}$. Indeed, it has been demonstrated that removal of SAP (using CPHPC, a SAP removal drug) from blood and CSF of a TASTPM transgenic mouse model of AD results in removal of it from the amyloid deposits, although the actual effect of CPHPC treatment on amyloid load was not investigated [326].

Secreted frizzled-related protein 3 is involved in the Wnt signaling pathway [327]. This pathway is fundamental to the development of the CNS and, in the adult brain, it is involved in the regulation of synapse plasticity and memory progress [328]. Using neuronal cell culture and an animal model, it was shown that $A \beta$ fibrilmediated toxicity can result in loss-of-function of Wnt signaling [329]. Dickkopf-related protein 3 is also a Wnt signaling pathway protein. The protein has been found to be produced locally and co-localized with $A \beta$ in the brain [134]. Several in vitro studies have demonstrated its binding to $A \beta[51,52,56]$, and it may have a particular affinity to fibrillar $A \beta$, to which it showed $26 \mathrm{nM}$ affinity, over oligomers [51].

Other proteins with fundamental roles in early development (e.g., olfactomedin-like protein 3), cell mobility (e.g., cytoplasmic actin 1), and antimicrobial and proteolytic activity (e.g., dermcidin) are found in senile plaques and bound to $A \beta$ in vitro, nevertheless, their links with $\mathrm{AD}$ is still scarcely described in the literature.

Finally, we want to briefly mention two important proteins that are not included in Table 1 due to the employed selection criteria: $\alpha$-synculein and tau. The roles of these proteins in $\mathrm{AD}$ have been extensively described in other reviews, e.g. [330, 331]. Although these are primarily intracellular proteins they are also found in CSF. $\alpha$-synculein was early associated with plaques as the origin of the non amyloid- $\beta$ component (NAC) [332, 333] but is better known as the key player in synucleinopathies, including Parkinson's disease, dementia with Lewy bodies and multiple system atrophy [334]. Lewy body co-pathology is indeed common in $\mathrm{AD}$ and a more extensive role of $\alpha$-synculein in $A D$ pathology is emerging [330]. In vitro experiments have confirmed interactions between $A \beta$ and $\alpha$-synculein but none of the studies using biological fluids (that constitute the basis for Table 1) identified the protein. This indicates that the origin of plaque-associated $\alpha$-synculein (NAC) may be intracellular (vide infra). Tau has already been mentioned as the main component in neurofibrillary tangles but it has also been found in plaques [31-33, 59]. This constitute one (of many) direct connection between amyloid and tangle pathologies although the role of plaque-associated tau in $\mathrm{AD}$ is most likely minor to that of its intracellular accumulation. Despite the fact that an increased tau level in CSF as an established AD biomarker, tau was not identified as a binder to $A \beta$ in our studies with CSF samples from $\mathrm{AD}$ patients $[50,51,56]$. Hence, like in the case with $\alpha$-synculein, tau in the plaques may originate from released intracellular aggregates.

\section{Network analysis}

In order to gain new insights from the assembled list of proteins we analyzed it (with the immunoglobulins excluded) by the STRING protein network tool [335]. The network obtained with the 'high confidence' setting is illustrated in Fig. 3. There is indeed a dense network of connections between the proteins on the list and we find A $\beta$ (APP) in a central position. The functional classes used in Table 1 are rather well reflected also in the network illustration. It seems that proteins involved in lipid metabolism or blood coagulation in general are found closer to APP than the other classes. The majority of the nodes without any connection are classified as "other proteins". STRING analysis also provides information about enriched properties of the network (Fig. 4). We note that characteristics related to various protein functions seem to be more enriched in the network than structural features. Hence, the protein composition of the plaques may be connected to the functional roles of the proteins rather than their structural and chemical properties. This is in line with absence of clear correlations between the binding to $A \beta$ fibrils and physicochemical properties observed in previous studies [53, 56]. This means that the network may provide information about biological processes that can be triggered or inhibited by $A \beta$ amyloid. The processes that are highlighted as enriched in this network include protein activation/regulation/metabolism (and thereby various signaling pathways), complement system, blood coagulation, inflammation and immune response. Interestingly the second most enriched KEGG pathway is "Staphylococcus aureus infection", which may indicate that $A \beta$ fibrils could trigger responses similar to bacteria infection.

\section{Intracellular proteins}

Although $A \beta$ amyloid plaques are per definition extracellular inclusions, investigations of plaques from brain tissue have revealed the presence of a large number of 


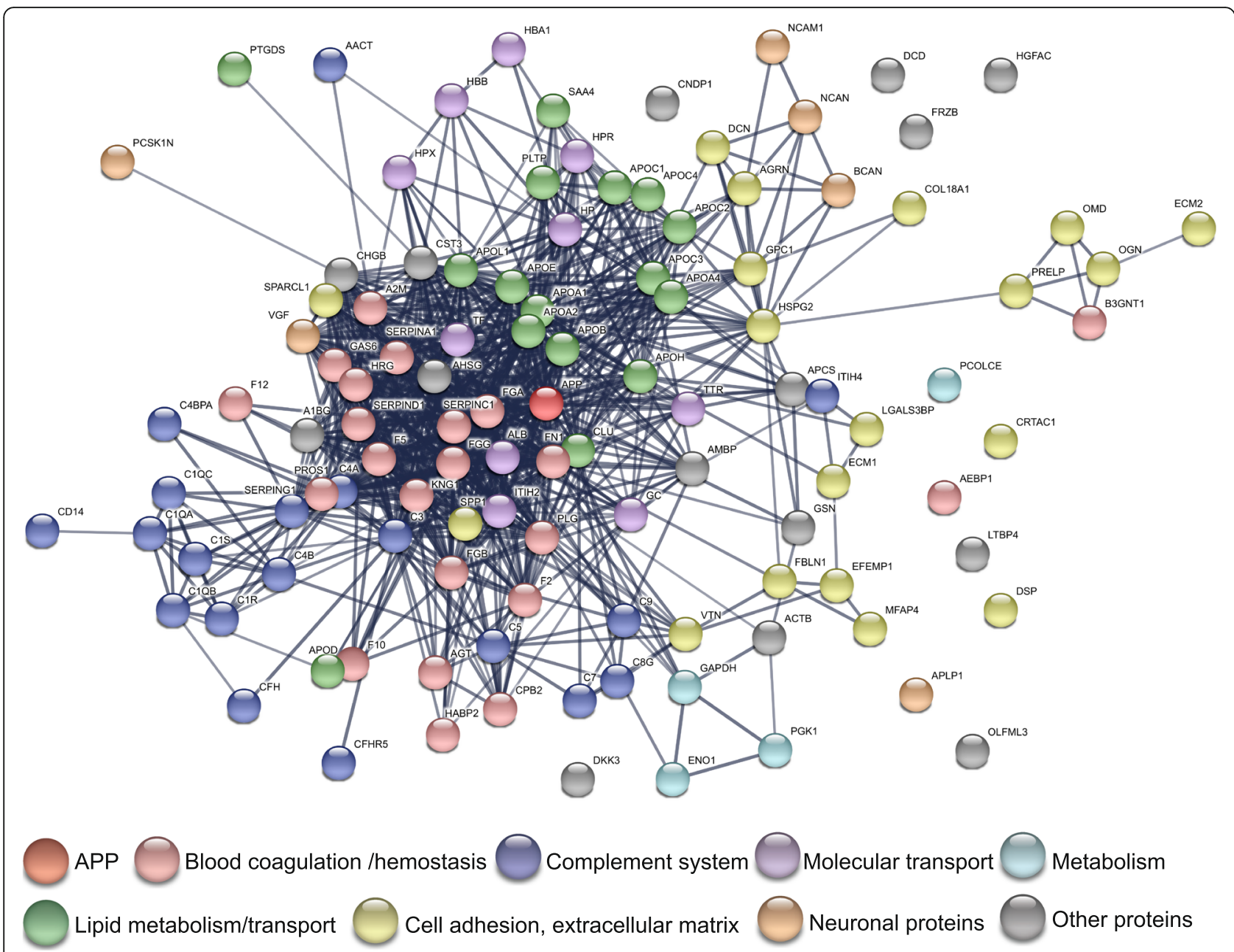

Fig. 3 STRING protein network analysis of the proteins in Table 1 (except immunoglobulins). The nodes are colored based on the functional classification used in the article and the thickness of the connecting lines show the confidence of the association

intracellular proteins. These are clearly parts of the plaques as they have been found by top-down studies of tissue [31-33] and Fig. 5 illustrates potential pathways by which intracellular components could associate with the plaques. $A \beta$ is produced in different cellular locations. Some release may occur directly from the plasma membrane $[336,337]$ but the main production happens in the endosomal compartment or trans-Golgi network followed by vesicle recycling into the extracellular space [338], where it, under certain circumstances, may begin to aggregate. The formed amyloid will rapidly associate with other extracellular components, as outlined in the present review. The amyloid plaques can activate the cellular defense and inflammation, mainly microglia but also astrocytes [339-341], that can bind to amyloid through various cell surface receptors e.g., Toll-like receptors (TLRs), scavenger receptors such as CD36 and TREM2 [342-345]. The plaques can then be phagocytosed with the lysosomal degradation machinery as destination. In this state the amyloid structure may associate with intracellular components. However, too high load of engulfed material could lead to lysosomal dysfunction and release of the aggregated material to the extracellular space [346].

An alternative route involves intracellular $A \beta$ accumulation (Fig. 5). $A \beta$ is produced in intracellular locations, including the trans-Golgi network, endoplasmic reticulum (ER), and endosomal, lysosomal and mitochondrial membranes [336]. Moreover, neurons (as well as other CNS cells) can actively take up $\mathrm{A} \beta$ (monomeric or aggregated) from the surrounding through a number of cell surface receptors, including the $\alpha 7$ nicotinic acetylcholine receptor $(\alpha 7 \mathrm{nAChR})$, low-density lipoprotein receptors (LDLR), the scavenger receptor for advanced glycation end products (RAGE), and N-methylD-aspartate (NMDA) receptors [336, 347-350]. Several reports have described intra-neuronal aggregation and amyloid formation of $\mathrm{A} \beta$ (e.g., [351-354]). This process 


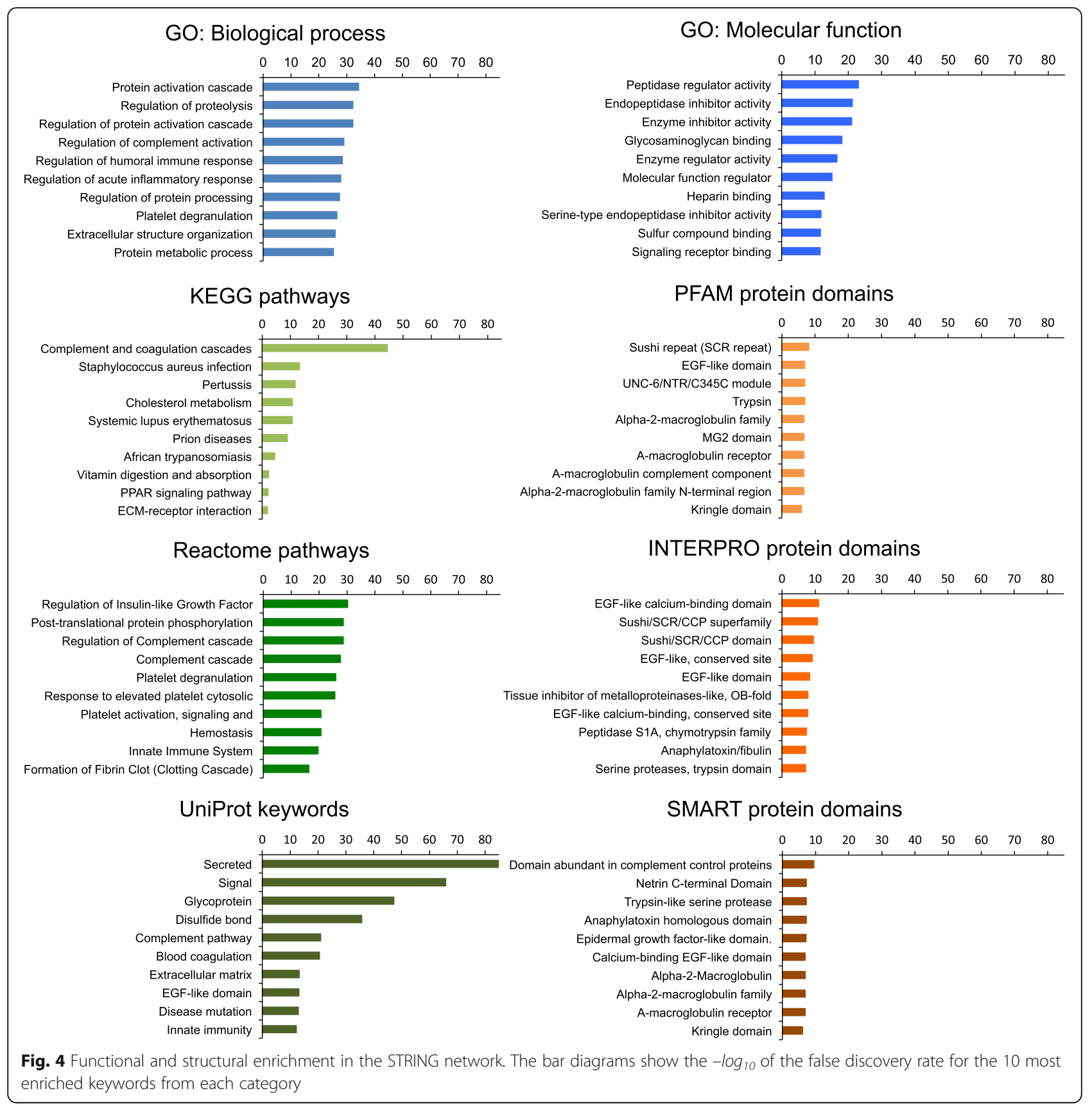

may eventually kill the cells and release the amyloid with the sequestered intracellular components [206]. Taken together, all the material indicated in Fig. 5 could be considered as potential components of the plaques, including $A \beta$ amyloid with sequestered extra- as well as intracellular components, activated cells attached by the surface receptors, intact cells with intracellular amyloid aggregates and debris from dead (and lysed) cells.

In vitro biochemical binding studies of intracellular proteins similar to those in biological fluids are few. Olschza et al. reported some proteins interacting with A $\beta$ in human embryonic kidney 293 (HEK293T) cells, including translation initiation factors, chromatin regulators, RNA processing proteins, mitochondrial membrane proteins and chaperones. It is not clear, however, what form(s) of $A \beta$ that was responsible for the interactions [45]. Another study used murine neuroblastoma N2a cells and investigated the binding of proteins to $A \beta 42$ oligomers [355]. They found ribosomal proteins, chaperones, and proteins associated with cytoskeleton or protein synthesis. Experimental protocols to identify interaction partners from an intracellular environment are indeed more challenging than in biological fluids but could also provide extremely valuable information, e.g., 


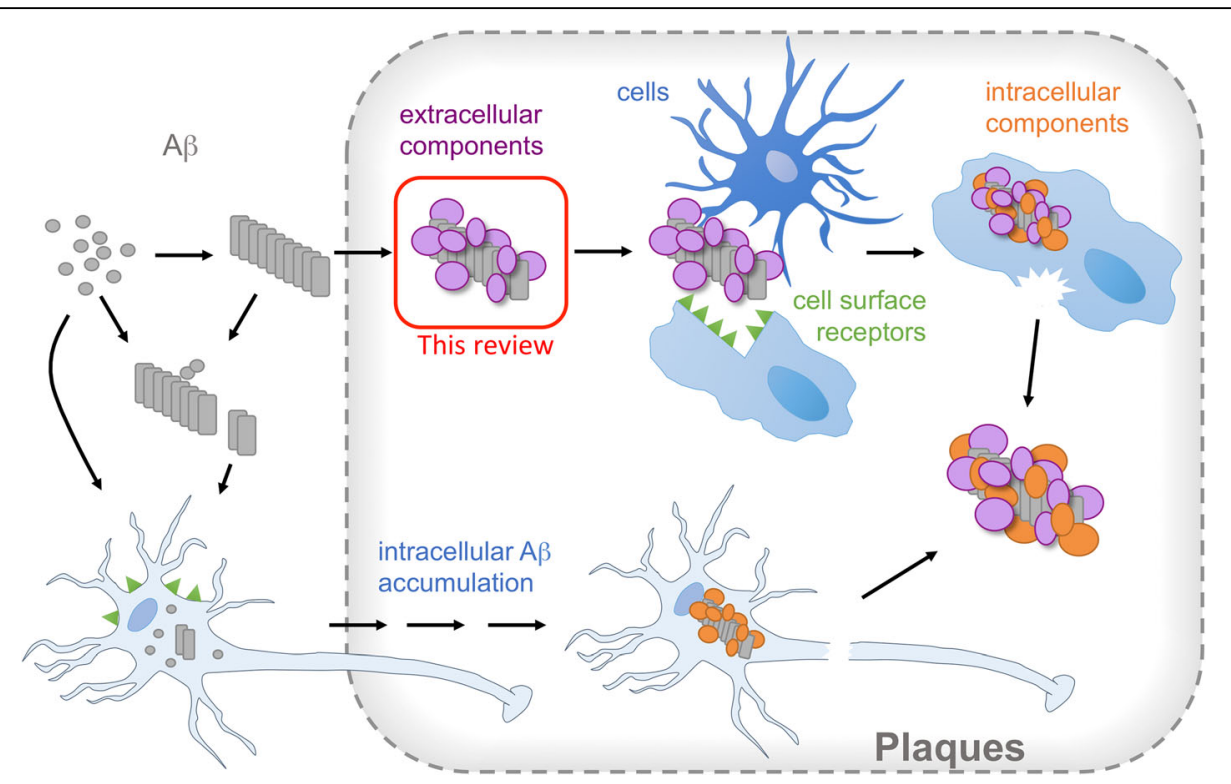

Fig. 5 Illustration of how extracellular and intracellular components may end up in senile plaques. Most of the produced $A \beta$ are secreted and can under certain circumstances aggregate in the extracellular environment. The amyloid will bind to extracellular components to form multicomponent aggregates. Amyloid deposits can also trigger cellular response through cell surface receptors leading to phagocytosis and co-accumulation of intracellular components. In another route, the extracellular amyloid can promote the formation of oligomeric A . These oligomers, as well as A $\beta$ monomers, can be internalized by cells and accumulate in the intracellular environment. Too high intracellular load of aggregated proteins may eventually lead to cell death and release of the aggregated material

from comparison of different cell types or even subcellular compartment.

\section{Conclusions}

Just by recognizing the normal and potential abnormal functions of the proteins listed in Table 1 it is evident that many of the proposed pathological mechanisms of $\mathrm{AD}$ are covered. This picture is also confirmed by the network analysis. With this in mind it appears unlikely that sequestration of biomolecules in the plaques is merely a side effect of $A \beta$ aggregation and $A \beta$-mediated toxicity. More likely, co-aggregation and alteration of the associated biochemical processes are part of the mechanisms by which amyloid formation leads to neurodegeneration. However, it still remains an open discussion which of the processes that are more important and how they may affect each other. To address these questions it is important to gain better understanding of the molecular events (how do the proteins bind to the plaque components and how does the binding affect their structure and function) as well as the physiological consequences. Hence, the multicomponent structures of senile plaques should be explored with both bottom-up and top-down approaches.

Among the outstanding questions regarding the molecular perspective are to decipher the details of the architecture of the multicomponent plaques; are they just random aggregates of sequestered proteins or is there some kind of order? In vitro binding studies suggest that many proteins can bind $A \beta$ with $K_{D}$ in the $\mu \mathrm{M}-\mathrm{nM}$ range, which suggest specific binding event rather than unspecific sequestration. Within the network there are also many proteins where mutual interactions are part of their biological function. Such interactions could be important in recruiting certain proteins to the plaques.

More knowledge is also needed regarding whether the bound proteins retain their native structure or if the interaction can lead to misfolding. It is intriguing that many of the proteins that associate with senile plaques in vivo or plaque-like particles in vitro are known to form amyloid themselves and to be associated with amyloid diseases. This group of proteins include immunoglobulins, apolipoproteins (A-I, AII, A-IV, C-II, C-III), serum amyloid $\mathrm{A}$, fibrinogen, cystatin $\mathrm{C}$, gelsolin, and transthyretin. Notably, NAC (i.e. $\alpha$-synuclein) [332, 333] is not found in Table 1 . There are also proteins with confirmed ability to form amyloid aggregates but without any (known) connection to disease, e.g. GAPDH [211, 212], cartilage acidic protein 1 [292] and vitronectin [293]. So far nothing is known about their conformational status when incorporated in the plaques.

How is further $A \beta$ aggregation affected by the binding of other proteins? As described above many of the sequestered proteins are known to affect $A \beta$ aggregation in vitro. Moreover, surface-catalyzed secondary nucleation seems to be a critical part in the amplification of $A \beta$ aggregates [356] and that process will certainly be 
affected by binding of other biomolecules to the fibril surfaces. The reduced fibrillation rates observed for $A \beta$ in CSF [44] is indeed in line with that assumption. Finally, it is also important to move on and explore how other biomolecules, e.g. lipids or proteoglycans, are incorporated in the plaques and to investigate the sequestration of intracellular components and whole cells, as illustrated in Fig. 5.

Embracing the multiprotein nature of amyloid deposits also expand the therapeutic opportunities. All proteins on the list are potential drug targets. Therapeutic effects could be achieved by inhibit binding or by modulating protein functions to restore loss-of-function effects or counteract toxic gain-of-function effects. Having the highly connected functional network in mind, even small alterations in the composition of plaques could have significant effects on the pathology.

\section{List of abbreviations}

a2M: Alpha-2-macroglobulin; AB: Amyloid $\beta$; A1AT: Alpha-1-antitrypsin; ACT: Alpha 1-antichymotrypsin; AD: Alzheimer's disease; APLP1: Amyloid-like protein 1; ApoA-I: Apolipoprotein A-I; ApoA-II: Apolipoprotein A-II; ApoAVI: Apolipoprotein A-VI; ApoB-100: Apolipoprotein B-100; ApoCI: Apolipoprotein C-I; ApoC-II: Apolipoprotein C-II; ApoC-III: Apolipoprotein CIII; ApoC-IV: Apolipoprotein C-IV; ApoD: Apolipoprotein D;

ApoE: Apolipoprotein E; ApoJ: Apolipoprotein J; APP: Amyloid $\beta$ precursor protein; C1q: Complement 1q; C1r: Complement 1r; C1s: Complement 1s; C3: Complement 3; C3aR1: Complement 3a receptor-1; C4: Complement 4; C5: Complement 5; C7: Complement 7; CAA: Cerebral amyloid angiopathy; CD: Circular dichroism; CLU: Clusterin; CNS: Central nervous system; CRTA C1: Cartilage acidic protein 1; CSF: Cerebrospinal fluid; CysC: Cystatin C; ECM: Extracellular matrix; ELISA: Enzyme linked immunosorbent assay; ENO1: Alpha-enolase; G3BP: Galectin-3-binding protein; GAPD

H: Glyceraldehyde-3-phosphate dehydrogenase; Gpc-1: Glypican-1; Hb: Hemoglobin; HDL: High-density lipoproteins; Hpt: Haptoglobin; Hpx: Hemopexin; IAPP: Islet amyloid polypeptide; ITIH2: Inter-alpha-trypsin inhibitor heavy chain H2; LC-MS/MS: Liquid chromatography coupled to tandem mass spectrometry; LCM: Laser capture microdissection; LRP2: Lipoprotein-related protein 2; MRM: Multiple reaction monitoring; NAC: Non amyloid- $\beta$ component; NCAM1: Neural cell adhesion molecule 1; NMR: Nuclear magnetic resonance; OPN: Osteopontin; PCPE 1: Procollagen C-endopeptidase enhancer 1; PET: Positron emission tomography; PGK1: Phosphoglycerate kinase 1; SAP: Serum amyloid P component; SEC: Size exclusion chromatography; SPR: Surface plasmon resonance; TEM: Transmission electron microscopy; TREM2: Triggering receptor expressed on myeloid cells 2; TTR: Transthyretin; WB: Western blot

\section{Acknowledgements}

Not applicable

\section{Authors' contributions}

M.M.R and C.L wrote and edited the manuscript. All authors read and approve the final manuscript.

\section{Funding}

The Swedish research council (VR, grant number 2016-03952), the Swedish Alzheimer Foundation (grant numbers AF-544641, AF-640331, AF-733821), and Olle Engkvist stiftelse (grant number 199-0446) are acknowledged for financial support. None of these funding sources played roles in design, writing, and editing of the manuscript.

Availability of data and materials

Not applicable

\section{Declarations}

Ethics approval and consent to participate

Not applicable.

\section{Consent for publication}

Not applicable.

\section{Competing interests}

The authors declare that they have no competing interests.

Received: 17 October 2020 Accepted: 11 June 2021

Published online: 28 August 2021

\section{References}

1. World Alzheimer Report 2019. Attitudes to dementia. London: ADI. 2019.

2. Olsson B, Lautner R, Andreasson U, Öhrfelt A, Portelius E, Bjerke M, et al. CSF and blood biomarkers for the diagnosis of Alzheimer's disease: a systematic review and meta-analysis. Lancet Neurol. 2016;15:673-84.

3. Zetterberg $\mathrm{H}$, Burnham SC. Blood-based molecular biomarkers for Alzheimer's disease. Mol Brain. 2019;12:26.

4. Matsuda H, Shigemoto $Y$, Sato N. Neuroimaging of Alzheimer's disease: focus on amyloid and tau PET. Jpn J Radiol. 2019;37:735-49.

5. DeTure MA, Dickson DW. The neuropathological diagnosis of Alzheimer's disease. Mol Neurodegener. 2019;14:32.

6. Márquez F, Yassa MA. Neuroimaging biomarkers for Alzheimer's disease. Mol Neurodegener. 2019;14:21.

7. Aizenstein HJ, Nebes RD, Saxton JA, Price JC, Mathis CA, Tsopelas ND, et al. Frequent amyloid deposition without significant cognitive impairment among the elderly. Arch Neurol. 2008;65:1509-17.

8. Querfurth HW, LaFerla FM. Alzheimer's disease. N Engl J Med. 2010;362:329-44

9. Alzheimer A. Über eine eigenartige Erkrankung der Hirnrinde. Allgemeine Zeitschrift fur Psychiatrie und Psychisch-gerichtliche Medizin. 1907;64:146-8.

10. Divry P. Etude histochimique des plaques. J Belge de Neurologie et de Psychiatrie. 1927:27:643-57.

11. Glenner GG, Wong CW. Alzheimer's disease: initial report of the purification and characterization of a novel cerebrovascular amyloid protein. Biochem Biophys Res Commun. 1984;120:885-90.

12. Masters CL, Simms G, Weinman NA, Multhaup G, McDonald BL, Beyreuther K. Amyloid plaque core protein in Alzheimer disease and Down syndrome. Proc Natl Acad Sci U S A. 1985;82:4245-9.

13. Brion JP, Couck AM, Passareiro E, Flament-Durand J. Neurofibrillary tangles of Alzheimer's disease: an immunohistochemical study. J Submicrosc Cytol. 1985:17:89-96.

14. van Duinen SG, Castaño EM, Prelli F, Bots GT, Luyendijk W, Frangione B. Hereditary cerebral hemorrhage with amyloidosis in patients of Dutch origin is related to Alzheimer disease. Proc Natl Acad Sci U S A. 1987;84: 5991-4.

15. Van Broeckhoven C, Haan J, Bakker E, Hardy JA, Van Hul W, Wehnert A, et al. Amyloid $\beta$ protein precursor gene and hereditary cerebral hemorrhage with amyloidosis (Dutch). Science. 1990;248:1120-2

16. Hardy J. Framing $\beta$-amyloid. Nat Genet. 1992;1:233-4.

17. Paravastu AK, Leapman RD, Yau WM, Tycko R. Molecular structural basis for polymorphism in Alzheimer's $\beta$-amyloid fibrils. Proc Natl Acad Sci U S A. 2008;105:18349-54.

18. Colvin MT, Silvers R, Ni QZ, Can TV, Sergeyev I, Rosay M, et al. Atomic resolution structure of monomorphic AB42 amyloid fibrils. J Am Chem Soc. 2016;138:9663-74

19. Wälti MA, Ravotti F, Arai H, Glabe CG, Wall JS, Böckmann A, et al. Atomicresolution structure of a disease-relevant $A \beta(1-42)$ amyloid fibril. Proc Natl Acad Sci U S A. 2016;113:E4976-84.

20. Gremer L, Schölzel D, Schenk C, Reinartz E, Labahn J, Ravelli RBG, et al. Fibril structure of amyloid- $\beta(1-42)$ by cryo-electron microscopy. Science. 2017;358: $116-9$.

21. Lambert MP, Barlow AK, Chromy BA, Edwards C, Freed R, Liosatos M, et al. Diffusible, nonfibrillar ligands derived from $A \beta 1-42$ are potent central nervous system neurotoxins. Proc Natl Acad Sci U S A. 1998;95:6448-53.

22. Cline EN, Bicca MA, Viola KL, Klein WL. The amyloid- $\beta$ oligomer hypothesis: beginning of the third decade. J Alzheimers Dis. 2018;64:S567-s610. 
23. Cohen SI, Linse S, Luheshi LM, Hellstrand E, White DA, Rajah L, et al. Proliferation of amyloid- $\beta 42$ aggregates occurs through a secondary nucleation mechanism. Proc Natl Acad Sci U S A. 2013;110:9758-63.

24. Meisl G, Yang X, Hellstrand E, Frohm B, Kirkegaard JB, Cohen SI, et al. Differences in nucleation behavior underlie the contrasting aggregation kinetics of the Aß40 and Aß42 peptides. Proc Natl Acad Sci U S A. 2014;111: 9384-9.

25. De Strooper B, Karran E. The cellular phase of Alzheimer's disease. Cell. 2016; 164:603-15.

26. Eikelenboom P, Stam FC. Immunoglobulins and complement factors in senile plaques. An immunoperoxidase study. Acta Neuropathol. 1982;57: 239-42.

27. Ishii T, Haga S. Identification of components of immunoglobulins in senile plaques by means of fluorescent antibody technique. Acta Neuropathol. 1975;32:157-62

28. McGeer PL, Klegeris A, Walker DG, Yasuhara O, McGeer EG. Pathological proteins in senile plaques. Tohoku J Exp Med. 1994;174:269-77.

29. Namba Y, Tomonaga M, Kawasaki H, Otomo E, Ikeda K. Apolipoprotein E immunoreactivity in cerebral amyloid deposits and neurofibrillary tangles in Alzheimer's disease and kuru plaque amyloid in Creutzfeldt-Jakob disease. Brain Res. 1991;541:163-6.

30. Corder EH, Saunders AM, Strittmatter WJ, Schmechel DE, Gaskell PC, Small GW, et al. Gene dose of apolipoprotein E type 4 allele and the risk of Alzheimer's disease in late onset families. Science. 1993;261:921-3.

31. Liao L, Cheng D, Wang J, Duong DM, Losik TG, Gearing M, et al. Proteomic characterization of postmortem amyloid plaques isolated by laser capture microdissection. J Biol Chem. 2004;279:37061-8.

32. Xiong F, Ge W, Ma C. Quantitative proteomics reveals distinct composition of amyloid plaques in Alzheimer's disease. Alzheimers Dement. 2019;15:429-40.

33. Bai B, Wang X, Li Y, Chen PC, Yu K, Dey KK, et al. Deep multilayer brain proteomics identifies molecular networks in Alzheimer's disease progression. Neuron. 2020;105:975-91.e7.

34. Söderberg L, Bogdanovic N, Axelsson B, Winblad B, Näslund J, Tjernberg LO. Analysis of single Alzheimer solid plaque cores by laser capture microscopy and nanoelectrospray/tandem mass spectrometry. Biochemistry. 2006;45: 9849-56.

35. Wippold FJ 2nd, Cairns N, Vo K, Holtzman DM, Morris JC. Neuropathology for the neuroradiologist: plaques and tangles. AJNR Am J Neuroradiol. 2008; 29:18-22.

36. O'Reilly FJ, Rappsilber J. Cross-linking mass spectrometry: methods and applications in structural, molecular and systems biology. Nat Struct Mol Biol. 2018;25:1000-8.

37. Chavez JD, Bruce JE. Chemical cross-linking with mass spectrometry: a tool for systems structural biology. Curr Opin Chem Biol. 2019:48:8-18.

38. Bai Y, Markham K, Chen F, Weerasekera R, Watts J, Horne P, et al. The in vivo brain interactome of the amyloid precursor protein. Mol Cell Proteomics. 2008;7:15-34.

39. Sinsky J, Majerova P, Kovac A, Kotlyar M, Jurisica I, Hanes J. Physiological tau interactome in brain and its link to tauopathies. J Proteome Res. 2020;19: 2429-42.

40. Nyström S, Bäck M, Nilsson KPR, Hammarström P. Imaging amyloid tissues stained with luminescent conjugated oligothiophenes by hyperspectral confocal microscopy and fluorescence lifetime imaging. J Vis Exp. 2017;

41. Fitzpatrick AW, Saibil HR. Cryo-EM of amyloid fibrils and cellular aggregates. Curr Opin Struct Biol. 2019;58:34-42.

42. Bäuerlein FJB, Saha I, Mishra A, Kalemanov M, Martínez-Sánchez A, Klein R, et al. In situ architecture and cellular interactions of PolyQ inclusions. Cell. 2017;171:179-87.e10

43. Guo Q, Lehmer C, Martínez-Sánchez A, Rudack T, Beck F, Hartmann H, et al. In situ structure of neuronal C9orf72 Poly-GA aggregates reveals proteasome recruitment. Cell. 2018;172:696-705.e12.

44. Frankel R, Törnquist M, Meisl G, Hansson O, Andreasson U, Zetterberg H, et al. Autocatalytic amplification of Alzheimer-associated A 342 peptide aggregation in human cerebrospinal fluid. Commun Biol. 2019;2:365.

45. Olzscha H, Schermann SM, Woerner AC, Pinkert S, Hecht MH, Tartaglia GG, et al. Amyloid-like aggregates sequester numerous metastable proteins with essential cellular functions. Cell. 2011;144:67-78.

46. Lynch I, Cedervall T, Lundqvist M, Cabaleiro-Lago C, Linse S, Dawson KA. The nanoparticle-protein complex as a biological entity; a complex fluids and surface science challenge for the 21st century. Adv Colloid Interface Sci. 2007;134-135:167-74.
47. Lynch I, Dawson KA, Linse S. Detecting cryptic epitopes created by nanoparticles. Sci STKE. 2006;327:pe14.

48. Ezzat K, Pernemalm M, Pålsson S, Roberts TC, Järver P, Dondalska A, et al. The viral protein corona directs viral pathogenesis and amyloid aggregation. Nat Commun. 2019;10:2331.

49. Malmberg M, Malm T, Gustafsson O, Sturchio A, Graff C, Espay AJ, et al. Disentangling the amyloid pathways: a mechanistic approach to etiology. Front Neurosci. 2020;14:256.

50. Rahman MM, Zetterberg H, Lendel $\mathrm{C}$, Härd T. Binding of human proteins to amyloid- $\beta$ protofibrils. ACS Chem Biol. 2015;10:766-74.

51. Rahman MM, Westermark GT, Zetterberg H, Härd T, Sandgren M. Protofibrillar and fibrillar amyloid- $\beta$ binding proteins in cerebrospinal fluid. J Alzheimers Dis. 2018;66:1053-64.

52. Juhl DW, Risor MW, Scavenius C, Rasmussen CB, Otzen D, Nielsen NC, et al. Conservation of the amyloid interactome across diverse fibrillar structures. Sci Rep. 2019;9:3863.

53. Nandakumar A, Xing Y, Aranha RR, Faridi A, Kakinen A, Javed I, et al. Human plasma protein corona of $A \beta$ amyloid and its impact on islet amyloid polypeptide cross-seeding. Biomacromolecules. 2020;21:988-98.

54. Pilkington EH, Gustafsson OJR, Xing Y, Hernandez-Fernaud J, Zampronio C, Kakinen $\mathrm{A}$, et al. Profiling the serum protein corona of fibrillar human islet amyloid polypeptide. ACS Nano. 2018;12:6066-78.

55. Madasamy S, Chaudhuri V, Kong R, Alderete B, Adams CM, Knaak TD, et al. Plaque array method and proteomics-based identification of biomarkers from Alzheimer's disease serum. Clin Chim Acta. 2015:441:79-85.

56. Chaudhary H, Meister SW, Zetterberg H, Löfblom J, Lendel C. Dissecting the structural organization of multiprotein amyloid aggregates using a bottomup approach. ACS Chem Neurosci. 2020;11:1447-57.

57. Han SH, Park JC, Mook-Jung I. Amyloid $\beta$-interacting partners in Alzheimer's disease: from accomplices to possible therapeutic targets. Prog Neurobiol. 2016;137:17-38.

58. Stewart KL, Radford SE. Amyloid plaques beyond A 3 : a survey of the diverse modulators of amyloid aggregation. Biophys Rev. 2017;9:405-19.

59. Drummond E, Nayak S, Faustin A, Pires G, Hickman RA, Askenazi M, et al. Proteomic differences in amyloid plaques in rapidly progressive and sporadic Alzheimer's disease. Acta Neuropathol. 2017;133:933-54.

60. Hondius DC, Eigenhuis KN, Morrema THJ, van der Schors RC, van Nierop P, Bugiani $\mathrm{M}$, et al. Proteomics analysis identifies new markers associated with capillary cerebral amyloid angiopathy in Alzheimer's disease. Acta Neuropathol Commun. 2018;6:46.

61. Hye A, Lynham S, Thambisetty M, Causevic M, Campbell J, Byers HL, et al. Proteome-based plasma biomarkers for Alzheimer's disease. Brain. 2006;129: 3042-50.

62. Hölttä M, Minthon L, Hansson O, Holmén-Larsson J, Pike I, Ward M, et al. An integrated workflow for multiplex CSF proteomics and peptidomicsidentification of candidate cerebrospinal fluid biomarkers of Alzheimer's disease. J Proteome Res. 2015;14:654-63.

63. Oyama R, Yamamoto $H$, Titani K. Glutamine synthetase, hemoglobin achain, and macrophage migration inhibitory factor binding to amyloid $\beta$ protein: their identification in rat brain by a novel affinity chromatography and in Alzheimer's disease brain by immunoprecipitation. Biochim Biophys Acta. 2000;1479:91-102.

64. Janciauskiene S, Rubin H, Lukacs CM, Wright HT. Alzheimer's peptide Aß1-42 binds to two $\beta$-sheets of a1-antichymotrypsin and transforms it from inhibitor to substrate. J Biol Chem. 1998;273:28360-4.

65. Janciauskiene S, Eriksson S, Wright HT. A specific structural interaction of Alzheimer's peptide Aß 1-42 with a1-antichymotrypsin. Nat Struct Biol. 1996; 3:668-71.

66. Hales CM, Dammer EB, Deng Q, Duong DM, Gearing M, Troncoso JC, et al. Changes in the detergent-insoluble brain proteome linked to amyloid and tau in Alzheimer's disease progression. Proteomics. 2016; 16:3042-53.

67. Abraham CR, Selkoe DJ, Potter H. Immunochemical identification of the serine protease inhibitor a1-antichymotrypsin in the brain amyloid deposits of Alzheimer's disease. Cell. 1988;52:487-501.

68. Engelhart MJ, Geerlings MI, Meijer J, Kiliaan A, Ruitenberg A, van Swieten JC, et al. Inflammatory proteins in plasma and the risk of dementia: the rotterdam study. Arch Neurol. 2004;61:668-72.

69. Hu Y, Hosseini A, Kauwe JS, Gross J, Cairns NJ, Goate AM, et al. Identification and validation of novel CSF biomarkers for early stages of Alzheimer's disease. Proteomics Clin Appl. 2007;1:1373-84. 
70. Rogers J, Cooper NR, Webster S, Schultz J, McGeer PL, Styren SD, et al. Complement activation by $\beta$-amyloid in Alzheimer disease. Proc Natl Acad Sci U S A. 1992:89:10016-20.

71. Webster S, Bonnell B, Rogers J. Charge-based binding of complement component C1q to the Alzheimer amyloid $\beta$-peptide. Am J Pathol. 1997; 150:1531-6.

72. Watson MD, Roher AE, Kim KS, Spiegel K, Emmerlin MR. Complement interactions with amyloid $\beta 1-42$ : a nidus for inflammation in $A D$ brains. Amyloid. 1997;4:147-56.

73. Zanjani H, Finch CE, Kemper C, Atkinson J, McKeel D, Morris JC, et al. Complement activation in very early Alzheimer disease. Alzheimer Dis Assoc Disord. 2005;19:55-66.

74. Khoonsari PE, Häggmark A, Lönnberg M, Mikus M, Kilander L, Lannfelt L, et al. Analysis of the cerebrospinal fluid proteome in Alzheimer's disease PLoS One. 2016;11:e0150672.

75. Brubaker WD, Crane A, Johansson JU, Yen K, Garfinkel K, Mastroeni D, et al. Peripheral complement interactions with amyloid $\beta$ peptide: erythrocyte clearance mechanisms. Alzheimers Dement. 2017;13:1397-409.

76. Zhang R, Barker L, Pinchev D, Marshall J, Rasamoelisolo M, Smith C, et al. Mining biomarkers in human sera using proteomic tools. Proteomics. 2004; 4:244-56.

77. Thambisetty M, Simmons A, Hye A, Campbell J, Westman E, Zhang Y, et al. Plasma biomarkers of brain atrophy in Alzheimer's disease. PLoS One. 2011; 6:e28527.

78. Finehout EJ, Franck Z, Choe LH, Relkin N, Lee KH. Cerebrospinal fluid proteomic biomarkers for Alzheimer's disease. Ann Neurol. 2007;61:120-9.

79. Wijte D, McDonnell LA, Balog Cl, Bossers K, Deelder AM, Swaab DF, et al. A novel peptidomics approach to detect markers of Alzheimer's disease in cerebrospinal fluid. Methods. 2012;56:500-7.

80. Yang $M H$, Yang $Y H$, Lu CY, Jong SB, Chen LJ, Lin YF, et al. Activitydependent neuroprotector homeobox protein: a candidate protein identified in serum as diagnostic biomarker for Alzheimer's disease. J Proteomics. 2012;75:3617-29.

81. Golabek A, Marques MA, Lalowski M, Wisniewski T. Amyloid $\beta$ binding proteins in vitro and in normal human cerebrospinal fluid. Neurosci Lett. 1995:191:79-82

82. Koudinov AR, Berezov TT, Kumar A, Koudinova NV. Alzheimer's amyloid $\beta$ interaction with normal human plasma high density lipoprotein: association with apolipoprotein and lipids. Clin Chim Acta. 1998;270:75-84.

83. Calero M, Rostagno A, Ghiso J. Search for amyloid-binding proteins by affinity chromatography. Methods Mol Biol. 2012;849:213-23.

84. Koldamova RP, Lefterov IM, Lefterova MI, Lazo JS. Apolipoprotein A-I directly interacts with amyloid precursor protein and inhibits $A \beta$ aggregation and toxicity. Biochemistry. 2001;40:3553-60.

85. Wilson LM, Pham CL, Jenkins AJ, Wade JD, Hill AF, Perugini MA, et al. High density lipoproteins bind $A \beta$ and apolipoprotein C-II amyloid fibrils. J Lipid Res. 2006:47:755-60

86. Wisniewski T, Golabek AA, Kida E, Wisniewski KE, Frangione B. Conformational mimicry in Alzheimer's disease. Role of apolipoproteins in amyloidogenesis. Am J Pathol. 1995;147:238-44.

87. Liu HC, Hu CJ, Chang JG, Sung SM, Lee LS, Yuan RY, et al. Proteomic identification of lower apolipoprotein A-I in Alzheimer's disease. Dement Geriatr Cogn Disord. 2006;21:155-61.

88. Kitamura Y, Usami R, Ichihara S, Kida H, Satoh M, Tomimoto H, et al. Plasma protein profiling for potential biomarkers in the early diagnosis of Alzheimer's disease. Neurol Res. 2017;39:231-8.

89. Shen L, Liao L, Chen C, Guo Y, Song D, Wang Y, et al. Proteomics analysis of blood serums from Alzheimer's disease patients using iTRAQ labeling technology. J Alzheimers Dis. 2017:56:361-78.

90. Khoonsari PE, Shevchenko G, Herman S, Remnestal J, Giedraitis V, Brundin R, et al. Improved differential diagnosis of Alzheimer's disease by integrating ELISA and mass spectrometry-based cerebrospinal fluid biomarkers. J Alzheimers Dis. 2019;67:639-51

91. Simonsen AH, McGuire J, Podust VN, Hagnelius NO, Nilsson TK, Kapaki E, et al. A novel panel of cerebrospinal fluid biomarkers for the differential diagnosis of Alzheimer's disease versus normal aging and frontotemporal dementia. Dement Geriatr Cogn Disord. 2007;24:434-40.

92. Shih Y-H, Tsai K-J, Lee C-W, Shiesh S-C, Chen W-T, Pai M-C, et al Apolipoprotein $C-$ III is an amyloid- $\beta$-binding protein and an early marker for Alzheimer's disease. J Alzheimers Dis. 2014:41:855-65.
93. Navarro A, Astudillo A, Valle E, Rey CG, Tolivia J. Immunohistochemical presence of apolipoprotein D in senile plaques. J Histotechnol. 2001;24:45-8.

94. Navarro A, Del Valle E, Astudillo A, Gonzalez del Rey C, Tolivia J. Immunohistochemical study of distribution of apolipoproteins $E$ and $D$ in human cerebral $\beta$ amyloid deposits. Exp Neurol. 2003;184:697-704.

95. Oláh Z, Kálmán J, Toth ME, Zvara A, Sántha M, Ivitz E, et al. Proteomic analysis of cerebrospinal fluid in Alzheimer's disease: wanted dead or alive. J Alzheimers Dis. 2015;44:1303-12.

96. Craig-Schapiro R, Kuhn M, Xiong C, Pickering EH, Liu J, Misko TP, et al. Multiplexed immunoassay panel identifies novel CSF biomarkers for Alzheimer's disease diagnosis and prognosis. PLoS One. 2011;6:e18850.

97. Paterson RW, Heywood WE, Heslegrave AJ, Magdalinou NK, Andreasson U, Sirka E, et al. A targeted proteomic multiplex CSF assay identifies increased malate dehydrogenase and other neurodegenerative biomarkers in individuals with Alzheimer's disease pathology. Transl Psychiatry. 2016;6:e952.

98. Vafadar-Isfahani B, Ball G, Coveney C, Lemetre C, Boocock D, Minthon L, et al. Identification of SPARC-like 1 protein as part of a biomarker panel for Alzheimer's disease in cerebrospinal fluid. J Alzheimers Dis. 2012;28:625-36.

99. Hammad SM, Ranganathan S, Loukinova E, Twal WO, Argraves WS. Interaction of apolipoprotein J-amyloid $\beta$-peptide complex with low density lipoprotein receptor-related protein-2/megalin. A mechanism to prevent pathological accumulation of amyloid $\beta$-peptide. J Biol Chem. 1997;272: 18644-9.

100. Calero M, Rostagno A, Matsubara E, Zlokovic B, Frangione B, Ghiso J. Apolipoprotein J (clusterin) and Alzheimer's disease. Microsc Res Tech. 2000; 50:305-15.

101. McGeer PL, Kawamata T, Walker DG. Distribution of clusterin in Alzheimer brain tissue. Brain Res. 1992:579:337-41.

102. Liao PC, Yu L, Kuo CC, Lin C, Kuo YM. Proteomics analysis of plasma for potential biomarkers in the diagnosis of Alzheimer's disease. Proteomics Clin Appl. 2007;1:506-12.

103. Yin GN, Lee HW, Cho JY, Suk K. Neuronal pentraxin receptor in cerebrospinal fluid as a potential biomarker for neurodegenerative diseases. Brain Res. 2009:1265:158-70.

104. Yu HL, Chertkow HM, Bergman H, Schipper HM. Aberrant profiles of native and oxidized glycoproteins in Alzheimer plasma. Proteomics. 2003:3:2240-8.

105. Hughes SR, Khorkova O, Goyal S, Knaeblein J, Heroux J, Riedel NG, et al. a2macroglobulin associates with $\beta$-amyloid peptide and prevents fibril formation. Proc Natl Acad Sci U S A. 1998;95:3275-80.

106. Du Y, Ni B, Glinn M, Dodel RC, Bales KR, Zhang Z, et al. a2-Macroglobulin as a ß-amyloid peptide-binding plasma protein. J Neurochem. 1997;69:299-305.

107. O'Bryant SE, Xiao G, Barber R, Reisch J, Doody R, Fairchild T, et al. A serum protein-based algorithm for the detection of Alzheimer disease. Arch Neurol. 2010;67:1077-81.

108. Kalaria RN, Golde T, Kroon SN, Perry G. Serine protease inhibitor antithrombin III and its messenger RNA in the pathogenesis of Alzheimer's disease. Am J Pathol. 1993:143:886-93.

109. Salza R, Lethias C, Ricard-Blum S. The multimerization state of the amyloid$\beta 42$ amyloid peptide governs its interaction network with the extracellular matrix. J Alzheimers Dis. 2017;56:991-1005.

110. Zamolodchikov D, Renne T, Strickland S. The Alzheimer's disease peptide $\beta$ amyloid promotes thrombin generation through activation of coagulation factor XII. J Thromb Haemost. 2016;14:995-1007.

111. Shibayama Y, Joseph K, Nakazawa Y, Ghebreihiwet B, Peerschke El, Kaplan AP. Zinc-dependent activation of the plasma kinin-forming cascade by aggregated $\beta$ amyloid protein. Clin Immunol. 1999;90:89-99.

112. Ahn HJ, Zamolodchikov D, Cortes-Canteli M, Norris EH, Glickman JF, Strickland S. Alzheimer's disease peptide $\beta$-amyloid interacts with fibrinogen and induces its oligomerization. Proc Natl Acad Sci U S A. 2010:107:21812-7.

113. Cortes-Canteli M, Paul J, Norris EH, Bronstein R, Ahn HJ, Zamolodchikov D, et al. Fibrinogen and $\beta$-amyloid association alters thrombosis and fibrinolysis: a possible contributing factor to Alzheimer's disease. Neuron. 2010;66:695-709.

114. Sainaghi PP, Bellan M, Lombino F, Alciato F, Carecchio M, Galimberti D, et al. Growth arrest specific 6 concentration is increased in the cerebrospinal fluid of patients with Alzheimer's disease. J Alzheimers Dis. 2017:55:59-65.

115. Hadley KC, Rakhit R, Guo H, Sun Y, Jonkman JE, McLaurin J, et al. Determining composition of micron-scale protein deposits in neurodegenerative disease by spatially targeted optical microproteomics. Elife. 2015;4 
116. Verdier $Y$, Földi I, Sergeant $N$, Fülöp L, Penke $Z$, Janáky $T$, et al. Characterization of the interaction between $A \beta 1-42$ and glyceraldehyde phosphodehydrogenase. J Pept Sci. 2008;14:755-62.

117. Milojevic J, Melacini G. Stoichiometry and affinity of the human serum albumin-Alzheimer's Aß peptide interactions. Biophys J. 2011;100:183-92.

118. Costa M, Ortiz AM, Jorquera J. Therapeutic albumin binding to remove amyloid- $\beta$. J Alzheimers Dis. 2012;29:159-70.

119. Rozga M, Kloniecki M, Jablonowska A, Dadlez M, Bal W. The binding constant for amyloid $A \beta 40$ peptide interaction with human serum albumin. Biochem Biophys Res Commun. 2007;364:714-8.

120. Algamal M, Ahmed R, Jafari N, Ahsan B, Ortega J, Melacini G. Atomicresolution map of the interactions between an amyloid inhibitor protein and amyloid $\beta(A \beta)$ peptides in the monomer and protofibril states. J Biol Chem. 2017;292:17158-68.

121. Costa R, Goncalves A, Saraiva MJ, Cardoso I. Transthyretin binding to AB peptide-impact on A $\beta$ fibrillogenesis and toxicity. FEBS Lett. 2008;582:936-42.

122. Buxbaum JN, Ye Z, Reixach N, Friske L, Levy C, Das P, et al. Transthyretin protects Alzheimer's mice from the behavioral and biochemical effects of A toxicity. Proc Natl Acad Sci U S A. 2008;105:2681-6.

123. Begcevic I, Brinc D, Brown M, Martinez-Morillo E, Goldhardt O, Grimmer T, et al. Brain-related proteins as potential CSF biomarkers of Alzheimer's disease: a targeted mass spectrometry approach. J Proteomics. 2018;182:12-20.

124. Brinkmalm G, Sjödin S, Simonsen AH, Hasselbalch SG, Zetterberg H, Brinkmalm A, et al. A parallel reaction monitoring mass spectrometric method for analysis of potential CSF biomarkers for Alzheimer's disease. Proteomics Clin Appl. 2018;12

125. van Steenoven I, Noli B, Cocco C, Ferri GL, Oeckl P, Otto M, et al. VGF peptides in cerebrospinal fluid of patients with dementia with lewy bodies. Int J Mol Sci. 2019;20

126. Cotman SL, Halfter W, Cole GJ. Agrin binds to $\beta$-amyloid (A $\beta$ ), accelerates a $\beta$ fibril formation, and is localized to $A \beta$ deposits in Alzheimer's disease brain. Mol Cell Neurosci. 2000;15:183-98.

127. Del Campo Milan M, Zuroff L, Jimenez CR, Scheltens P, Teunissen CE. Can agrin cerebrospinal fluid concentration be used as an early biomarker for Alzheimer's disease? Alzheimers Dement (Amst). 2015;1:75-80.

128. Snow AD, Kinsella MG, Parks E, Sekiguchi RT, Miller JD, Kimata K, et al. Differential binding of vascular cell-derived proteoglycans (perlecan, biglycan, decorin, and versican) to the $\beta$-amyloid protein of Alzheimer's disease. Arch Biochem Biophys. 1995;320:84-95.

129. Snow AD, Mar H, Nochlin D, Kresse H, Wight TN. Peripheral distribution of dermatan sulfate proteoglycans (decorin) in amyloid-containing plaques and their presence in neurofibrillary tangles of Alzheimer's disease. J Histochem Cytochem. 1992;40:105-13.

130. Watanabe N, Araki W, Chui D-H, Makifuchi T, Ihara Y, Tabira T. Glypican-1 as an $A \beta$ binding HSPG in the human brain: its localization in DIG domains and possible roles in the pathogenesis of Alzheimer's disease. FASEB J. 2004; 18:1013-5.

131. Akiyama H, Kawamata T, Dedhar S, McGeer PL. Immunohistochemical localization of vitronectin, its receptor and $\beta-3$ integrin in Alzheimer brain tissue. J Neuroimmunol. 1991;32:19-28.

132. Selenica ML, Wang X, Ostergaard-Pedersen L, Westlind-Danielsson A, Grubb A. Cystatin $C$ reduces the in vitro formation of soluble A 1-42 oligomers and protofibrils. Scand J Clin Lab Invest. 2007;67:179-90.

133. Sastre M, Calero M, Pawlik M, Mathews PM, Kumar A, Danilov V, et al. Binding of cystatin $C$ to Alzheimer's amyloid $\beta$ inhibits in vitro amyloid fibril formation. Neurobiol Aging. 2004;25:1033-43.

134. Bruggink KA, Kuiperij HB, Gloerich J, Otte-Höller I, Rozemuller AJM, Claassen JAHR, et al. Dickkopf-related protein 3 is a potential $A \beta$-associated protein in Alzheimer's disease. J Neurochem. 2015;134:1152-62.

135. Chauhan VP, Ray I, Chauhan A, Wisniewski HM. Binding of gelsolin, a secretory protein, to amyloid $\beta$-protein. Biochem Biophys Res Commun. 1999:258:241-6

136. Yu Y, Sun X, Tang D, Li C, Zhang L, Nie D, et al. Gelsolin bound $\beta$-amyloid peptides(1-40/1-42): electrochemical evaluation of levels of soluble peptide associated with Alzheimer's disease. Biosens Bioelectron. 2015;68:115-21.

137. Yu Y, Zhang L, Li C, Sun X, Tang D, Shi G. A method for evaluating the level of soluble $\beta$-amyloid(1-40/1-42) in Alzheimer's disease based on the binding of gelsolin to $\beta$-amyloid peptides. Angew Chem Int Ed Engl. 2014:53:12832-5.

138. Park SA, Jung JM, Park JS, Lee JH, Park B, Kim HJ, et al. SWATH-MS analysis of cerebrospinal fluid to generate a robust battery of biomarkers for Alzheimer's disease. Sci Rep. 2020;10:7423.
139. Hamazaki $\mathrm{H}$. Ca(2+)-dependent binding of human serum amyloid $\mathrm{P}$ component to Alzheimer's $\beta$-amyloid peptide. J Biol Chem. 1995;270: 10392-4.

140. Gaskin F, Finley J, Fang Q, Xu S, Fu SM. Human antibodies reactive with $\beta$ amyloid protein in Alzheimer's disease. J Exp Med. 1993;177:1181-6.

141. Du Y, Dodel R, Hampel H, Buerger K, Lin S, Eastwood B, et al. Reduced levels of amyloid $\beta$-peptide antibody in Alzheimer disease. Neurology. 2001; 57:801-5.

142. Weksler ME, Relkin N, Turkenich R, LaRusse S, Zhou L, Szabo P. Patients with Alzheimer disease have lower levels of serum anti-amyloid peptide antibodies than healthy elderly individuals. Exp Gerontol. 2002;37:943-8.

143. Taguchi H, Planque S, Nishiyama Y, Symersky J, Boivin S, Szabo P, et al. Autoantibody-catalyzed hydrolysis of amyloid $\beta$ peptide. J Biol Chem. 2008; 283:4714-22.

144. Colasanti T, Barbati C, Rosano G, Malorni W, Ortona E. Autoantibodies in patients with Alzheimer's disease: pathogenetic role and potential use as biomarkers of disease progression. Autoimmun Rev. 2010;9:807-11.

145. Stephan AH, Madison DV, Mateos JM, Fraser DA, Lovelett EA, Coutellier L, et al. A dramatic increase of C1q protein in the CNS during normal aging. J Neurosci. 2013;33:13460-74.

146. Hong S, Beja-Glasser VF, Nfonoyim BM, Frouin A, Li S, Ramakrishnan S, et al. Complement and microglia mediate early synapse loss in Alzheimer mouse models. Science. 2016;352:712-6.

147. Sárvári M, Vágó I, Wéber CS, Nagy J, Gál P, Mák M, et al. Inhibition of C1q- $\beta$ amyloid binding protects hippocampal cells against complement mediated toxicity. J Neuroimmunol. 2003;137:12-8.

148. Webster S, O'Barr S, Rogers J. Enhanced aggregation and $\beta$ structure of amyloid $\beta$ peptide after coincubation with C1q. J Neurosci Res. 1994;39: 448-56.

149. Bergamaschini L, Canziani S, Bottasso B, Cugno M, Braidotti P, Agostoni A. Alzheimer's $\beta$-amyloid peptides can activate the early components of complement classical pathway in a C1q-independent manner. Clin Exp Immunol. 1999;115:526-33.

150. Shen Y, Sullivan T, Lee CM, Meri S, Shiosaki K, Lin CW. Induced expression of neuronal membrane attack complex and cell death by Alzheimer's $\beta$ amyloid peptide. Brain Res. 1998;796:187-97.

151. Wu T, Dejanovic B, Gandham VD, Gogineni A, Edmonds R, Schauer S, et al. Complement $\mathrm{C} 3$ is activated in human $\mathrm{AD}$ brain and is required for neurodegeneration in mouse models of amyloidosis and tauopathy. Cell Rep. 2019;28:2111-23.e6.

152. Shi Q, Colodner KJ, Matousek SB, Merry K, Hong S, Kenison JE, et al. Complement C3-deficient mice fail to display age-related hippocampal decline. J Neurosci. 2015;35:13029-42.

153. Lian $H$, Litvinchuk A, Chiang AC, Aithmitti N, Jankowsky JL, Zheng $H$. Astrocyte-microglia cross talk through complement activation modulates amyloid pathology in mouse models of Alzheimer's disease. J Neurosci. 2016;36:577-89.

154. Maier M, Peng Y, Jiang L, Seabrook TJ, Carroll MC, Lemere CA. Complement C3 deficiency leads to accelerated amyloid $\beta$ plaque deposition and neurodegeneration and modulation of the microglia/macrophage phenotype in amyloid precursor protein transgenic mice. J Neurosci. 2008; 28:6333-41

155. Shi Q, Chowdhury S, Ma R, Le KX, Hong S, Caldarone BJ, et al. Complement C3 deficiency protects against neurodegeneration in aged plaque-rich APP/ PS1 mice. Sci Transl Med. 2017:9

156. Padmanabhan J, Levy M, Dickson DW, Potter H. a1-antichymotrypsin, an inflammatory protein overexpressed in Alzheimer's disease brain, induces tau phosphorylation in neurons. Brain. 2006;129:3020-34.

157. DeKosky ST, Ikonomovic MD, Wang X, Farlow M, Wisniewski S, Lopez OL, et al. Plasma and cerebrospinal fluid a1-antichymotrypsin levels in Alzheimer's disease: correlation with cognitive impairment. Ann Neurol. 2003:53:81-90.

158. Zhao N, Ren Y, Yamazaki Y, Qiao W, Li F, Felton LM, et al. Alzheimer's risk factors age, APOE genotype, and sex drive distinct molecular pathways. Neuron. 2020;106:727-42.e6.

159. Ma J, Yee A, Brewer HB Jr, Das S, Potter H. Amyloid-associated proteins a 1antichymotrypsin and apolipoprotein E promote assembly of Alzheimer $\beta$ protein into filaments. Nature. 1994;372:92-4.

160. Nilsson LN, Bales KR, DiCarlo G, Gordon MN, Morgan D, Paul SM, et al. a-1antichymotrypsin promotes $\beta$-sheet amyloid plaque deposition in a transgenic mouse model of Alzheimer's disease. J Neurosci. 2001;21:1444-51. 
161. Hamilton JA, Hillard CJ, Spector AA, Watkins PA. Brain uptake and utilization of fatty acids, lipids and lipoproteins: application to neurological disorders. J Mol Neurosci. 2007;33:2-11.

162. Burke KA, Yates EA, Legleiter J. Amyloid-forming proteins alter the local mechanical properties of lipid membranes. Biochemistry. 2013;52:808-17.

163. Liao CR, Rak M, Lund J, Unger M, Platt E, Albensi BC, et al. Synchrotron FTIR reveals lipid around and within amyloid plaques in transgenic mice and Alzheimer's disease brain. Analyst. 2013;138:3991-7.

164. Kiskis J, Fink H, Nyberg L, Thyr J, Li JY, Enejder A. Plaque-associated lipids in Alzheimer's diseased brain tissue visualized by nonlinear microscopy. Sci Rep. 2015;5:13489.

165. Lambert JC, Heath S, Even G, Campion D, Sleegers K, Hiltunen M, et al. Genome-wide association study identifies variants at CLU and CR1 associated with Alzheimer's disease. Nat Genet. 2009;41:1094-9.

166. Harold D, Abraham R, Hollingworth P, Sims R, Gerrish A, Hamshere ML, et al. Genome-wide association study identifies variants at CLU and PICALM associated with Alzheimer's disease. Nat Genet. 2009:41:1088-93.

167. Shi Y, Holtzman DM. Interplay between innate immunity and Alzheimer disease: APOE and TREM2 in the spotlight. Nat Rev Immunol. 2018;18:759-72.

168. Saunders AM, Strittmatter WJ, Schmechel D, George-Hyslop PH, PericakVance MA, Joo SH, et al. Association of apolipoprotein E allele epsilon 4 with late-onset familial and sporadic Alzheimer's disease. Neurology. 1993; 43:1467-72.

169. Strittmatter WJ, Saunders AM, Schmechel D, Pericak-Vance M, Enghild J, Salvesen GS, et al. Apolipoprotein E: high-avidity binding to $\beta$-amyloid and increased frequency of type 4 allele in late-onset familial Alzheimer disease. Proc Natl Acad Sci U S A. 1993;90:1977-81.

170. Strittmatter WJ, Weisgraber KH, Huang DY, Dong LM, Salvesen GS, PericakVance $M$, et al. Binding of human apolipoprotein $E$ to synthetic amyloid $\beta$ peptide: isoform-specific effects and implications for late-onset Alzheimer disease. Proc Natl Acad Sci U S A. 1993;90:8098-102.

171. Tokuda T, Calero M, Matsubara E, Vidal R, Kumar A, Permanne B, et al. Lipidation of apolipoprotein $E$ influences its isoform-specific interaction with Alzheimer's amyloid $\beta$ peptides. Biochem J. 2000;348(Pt 2):359-65.

172. Huynh TV, Davis AA, Ulrich JD, Holtzman DM. Apolipoprotein E and Alzheimer's disease: the influence of apolipoprotein $E$ on amyloid- $\beta$ and other amyloidogenic proteins. J Lipid Res. 2017;58:824-36.

173. Hashimoto T, Serrano-Pozo A, Hori Y, Adams KW, Takeda S, Banerii AO, et al. Apolipoprotein $\mathrm{E}$, especially apolipoprotein $\mathrm{E} 4$, increases the oligomerization of amyloid $\beta$ peptide. J Neurosci. 2012;32:15181-92.

174. Castano EM, Prelli F, Wisniewski T, Golabek A, Kumar RA, Soto C, et al. Fibrillogenesis in Alzheimer's disease of amyloid $\beta$ peptides and apolipoprotein E. Biochem J. 1995;306(Pt 2):599-604.

175. Wisniewski T, Castaño EM, Golabek A, Vogel T, Frangione B. Acceleration of Alzheimer's fibril formation by apolipoprotein E in vitro. Am J Pathol. 1994; 145:1030-5.

176. Youmans KL, Tai LM, Nwabuisi-Heath E, Jungbauer L, Kanekiyo T, Gan M et al. APOE4-specific changes in A $\beta$ accumulation in a new transgenic mouse model of Alzheimer disease. J Biol Chem. 2012;287:41774-86.

177. Liu CC, Zhao N, Fu Y, Wang N, Linares C, Tsai CW, et al. ApoE4 accelerates early seeding of amyloid pathology. Neuron. 2017;96:1024-32.e3.

178. Shi Y, Yamada K, Liddelow SA, Smith ST, Zhao L, Luo W, et al. ApoE4 markedly exacerbates tau-mediated neurodegeneration in a mouse mode of tauopathy. Nature. 2017;549:523-7.

179. Cerf E, Gustot A, Goormaghtigh E, Ruysschaert JM, Raussens V. High ability of apolipoprotein E4 to stabilize amyloid- $\beta$ peptide oligomers, the pathological entities responsible for Alzheimer's disease. FASEB J. 2011;25: 1585-95.

180. Wood SJ, Chan W, Wetzel R. An ApoE-Aß inhibition complex in A fibril extension. Chem Biol. 1996;3:949-56.

181. Garai K, Verghese PB, Baban B, Holtzman DM, Frieden C. The binding of apolipoprotein $E$ to oligomers and fibrils of amyloid- $\beta$ alters the kinetics of amyloid aggregation. Biochemistry. 2014;53:6323-31.

182. Wood SJ, Chan W, Wetzel R. Seeding of A fibril formation is inhibited by all three isotypes of apolipoprotein E. Biochemistry. 1996:35:12623-8.

183. Wisniewski T, Drummond E. APOE-amyloid interaction: therapeutic targets. Neurobiol Dis. 2020;138:104784

184. Scheidt T, Łapińska U, Kumita JR, Whiten DR, Klenerman D, Wilson MR, et al. Secondary nucleation and elongation occur at different sites on Alzheimer's amyloid- $\beta$ aggregates. Sci Adv. 2019;5:eaau3112
185. May PC, Lampert-Etchells M, Johnson SA, Poirier J, Masters JN, Finch CE. Dynamics of gene expression for a hippocampal glycoprotein elevated in Alzheimer's disease and in response to experimental lesions in rat. Neuron. 1990:5:831-9.

186. Foster EM, Dangla-Valls A, Lovestone S, Ribe EM, Buckley NJ. Clusterin in Alzheimer's disease: mechanisms, genetics, and lessons from other pathologies. Front Neurosci. 2019;13:164.

187. Narayan P, Meehan S, Carver JA, Wilson MR, Dobson CM, Klenerman D. Amyloid- $\beta$ oligomers are sequestered by both intracellular and extracellular chaperones. Biochemistry. 2012;51:9270-6.

188. Yerbury JJ, Poon S, Meehan S, Thompson B, Kumita JR, Dobson CM, et al. The extracellular chaperone clusterin influences amyloid formation and toxicity by interacting with prefibrillar structures. FASEB J. 2007;21:2312-22

189. Matsubara E, Soto C, Governale S, Frangione B, Ghiso J. Apolipoprotein J and Alzheimer's amyloid $\beta$ solubility. Biochem J. 1996;316(Pt 2):671-9.

190. Wojtas AM, Sens JP, Kang SS, Baker KE, Berry TJ, Kurti A, et al. Astrocytederived clusterin suppresses amyloid formation in vivo. Mol Neurodegener. 2020;15:71.

191. Wojtas AM, Kang SS, Olley BM, Gatherer M, Shinohara M, Lozano PA, et al. Loss of clusterin shifts amyloid deposition to the cerebrovasculature via disruption of perivascular drainage pathways. Proc Natl Acad Sci U S A. 2017;114:E6962-e71.

192. Bell RD, Sagare AP, Friedman AE, Bedi GS, Holtzman DM, Deane R, et al. Transport pathways for clearance of human Alzheimer's amyloid $\beta$-peptide and apolipoproteins $\mathrm{E}$ and $\mathrm{J}$ in the mouse central nervous system. J Cereb Blood Flow Metab. 2007;27:909-18.

193. Paula-Lima AC, Tricerri MA, Brito-Moreira J, Bomfim TR, Oliveira FF, Magdesian $\mathrm{MH}$, et al. Human apolipoprotein A-I binds amyloid- $\beta$ and prevents A $\beta$-induced neurotoxicity. Int J Biochem Cell Biol. 2009:41:1361-70.

194. Padayachee ER, Zetterberg H, Portelius E, Borén J, Molinuevo JL, Andreasen $N$, et al. Cerebrospinal fluid-induced retardation of amyloid $\beta$ aggregation correlates with Alzheimer's disease and the APOE $\varepsilon 4$ allele. Brain Res. 1651; 2016:11-6.

195. Yamauchi K, Tozuka M, Hidaka H, Nakabayashi T, Sugano M, Kondo Y, et al. Effect of apolipoprotein All on the interaction of apolipoprotein $E$ with $\beta$ amyloid: some apo(E-All) complexes inhibit the internalization of $\beta$-amyloid in cultures of neuroblastoma cells. J Neurosci Res. 2000;62:608-14.

196. Cui Y, Huang M, He Y, Zhang S, Luo Y. Genetic ablation of apolipoprotein A-IV accelerates Alzheimer's disease pathogenesis in a mouse model. Am J Pathol. 2011;178:1298-308.

197. Di Marco LY, Venneri A, Farkas E, Evans PC, Marzo A, Frangi AF. Vascular dysfunction in the pathogenesis of Alzheimer's disease-a review of endothelium-mediated mechanisms and ensuing vicious circles. Neurobiol Dis. 2015:82:593-606.

198. Chen ZL, Revenko AS, Singh P, MacLeod AR, Norris EH, Strickland S. Depletion of coagulation factor XII ameliorates brain pathology and cognitive impairment in Alzheimer disease mice. Blood. 2017;129:2547-56.

199. Merlini M, Rafalski VA, Rios Coronado PE, Gill TM, Ellisman M, Muthukumar $\mathrm{G}$, et al. Fibrinogen induces microglia-mediated spine elimination and cognitive impairment in an Alzheimer's disease model. Neuron. 2019;101: 1099-108.e6.

200. Zamolodchikov D, Berk-Rauch HE, Oren DA, Stor DS, Singh PK, Kawasaki M, et al. Biochemical and structural analysis of the interaction between $\beta$ amyloid and fibrinogen. Blood. 2016;128:1144-51.

201. Ahn HJ, Chen ZL, Zamolodchikov D, Norris EH, Strickland S. Interactions of $\beta$-amyloid peptide with fibrinogen and coagulation factor XII may contribute to Alzheimer's disease. Curr Opin Hematol. 2017;24:427-31.

202. Gurwitz D. The Alzheimer's disease peptide $\beta$-amyloid promotes thrombin generation through activation of coagulation factor XIl: comment. J Thromb Haemost. 2016;14:1488-9.

203. Gold M, Dolga AM, Koepke J, Mengel D, Culmsee C, Dodel R, et al. a1antitrypsin modulates microglial-mediated neuroinflammation and protects microglial cells from amyloid- $\beta$-induced toxicity. J Neuroinflammation. 2014; 11:165.

204. Yerbury JJ, Kumita JR, Meehan S, Dobson CM, Wilson MR. a2-Macroglobulin and haptoglobin suppress amyloid formation by interacting with prefibrillar protein species. J Biol Chem. 2009;284:4246-54.

205. Cordonnier C, van der Flier WM, Sluimer JD, Leys D, Barkhof F, Scheltens $P$. Prevalence and severity of microbleeds in a memory clinic setting. Neurology. 2006;66:1356-60. 
206. D'Andrea MR, Nagele RG, Wang HY, Peterson PA, Lee DH. Evidence that neurones accumulating amyloid can undergo lysis to form amyloid plaques in Alzheimer's disease. Histopathology. 2001;38:120-34.

207. Butterfield DA, Hardas SS, Lange MLB. Oxidatively modified glyceraldehyde3-phosphate dehydrogenase (GAPDH) and Alzheimer's disease: many pathways to neurodegeneration. J Alzheimers Dis. 2010;20:369-93.

208. Wang Q, Woltjer RL, Cimino PJ, Pan C, Montine KS, Zhang J, et al. Proteomic analysis of neurofibrillary tangles in Alzheimer disease identifies GAPDH as a detergent-insoluble paired helical filament tau binding protein. FASEB J. 2005;19:869-71.

209. Yamaji R, Chatani E, Harada N, Sugimoto K, Inui H, Nakano Y. Glyceraldehyde-3-phosphate dehydrogenase in the extracellular space inhibits cell spreading. Biochim Biophys Acta. 2005;1726:261-71.

210. Sheokand N, Kumar S, Malhotra H, Tillu V, Raje Cl, Raje M. Secreted glyceraldehye-3-phosphate dehydrogenase is a multifunctional autocrine transferrin receptor for cellular iron acquisition. Biochim Biophys Acta. 2013; 1830:3816-27.

211. Nakajima H, Amano W, Fujita A, Fukuhara A, Azuma YT, Hata F, et al. The active site cysteine of the proapoptotic protein glyceraldehyde-3-phosphate dehydrogenase is essential in oxidative stress-induced aggregation and cell death. J Biol Chem. 2007:282:26562-74.

212. Nakajima H, Amano W, Fukuhara A, Kubo T, Misaki S, Azuma YT, et al. An aggregate-prone mutant of human glyceraldehyde-3-phosphate dehydrogenase augments oxidative stress-induced cell death in SH-SY5Y cells. Biochem Biophys Res Commun. 2009;390:1066-71.

213. Itakura M, Nakajima H, Kubo T, Semi Y, Kume S, Higashida S, et al. Glyceraldehyde-3-phosphate dehydrogenase aggregates accelerate amyloid- $\beta$ amyloidogenesis in Alzheimer disease. J Biol Chem. 2015;290: 14493-503.

214. Díaz-Ramos A, Roig-Borrellas A, García-Melero A, López-Alemany R. aEnolase, a multifunctional protein: its role on pathophysiological situations. J Biomed Biotechnol. 2012;2012:156795.

215. Butterfield DA, Lange ML. Multifunctional roles of enolase in Alzheimer's disease brain: beyond altered glucose metabolism. J Neurochem. 2009;111: 915-33

216. Carrette O, Burgess JA, Burkhard PR, Lang C, Côte M, Rodrigo N, et al. Changes of the cortex proteome and Apolipoprotein $\mathrm{E}$ in transgenic mouse models of Alzheimer's disease. J Chromatogr B Analyt Technol Biomed Life Sci. 2006;840:1-9.

217. Butterfield DA, Lange MLB. Multifunctional roles of enolase in Alzheimer's disease brain: beyond altered glucose metabolism. J Neurochem. 2009;111: 915-33.

218. Shen L, Chen C, Yang A, Chen Y, Liu Q, Ni J. Redox proteomics identification of specifically carbonylated proteins in the hippocampi of triple transgenic Alzheimer's disease mice at its earliest pathological stage. J Proteomics. 2015;123:101-13.

219. Salza R, Peysselon F, Chautard E, Faye C, Moschcovich L, Weiss T, et al. Extended interaction network of procollagen C-proteinase enhancer-1 in the extracellular matrix. Biochem J. 2014;457:137-49.

220. Morimoto H, Wada J, Font B, Mott JD, Hulmes DJ, Ookoshi T, et al. Procollagen C-proteinase enhancer-1 (PCPE-1) interacts with $\beta 2$ microglobulin ( $\beta 2-m)$ and may help initiate $\beta 2-m$ amyloid fibril formation in connective tissues. Matrix Biol. 2008;27:211-9.

221. Richter F, Meurers BH, Zhu C, Medvedeva VP, Chesselet MF. Neurons express hemoglobin $\alpha$ - and $\beta$-chains in rat and human brains. J Comp Neurol. 2009;515:538-47.

222. Biagioli M, Pinto $M$, Cesselli D, Zaninello M, Lazarevic D, Roncaglia P, et al. Unexpected expression of $\mathrm{a}$ - and $\beta$-globin in mesencephalic dopaminergic neurons and glial cells. Proc Natl Acad Sci U S A. 2009;106:15454.

223. Schelshorn DW, Schneider A, Kuschinsky W, Weber D, Krüger C, Dittgen T, et al. Expression of hemoglobin in rodent neurons. J Cereb Blood Flow Metab. 2009;29:585-95.

224. Chuang JY, Lee CW, Shih YH, Yang T, Yu L, Kuo YM. Interactions between amyloid- $\beta$ and hemoglobin: implications for amyloid plaque formation in Alzheimer's disease. PLoS One. 2012;7:e33120.

225. Schonberger SJ, Edgar PF, Kydd R, Faull RL, Cooper GJ. Proteomic analysis of the brain in Alzheimer's disease: molecular phenotype of a complex disease process. Proteomics. 2001;1:1519-28.

226. Wu CW, Liao PC, Yu L, Wang ST, Chen ST, Wu CM, et al. Hemoglobin promotes $A \beta$ oligomer formation and localizes in neurons and amyloid deposits. Neurobiol Dis. 2004;17:367-77.
227. Gregory A, Hayflick SJ. Neurodegeneration with brain iron accumulation. Folia Neuropathol. 2005;43:286-96.

228. Berg D, Youdim MB. Role of iron in neurodegenerative disorders. Top Magn Reson Imaging. 2006;17:5-17.

229. Atamna H, Frey WH 2nd. A role for heme in Alzheimer's disease: heme binds amyloid $\beta$ and has altered metabolism. Proc Natl Acad Sci U S A. 2004;101:11153-8

230. Atamna H, Frey WH 2nd, Ko N. Human and rodent amyloid- $\beta$ peptides differentially bind heme: relevance to the human susceptibility to Alzheimer's disease. Arch Biochem Biophys. 2009;487:59-65.

231. Atamna $H$, Boyle K. Amyloid- $\beta$ peptide binds with heme to form a peroxidase: relationship to the cytopathologies of Alzheimer's disease. Proc Natl Acad Sci U S A. 2006;103:3381-6.

232. Flemmig J, Zámocký M, Alia A. Amyloid $\beta$ and free heme: bloody new insights into the pathogenesis of Alzheimer's disease. Neural Regen Res. 2018;13:1170-4.

233. Al-Hilaly YK, Williams TL, Stewart-Parker M, Ford L, Skaria E, Cole M, et al. A central role for dityrosine crosslinking of Amyloid- $\beta$ in Alzheimer's disease. Acta Neuropathol Commun. 2013;1:83.

234. Wassell J. Haptoglobin: function and polymorphism. Clinical laboratory. 2000;46:547-52

235. Morello N, Tonoli E, Logrand F, Fiorito V, Fagoonee S, Turco E, et al. Haemopexin affects iron distribution and ferritin expression in mouse brain. J Cell Mol Med. 2009;13:4192-204.

236. Yerbury JJ, Rybchyn MS, Easterbrook-Smith SB, Henriques C, Wilson MR. The acute phase protein haptoglobin is a mammalian extracellular chaperone with an action similar to clusterin. Biochemistry. 2005;44:10914-25.

237. Spagnuolo MS, Maresca B, La Marca V, Carrizzo A, Veronesi C, Cupidi C, et al. Haptoglobin interacts with apolipoprotein $\mathrm{E}$ and $\beta$-amyloid and influences their crosstalk. ACS Chem Neurosci. 2014:5:837-47.

238. Watanabe J, Grijalva V, Hama S, Barbour K, Berger FG, Navab M, et al. Hemoglobin and its scavenger protein haptoglobin associate with apoA-1containing particles and influence the inflammatory properties and function of high density lipoprotein. J Biol Chem. 2009;284:18292-301.

239. Stanyon HF, Viles $J H$. Human serum albumin can regulate amyloid- $\beta$ peptide fiber growth in the brain interstitium: implications for Alzheimer disease. J Biol Chem. 2012;287:28163-8.

240. Biere AL, Ostaszewski B, Stimson ER, Hyman BT, Maggio JE, Selkoe DJ. Amyloid $\beta$-peptide is transported on lipoproteins and albumin in human plasma. J Biol Chem. 1996;271:32916-22.

241. Milojevic J, Raditsis A, Melacini G. Human serum albumin inhibits $A \beta$ fibrillization through a "monomer-competitor" mechanism. Biophys J. 2009; 97:2585-94

242. Bode DC, Stanyon HF, Hirani T, Baker MD, Nield J, Viles JH. Serum albumin's protective inhibition of amyloid- $\beta$ fiber formation is suppressed by cholesterol, fatty acids and warfarin. J Mol Biol. 2018;430:919-34.

243. Ezra A, Rabinovich-Nikitin I, Rabinovich-Toidman P, Solomon B. Multifunctional effect of human serum albumin reduces Alzheimer's disease related pathologies in the $3 x \operatorname{Tg}$ mouse model. J Alzheimers Dis. 2016;50: 175-88.

244. Llewellyn DJ, Langa KM, Friedland RP, Lang IA. Serum albumin concentration and cognitive impairment. Curr Alzheimer Res. 2010;7: 91-6.

245. Yamamoto K, Shimada H, Koh H, Ataka S, Miki T. Serum levels of albuminamyloid $\beta$ complexes are decreased in Alzheimer's disease. Geriatr Gerontol Int. 2014;14:716-23.

246. Boada M, Ortiz P, Anaya F, Hernández I, Muñoz J, Núñez L, et al. Amyloidtargeted therapeutics in Alzheimer's disease: use of human albumin in plasma exchange as a novel approach for $A \beta$ mobilization. Drug News Perspect. 2009;22:325-39.

247. Boada M, López OL, Olazarán J, Núñez L, Pfeffer M, Paricio M, et al. A randomized, controlled clinical trial of plasma exchange with albumin replacement for Alzheimer's disease: primary results of the AMBAR Study. Alzheimers Dement. 2020;16:1412-25.

248. Robbins J. Transthyretin from discovery to now. Clin Chem Lab Med. 2002; 40:1183-90.

249. Du J, Cho PY, Yang DT, Murphy RM. Identification of $\beta$-amyloid-binding sites on transthyretin. Protein Eng Des Sel. 2012;25:337-45.

250. Schwarzman AL, Goldgaber D. Interaction of transthyretin with amyloid $\beta$ protein: binding and inhibition of amyloid formation. Ciba Found Symp. 1996;199:146-60. discussion 60-4 
251. Kuo YM, Emmerling MR, Lampert HC, Hempelman SR, Kokjohn TA, Woods AS, et al. High levels of circulating A 442 are sequestered by plasma proteins in Alzheimer's disease. Biochem Biophys Res Commun. 1999;257:787-91.

252. Ribeiro CA, Oliveira SM, Guido LF, Magalhaes A, Valencia G, Arsequell G, et al. Transthyretin stabilization by iododiflunisal promotes amyloid- $\beta$ peptide clearance, decreases its deposition, and ameliorates cognitive deficits in an Alzheimer's disease mouse model. J Alzheimers Dis. 2014;39: 357-70.

253. Hansson SF, Andreasson U, Wall M, Skoog I, Andreasen N, Wallin A, et al. Reduced levels of amyloid- $\beta$-binding proteins in cerebrospinal fluid from Alzheimer's disease patients. J Alzheimers Dis. 2009;16:389-97.

254. Ghadami SA, Chia S, Ruggeri FS, Meisl G, Bemporad F, Habchi J, et al. Transthyretin inhibits primary and secondary nucleations of amyloid- $\beta$ peptide aggregation and reduces the toxicity of its oligomers. Biomacromolecules. 2020;21:1112-25.

255. Reed MJ, Damodarasamy M, Pathan JL, Chan CK, Spiekerman C, Wight TN, et al. Increased hyaluronan and TSG-6 in association with neuropathologic changes of Alzheimer's disease. J Alzheimers Dis. 2019;67:91-102.

256. Wang T, Xu SF, Fan YG, Li LB, Guo C. Iron pathophysiology in Alzheimer's diseases. Adv Exp Med Biol. 2019;1173:67-104.

257. Cho K, Jang YJ, Lee SJ, Jeon YN, Shim YL, Lee JY, et al. TLQP-21 mediated activation of microglial BV2 cells promotes clearance of extracellular fibril amyloid- $\beta$. Biochem Biophys Res Commun. 2020;524:764-71.

258. El Gaamouch F, Audrain M, Lin WJ, Beckmann N, Jiang C, Hariharan S, et al. VGF-derived peptide TLQP-21 modulates microglial function through C3aR1 signaling pathways and reduces neuropathology in 5xFAD mice. Mol Neurodegener. 2020;15:4.

259. Beckmann ND, Lin WJ, Wang M, Cohain AT, Charney AW, Wang P, et al. Multiscale causal networks identify VGF as a key regulator of Alzheimer's disease. Nat Commun. 2020;11:3942.

260. Fricker LD, McKinzie AA, Sun J, Curran E, Qian Y, Yan L, et al. Identification and characterization of proSAAS, a granin-like neuroendocrine peptide precursor that inhibits prohormone processing. J Neurosci. 2000;20:639-48

261. Helwig M, Hoshino A, Berridge C, Lee SN, Lorenzen N, Otzen DE, et al. The neuroendocrine protein 7B2 suppresses the aggregation of neurodegenerative disease-related proteins. J Biol Chem. 2013;288:1114-24.

262. Kikuchi K, Arawaka S, Koyama S, Kimura H, Ren CH, Wada M, et al. An Nterminal fragment of ProSAAS (a granin-like neuroendocrine peptide precursor) is associated with tau inclusions in Pick's disease. Biochem Biophys Res Commun. 2003;308:646-54.

263. Wada M, Ren CH, Koyama S, Arawaka S, Kawakatsu S, Kimura H, et al. A human granin-like neuroendocrine peptide precursor (proSAAS) immunoreactivity in tau inclusions of Alzheimer's disease and parkinsonismdementia complex on Guam. Neurosci Lett. 2004;356:49-52.

264. Hoshino A, Helwig M, Rezaei S, Berridge C, Eriksen JL, Lindberg I. A novel function for proSAAS as an amyloid anti-aggregant in Alzheimer's disease. J Neurochem. 2014;128:419-30.

265. Peinado JR, Sami F, Rajpurohit N, Lindberg I. Blockade of islet amyloid polypeptide fibrillation and cytotoxicity by the secretory chaperones 7B2 and proSAAS. FEBS Lett. 2013;587:3406-11

266. Jarvela TS, Lam HA, Helwig M, Lorenzen N, Otzen DE, McLean PJ, et al. The neural chaperone proSAAS blocks a-synuclein fibrillation and neurotoxicity. Proc Natl Acad Sci U S A. 2016;113:E4708-15.

267. Gnanapavan S, Giovannoni G. Neural cell adhesion molecules in brain plasticity and disease. Mult Scler Relat Disord. 2013;2:13-20.

268. Chen KP, Dou F. Selective interaction of amyloid precursor protein with different isoforms of neural cell adhesion molecule. J Mol Neurosci. 2012;46: 203-9.

269. Kallapur SG, Akeson RA. The neural cell adhesion molecule (NCAM) heparin binding domain binds to cell surface heparan sulfate proteoglycans. J Neurosci Res. 1992;33:538-48.

270. Leshchys'ka I, Liew HT, Shepherd C, Halliday GM, Stevens CH, Ke YD, et al. A $\beta$-dependent reduction of NCAM2-mediated synaptic adhesion contributes to synapse loss in Alzheimer's disease. Nat Commun. 2015;6: 8836.

271. Frischknecht $\mathrm{R}$, Seidenbecher $\mathrm{Cl}$. Brevican: a key proteoglycan in the perisynaptic extracellular matrix of the brain. Int J Biochem Cell Biol. 2012; 44:1051-4.

272. Mohamedi Y, Fontanil T, Cobo T, Cal S, Obaya AJ. New insights into ADAM TS metalloproteases in the central nervous system. Biomolecules. 2020;10
273. Ajmo JM, Bailey LA, Howell MD, Cortez LK, Pennypacker KR, Mehta HN, et al. Abnormal post-translational and extracellular processing of brevican in plaquebearing mice over-expressing APPsw. J Neurochem. 2010;113:784-95.

274. Müller UC, Deller T, Korte M. Not just amyloid: physiological functions of the amyloid precursor protein family. Nat Rev Neurosci. 2017;18:281-98.

275. Li Q, Südhof TC. Cleavage of amyloid- $\beta$ precursor protein and amyloid- $\beta$ precursor-like protein by BACE 1. J Biol Chem. 2004;279:10542-50.

276. Eggert S, Paliga K, Soba P, Evin G, Masters CL, Weidemann A, et al. The proteolytic processing of the amyloid precursor protein gene family members APLP-1 and APLP-2 involves $\alpha-, \beta-, \gamma$-, and $\varepsilon$-like cleavages: modulation of APLP-1 processing by n-glycosylation. J Biol Chem. 2004;279: 18146-56.

277. Bayer TA, Paliga K, Weggen S, Wiestler OD, Beyreuther K, Multhaup G. Amyloid precursor-like protein 1 accumulates in neuritic plaques in Alzheimer's disease. Acta Neuropathol. 1997;94:519-24.

278. McNamara MJ, Ruff CT, Wasco W, Tanzi RE, Thinakaran G, Hyman BT. Immunohistochemical and in situ analysis of amyloid precursor-like protein1 and amyloid precursor-like protein-2 expression in Alzheimer disease and aged control brains. Brain Res. 1998;804:45-51.

279. White AR, Maher F, Brazier MW, Jobling MF, Thyer J, Stewart LR, et al. Diverse fibrillar peptides directly bind the Alzheimer's amyloid precursor protein and amyloid precursor-like protein 2 resulting in cellular accumulation. Brain Res. 2003;966:231-44.

280. Singh B, Su YC, Riesbeck K. Vitronectin in bacterial pathogenesis: a host protein used in complement escape and cellular invasion. Mol Microbiol. 2010;78:545-60

281. Sandwall E, O'Callaghan P, Zhang X, Lindahl U, Lannfelt L, Li JP. Heparan sulfate mediates amyloid- $\beta$ internalization and cytotoxicity. Glycobiology. 2010;20:533-41.

282. Jendresen CB, Cui H, Zhang X, Vlodavsky I, Nilsson LN, Li JP. Overexpression of heparanase lowers the amyloid burden in amyloid- $\beta$ precursor protein transgenic mice. J Biol Chem. 2015;290:5053-64.

283. Liu CC, Zhao N, Yamaguchi Y, Cirrito JR, Kanekiyo T, Holtzman DM, et al. Neuronal heparan sulfates promote amyloid pathology by modulating brain amyloid- $\beta$ clearance and aggregation in Alzheimer's disease. Sci Transl Med. 2016:8:332ra44

284. Donahue JE, Berzin TM, Rafii MS, Glass DJ, Yancopoulos GD, Fallon JR, et al. Agrin in Alzheimer's disease: altered solubility and abnormal distribution within microvasculature and brain parenchyma. Proc Natl Acad Sci U S A. 1999;96:6468-72.

285. Rauch SM, Huen K, Miller MC, Chaudry H, Lau M, Sanes JR, et al. Changes in brain $\beta$-amyloid deposition and aquaporin 4 levels in response to altered agrin expression in mice. J Neuropathol Exp Neurol. 2011;70:1124-37.

286. Berzin TM, Zipser BD, Rafii MS, Kuo-Leblanc V, Yancopoulos GD, Glass DJ, et al. Agrin and microvascular damage in Alzheimer's disease. Neurobiol Aging. 2000;21:349-55.

287. van Horssen J, Kleinnijenhuis J, Maass CN, Rensink AA, Otte-Höller I, David G, et al. Accumulation of heparan sulfate proteoglycans in cerebellar senile plaques. Neurobiol Aging. 2002;23:537-45.

288. van Horssen J, Otte-Höller I, David G, Maat-Schieman ML, van den Heuvel $L P$, Wesseling $P$, et al. Heparan sulfate proteoglycan expression in cerebrovascular amyloid $\beta$ deposits in Alzheimer's disease and hereditary cerebral hemorrhage with amyloidosis (Dutch) brains. Acta Neuropathol. 2001;102:604-14.

289. Timmer NM, van Horssen J, Otte-Holler I, Wilhelmus MM, David G, van Beers J, et al. Amyloid $\beta$ induces cellular relocalization and production of agrin and glypican-1. Brain Res. 2009;1260:38-46.

290. Taylor DR, Whitehouse IJ, Hooper NM. Glypican-1 mediates both prion protein lipid raft association and disease isoform formation. PLoS Pathog. 2009;5:e1000666.

291. Steck E, Bräun J, Pelttari K, Kadel S, Kalbacher H, Richter W. Chondrocyte secreted CRTAC1: a glycosylated extracellular matrix molecule of human articular cartilage. Matrix Biol. 2007;26:30-41.

292. Anjos L, Morgado I, Guerreiro M, Cardoso JC, Melo EP, Power DM. Cartilage acidic protein 1, a new member of the $\beta$-propeller protein family with amyloid propensity. Proteins. 2017;85:242-55.

293. Shin TM, Isas JM, Hsieh CL, Kayed R, Glabe CG, Langen R, et al. Formation of soluble amyloid oligomers and amyloid fibrils by the multifunctional protein vitronectin. Mol Neurodegener. 2008;3:16.

294. Wung JK, Perry G, Kowalski A, Harris PL, Bishop GM, Trivedi MA, et al. Increased expression of the remodeling- and tumorigenic-associated factor 
osteopontin in pyramidal neurons of the Alzheimer's disease brain. Curr Alzheimer Res. 2007;4:67-72.

295. Carecchio M, Comi C. The role of osteopontin in neurodegenerative diseases. J Alzheimers Dis. 2011;25:179-85

296. Brown A. Osteopontin: a key link between immunity, inflammation and the central nervous system. Transl Neurosci. 2012;3:288-93.

297. Grand Moursel L, van der Graaf LM, Bulk M, van Roon-Mom WMC, van der Weerd L. Osteopontin and phospho-SMAD2/3 are associated with calcification of vessels in D-CAA, an hereditary cerebral amyloid angiopathy. Brain Pathol. 2019;29:793-802.

298. Rentsendorj A, Sheyn J, Fuchs DT, Daley D, Salumbides BC, Schubloom HE, et al. A novel role for osteopontin in macrophage-mediated amyloid- $\beta$ clearance in Alzheimer's models. Brain Behav Immun. 2018;67:163-80.

299. Seki T, Kanagawa M, Kobayashi K, Kowa H, Yahata N, Maruyama K, et al. Galectin 3-binding protein suppresses amyloid- $\beta$ production by modulating $\beta$-cleavage of amyloid precursor protein. J Biol Chem. 2020;295:3678-91.

300. Ohsawa I, Takamura C, Kohsaka S. Fibulin-1 binds the amino-terminal head of $\beta$-amyloid precursor protein and modulates its physiological function. J Neurochem. 2001;76:1411-20.

301. Asch E, Podack E. Vitronectin binds to activated human platelets and plays a role in platelet aggregation. J Clin Invest. 1990;85:1372-8.

302. Tran H, Tanaka A, Litvinovich SV, Medved LV, Haudenschild CC, Argraves WS. The interaction of fibulin-1 with fibrinogen. A potential role in hemostasis and thrombosis. J Biol Chem. 1995;270:19458-64.

303. Xu G, Xia Z, Deng F, Liu L, Wang Q, Yu Y, et al. Inducible LGALS3BP/90K activates antiviral innate immune responses by targeting TRAF6 and TRAF3 complex. PLoS Pathog. 2019;15:e1008002.

304. Bobek LA, Levine MJ. Cystatins - inhibitors of cysteine proteinases. Crit Rev Oral Biol Med. 1992;3:307-32.

305. Håkansson K, Huh C, Grubb A, Karlsson S, Abrahamson M. Mouse and rat cystatin C: Escherichia coli production, characterization and tissue distribution. Comp Biochem Physiol B Biochem Mol Biol. 1996;114:303-11.

306. Levy E, Jaskolski M, Grubb A. The role of cystatin C in cerebral amyloid angiopathy and stroke: cell biology and animal models. Brain Pathol. 2006; 16:60-70.

307. Kaeser SA, Herzig MC, Coomaraswamy J, Kilger E, Selenica ML, Winkler DT, et al. Cystatin C modulates cerebral $\beta$-amyloidosis. Nat Genet. 2007;39:1437-9.

308. Tizon B, Ribe EM, Mi W, Troy CM, Levy E. Cystatin C protects neuronal cells from amyloid- $\beta$-induced toxicity. J Alzheimers Dis. 2010;19:885-94.

309. Gudmundsson G, Hallgrímsson J, Jónasson TA, Bjarnason O. Hereditary cerebral haemorrhage with amyloidosis. Brain. 1972;95:387-404.

310. Wen D, Corina K, Chow EP, Miller S, Janmey PA, Pepinsky RB. The plasma and cytoplasmic forms of human gelsolin differ in disulfide structure. Biochemistry. 1996;35:9700-9.

311. Paunio T, Kiuru S, Karonen S-L, Palo J, Peltonen L. Quantification of serum and cerebrospinal fluid gelsolin in familial amyloidosis, Finnish type (AGel). Amyloid. 1994;1:80-9.

312. Meretoja J. Familial systemic paramyloidosis with lattice dystrophy of the cornea, progressive cranial neuropathy, skin changes and various internal symptoms. A previously unrecognized heritable syndrome. Ann Clin Res. 1969;: $: 314-24$

313. Sari Kiuru-Enari MH. Hereditary gelsolin amyloidosis. Amsterdam: Elsevier; 2013.

314. Ray I, Chauhan A, Wegiel J, Chauhan VP. Gelsolin inhibits the fibrillization of amyloid $\beta$-protein, and also defibrillizes its preformed fibrils. Brain Res. 2000; 853:344-51.

315. Matsuoka Y, Saito M, LaFrancois J, Saito M, Gaynor K, Olm V, et al. Novel therapeutic approach for the treatment of Alzheimer's disease by peripheral administration of agents with an affinity to $\beta$-amyloid. J Neurosci. 2003;23: 29-33.

316. Hirko AC, Meyer EM, King MA, Hughes JA. Peripheral transgene expression of plasma gelsolin reduces amyloid in transgenic mouse models of Alzheimer's disease. Mol Ther. 2007:15:1623-9.

317. Rowe IF, Jensson O, Lewis PD, Candy J, Tennent GA, Pepys MB. Immunohistochemical demonstration of amyloid $\mathrm{P}$ component in cerebrovascular amyloidosis. Neuropathol Appl Neurobiol. 1984;10:53-61.

318. Coria F, Castaño E, Prelli F, Larrondo-Lillo M, van Duinen S, Shelanski ML, et al. Isolation and characterization of amyloid $\mathrm{P}$ component from Alzheimer's disease and other types of cerebral amyloidosis. Lab Invest. 1988:58:454-8.

319. Duong T, Pommier EC, Scheibel AB. Immunodetection of the amyloid P component in Alzheimer's disease. Acta Neuropathol. 1989;78:429-37.
320. Botto M, Hawkins PN, Bickerstaff MCM, Herbert J, Bygrave AE, McBride A, et al. Amyloid deposition is delayed in mice with targeted deletion of the serum amyloid P component gene. Nat Med. 1997;3:855-9.

321. Mold M, Shrive AK, Exley C. Serum amyloid P component accelerates the formation and enhances the stability of amyloid fibrils in a physiologically significant under-saturated solution of amyloid- $\beta$ 42. J Alzheimers Dis. 2012; 29:875-81.

322. Tennent GA, Lovat LB, Pepys MB. Serum amyloid P component prevents proteolysis of the amyloid fibrils of Alzheimer disease and systemic amyloidosis. Proc Natl Acad Sci U S A. 1995;92:4299-303.

323. Mulder SD, Nielsen HM, Blankenstein MA, Eikelenboom P, Veerhuis R. Apolipoproteins $E$ and $J$ interfere with amyloid- $\beta$ uptake by primary human astrocytes and microglia in vitro. Glia. 2014;62:493-503.

324. Urbányi Z, Lakics V, Erdö SL. Serum amyloid P component-induced cell death in primary cultures of rat cerebral cortex. Eur J Pharmacol. 1994;270: 375-8.

325. Duong T, Acton PJ, Johnson RA. The in vitro neuronal toxicity of pentraxins associated with Alzheimer's disease brain lesions. Brain Res. 1998;813:303-12.

326. Al-Shawi R, Tennent GA, Millar DJ, Richard-Londt A, Brandner S, Werring DJ, et al. Pharmacological removal of serum amyloid $P$ component from intracerebral plaques and cerebrovascular $A \beta$ amyloid deposits in vivo. Open Biol. 2016;6:150202.

327. Askevold ET, Aukrust P, Nymo SH, Lunde IG, Kaasbøll OJ, Aakhus S, et al. The cardiokine secreted frizzled-related protein 3, a modulator of Wnt signalling, in clinical and experimental heart failure. J Int Med. 2014;275:621-30.

328. Ng LF, Kaur P, Bunnag N, Suresh J, Sung ICH, Tan QH, et al. WNT signaling in disease. Cells. 2019;8

329. De Ferrari GV, Chacón MA, Barría MI, Garrido JL, Godoy JA, Olivares G, et al. Activation of Wnt signaling rescues neurodegeneration and behavioral impairments induced by $\beta$-amyloid fibrils. Mol Psychiatry. 2003:8:195-208.

330. Twohig D, Nielsen HM. a-synuclein in the pathophysiology of Alzheimer's disease. Mol Neurodegener. 2019;14:23.

331. Wang Y, Mandelkow E. Tau in physiology and pathology. Nat Rev Neurosci. 2016;17:5-21.

332. Uéda K, Fukushima H, Masliah E, Xia Y, Iwai A, Yoshimoto M, et al. Molecular cloning of CDNA encoding an unrecognized component of amyloid in Alzheimer disease. Proc Natl Acad Sci U S A. 1993;90:11282-6.

333. Masliah E, Iwai A, Mallory M, Uéda K, Saitoh T. Altered presynaptic protein NACP is associated with plaque formation and neurodegeneration in Alzheimer's disease. Am J Pathol. 1996;148:201-10.

334. Goedert M. a-synuclein and neurodegenerative diseases. Nat Rev Neurosci. 2001;2:492-501.

335. Szklarczyk D, Gable AL, Lyon D, Junge A, Wyder S, Huerta-Cepas J, et al. STRI NG v11: protein-protein association networks with increased coverage, supporting functional discovery in genome-wide experimental datasets. Nucleic Acids Res. 2019;47:D607-d13.

336. LaFerla FM, Green KN, Oddo S. Intracellular amyloid- $\beta$ in Alzheimer's disease. Nat Rev Neurosci. 2007:8:499-509.

337. Kinoshita A, Fukumoto H, Shah T, Whelan CM, Irizarry MC, Hyman BT. Demonstration by FRET of BACE interaction with the amyloid precursor protein at the cell surface and in early endosomes. J Cell Sci. 2003;116: $3339-46$.

338. O'Brien RJ, Wong PC. Amyloid precursor protein processing and Alzheimer's disease. Annu Rev Neurosci. 2011;34:185-204.

339. Bartels T, De Schepper S, Hong S. Microglia modulate neurodegeneration in Alzheimer's and Parkinson's diseases. Science. 2020;370:66-9.

340. Kwon HS, Koh SH. Neuroinflammation in neurodegenerative disorders: the roles of microglia and astrocytes. Transl Neurodegener. 2020;9:42.

341. Brown MR, Radford SE, Hewitt EW. Modulation of $\beta$-amyloid fibril formation in Alzheimer's disease by microglia and infection. Front Mol Neurosci. 2020; 13:609073.

342. Bamberger ME, Harris ME, McDonald DR, Husemann J, Landreth GE. A cell surface receptor complex for fibrillar $\beta$-amyloid mediates microglial activation. J Neurosci. 2003:23:2665-74.

343. Jana M, Palencia CA, Pahan K. Fibrillar amyloid- $\beta$ peptides activate microglia via TLR2: implications for Alzheimer's disease. J Immunol. 2008;181:7254-62.

344. Zhao $Y$, Wu X, Li X, Jiang LL, Gui X, Liu Y, et al. TREM2 is a receptor for $\beta$ amyloid that mediates microglial function. Neuron. 2018;97:1023-31.e7.

345. Jones RS, Minogue AM, Connor TJ, Lynch MA. Amyloid- $\beta$-induced astrocytic phagocytosis is mediated by CD36, CD47 and RAGE. J Neuroimmune Pharmacol. 2013;8:301-11. 
346. Söllvander S, Nikitidou E, Brolin R, Söderberg L, Sehlin D, Lannfelt L, et al. Accumulation of amyloid- $\beta$ by astrocytes result in enlarged endosomes and microvesicle-induced apoptosis of neurons. Mol Neurodegener. 2016;11:38.

347. Yan SD, Chen X, Fu J, Chen M, Zhu H, Roher A, et al. RAGE and amyloid- $\beta$ peptide neurotoxicity in Alzheimer's disease. Nature. 1996;382:685-91.

348. Nagele RG, D'Andrea MR, Anderson WJ, Wang HY. Intracellular accumulation of $\beta$-amyloid(1-42) in neurons is facilitated by the a7 nicotinic acetylcholine receptor in Alzheimer's disease. Neuroscience. 2002;110:199-211.

349. Snyder EM, Nong Y, Almeida CG, Paul S, Moran T, Choi EY, et al. Regulation of NMDA receptor trafficking by amyloid- $\beta$. Nat Neurosci. 2005;8:1051-8.

350. Bu G, Cam J, Zerbinatti C. LRP in amyloid- $\beta$ production and metabolism. Ann N Y Acad Sci. 2006;1086:35-53.

351. Gouras GK, Tsai J, Näslund J, Vincent B, Edgar M, Checler F, et al. Intraneuronal Aß42 accumulation in human brain. Am J Pathol. 2000;156: $15-20$.

352. Mochizuki A, Tamaoka A, Shimohata A, Komatsuzaki Y, Shoji S. Aß42positive non-pyramidal neurons around amyloid plaques in Alzheimer's disease. Lancet. 2000;355:42-3.

353. Friedrich RP, Tepper K, Rönicke R, Soom M, Westermann M, Reymann K, et al. Mechanism of amyloid plaque formation suggests an intracellular basis of AB pathogenicity. Proc Natl Acad Sci U S A. 2010;107:1942-7.

354. Wirths $\mathrm{O}$, Bayer TA. Intraneuronal $A B$ accumulation and neurodegeneration: lessons from transgenic models. Life Sci. 2012;91:1148-52.

355. Manzoni C, Colombo L, Bigini P, Diana V, Cagnotto A, Messa M, et al. The molecular assembly of amyloid $A \beta$ controls its neurotoxicity and binding to cellular proteins. PLoS One. 2011;6:e24909.

356. Törnquist M, Michaels TCT, Sanagavarapu K, Yang X, Meisl G, Cohen SIA, et al. Secondary nucleation in amyloid formation. Chem Commun (Camb). 2018:54:8667-84

\section{Publisher's Note}

Springer Nature remains neutral with regard to jurisdictional claims in published maps and institutional affiliations.

Ready to submit your research? Choose BMC and benefit from:

- fast, convenient online submission

- thorough peer review by experienced researchers in your field

- rapid publication on acceptance

- support for research data, including large and complex data types

- gold Open Access which fosters wider collaboration and increased citations

- maximum visibility for your research: over $100 \mathrm{M}$ website views per year

At $\mathrm{BMC}$, research is always in progress.

Learn more biomedcentral.com/submissions 